\title{
Scanning Transmission X-ray Microscopy: Applications in Atmospheric Aerosol Research
}

\author{
Ryan C. Moffet, Alexei V. Tivanski, and Mary K. Gilles \\ Chemical Sciences Division, Lawrence Berkeley National Laboratory, \\ 1 Cyclotron Road, MS 6R2100, Berkeley, California, 94720 USA \\ Email: $\underline{\text { mkgilles@1bl.gov }}$
}

Scanning transmission x-ray microscopy (STXM) combines x-ray microscopy and near edge $\mathrm{x}$-ray absorption fine structure spectroscopy (NEXAFS). This combination provides spatially resolved bonding and oxidation state information. While there are reviews relevant to STXM/NEXAFS applications in other environmental fields ${ }^{1-4}$ (and magnetic materials ${ }^{5}$ ) this chapter focuses on atmospheric aerosols. It provides an introduction to this technique in a manner approachable to non-experts. It begins with relevant background information on synchrotron radiation sources and a description of NEXAFS spectroscopy. The bulk of the chapter provides a survey of STXM/NEXAFS aerosol studies and is organized according to the type of aerosol investigated. The purpose is to illustrate the current range and recent growth of scientific investigations employing STXM-NEXAFS to probe atmospheric aerosol morphology, surface coatings, mixing states, and atmospheric processing.

Submitted chapter for book "Fundamentals and Applications of Aerosol Spectroscopy" to be published by Taylor and Francis Books, Inc. in 2010 (editors Jonathan Reid and Ruth Signorell) 


\section{LEGAL DISCLAIMER}

This document was prepared as an account of work sponsored by the United States Government. While this document is believed to contain correct information, neither the United States Government nor any agency thereof, nor The Regents of the University of California, nor any of their employees, makes any warranty, express or implied, or assumes any legal responsibility for the accuracy, completeness, or usefulness of any information, apparatus, product, or process disclosed, or represents that its use would not infringe privately owned rights. Reference herein to any specific commercial product, process, or service by its trade name, trademark, manufacturer, or otherwise, does not necessarily constitute or imply its endorsement, recommendation, or favoring by the United States Government or any agency thereof, or The Regents of the University of California. The views and opinions of authors expressed herein do not necessarily state or reflect those of the United States Government or any agency thereof or The Regents of the University of California. 


\section{Synchrotron Background}

Scanning transmission x-ray microscopy (STXM) is performed at synchrotron light sources, which produce intense and tunable x-ray beams. An exceptional reference is provided by Attwood, ${ }^{6}$ hence, only a few basic concepts are presented here. Workshops and introductory short courses are often available to introduce those unfamiliar with the field, and interested readers should consult websites for individual light sources.

1. Storage Rings and Insertion Devices

\subsection{An Electron's Life in the Synchrotron}

Electrodynamics tells us that a charged particle under the influence of a magnetic force emits radiation. Synchrotrons exploit this by subjecting relativistic electrons (i.e. those traveling at $99.999985 \%$ of the speed of light) to magnetic fields thereby, causing them to emit radiation. Electrons produced by an electron gun are contained in an ultra high vacuum tube (to minimize their loss via collision with gas species) and are accelerated to relativistic velocities using radio frequency cavities. Electrons are subjected to magnetic forces as they pass through an insertion device resulting in emission of synchrotron radiation in a cone tangent to the trajectory of the electron. From each insertion device the photons are emitted and directed down a beamline to an experiment. A spread of photon energies are produced in the insertion device and a monochromator provides additional energy selection. Depending upon the monochromator (and gratings) the energy resolution may vary by an order of magnitude or more. Typically STXMs are on beamlines with resolutions on the order of $20-40 \mathrm{meV}$ (at $\sim 300 \mathrm{eV}$ ). At the end of each beamline there may be one (or more) experiments (endstations) either permanently attached to the beamline or temporarily attached for a specific set of experiments. The schematic in Fig. 1 shows a synchrotron, an insertion device (undulator), and the primary components of a STXM. More specific details on synchrotrons and insertion devices are available in Attwood ${ }^{6}$ as well as on individual synchrotron websites. The following section discusses only the most relevant 
concepts for atmospheric (or environmental) scientists wishing to understand or pursue STXM/NEXAFS experiments at a synchrotron.

\subsection{Synchrotron Operation Modes}

Synchrotrons operate in a variety of modes: multi-bunch, top-off, and 2-bunch. In multibunch mode a set number of electron bunches are in the synchrotron $(\sim 300)$. For most experiments, the timing between these bunches is short ( few nanoseconds) compared to the timescale for detection and the synchrotron is treated as a continuous photon source. As electrons pass through an insertion device they lose energy as synchrotron radiation (emit photons). This energy is then replenished to the electrons using radio frequency cavities. The time between electron bunches is determined by the frequency used to accelerate the electrons. Over the course of several hours (4 to 12) the electron beam current decreases due to collisions with gas molecules and other loss processes. The decreasing number of electrons within bunches produces a corresponding decrease in photon flux.

When the photon flux is sufficiently low the electron beam is forcibly lost ("dumped") and the synchrotron is "injected" with new bunches of electrons resulting in an increase in photon flux. In two-bunch mode there are only two bunches of electrons circulating in the synchrotron. The time between these two bunches is larger and is often used for experiments in which time is a parameter (for example, time of flight coincidence experiments). Due to fewer electron bunches in the synchrotron the photon flux is also correspondingly lower. Several synchrotrons now operate in top-off mode where injection of new electrons into the synchrotron is quasi-continuous. In this mode, fresh electron bunches are injected into the ring approximately every half minute to replenish any decrease in electron current. Top-off mode significantly increases the average photon flux available as the beam current remains roughly constant over a period of approximately a week. Additionally, unlike multi-bunch mode there is no downtime for injecting fresh electron bunches into the synchrotron. Hence, several hours per day previously used for "injection" are recovered as usable experimental time. Due to the higher 
average photon flux, particular care must be taken to minimize any potential radiation damage to samples. STXM/NEXAFS data on atmospheric aerosols is generally acquired using multi-bunch or top-off mode; the low flux during two-bunch mode would result in prohibitively long data acquisition times.

\subsection{Insertion Devices}

To produce synchrotron radiation several types of magnetic structures (discussed in detail in Attwood ${ }^{6}$ ) are used: wigglers, bending magnets and undulators. Insertion devices differ in spatial focusing, energy spread and polarization. Undulators and bending magnets are employed in current STXM instruments. There are a few important differences between these two insertion devices. A bending magnet emits radiation in a wider angle than an undulator. Undulators produce highly collimated, partially coherent radiation with a narrower energy range (frequency spread) having higher photon fluxes than bending magnets. Depending upon the insertion device, the contribution from higher harmonics (photons whose frequency is a multiple of the fundamental frequency) can vary significantly. In addition, the broader energy range produced by a bending magnet makes the alignment of some of the STXM optical components more stringent. Another important difference is that the linear polarization of the synchrotron radiation is fixed for a bending magnet and can be rotated for an undulator (which can also produce circularly or elliptically polarized light).

\subsection{Beamline Optical Components}

Key optical components between the insertion device and a STXM are indicated in Fig. 1. The monochromator is an important beamline component for STXM/NEXAFS studies. Depending upon its design, there may be entrance and/or exit slits, or it may be slitless. Monochromators can have a single grating or multiple gratings blazed onto a single substrate and the gratings switched depending upon the relative importance of energy, flux or spectral resolution in a particular experiment. A fundamental difference between optics in other energy regions, such as visible or infrared is that all optical components can absorb x-ray radiation. As reflectivity is enhanced at oblique angles, beamline optics are normally employed in a grazing 
incidence configuration. Typically, STXMs are coupled with high spectral resolution monochromators that enable functional groups within carbon spectra to be resolved. Depending upon the energy region of interest, energy calibration is performed with gaseous $\mathrm{CO}_{2}, \mathrm{O}_{2}$ or $\mathrm{N}_{2}$. To maintain photon beam alignment, slits and positioning mirrors (not shown in Fig. 1) are coupled by a feedback system. Although Fig. 1 indicates a single endstation, some beamlines have a mirror that directs the photon beam into separate experiments. Specific synchrotron websites normally contain datasheets for each beamline providing information about the endstations, insertion devices, energy range, and monochromators.

\subsection{Beamline Carbon Contamination}

Since carbon is a major component of atmospheric aerosols, the STXM has filled a unique niche by providing detailed information at the carbon K-edge (290 eV). However, one critical issue that arises in examining carbonaceous samples is that often beamline components (gratings, zone plates, mirrors) are contaminated with carbon. This arises from the materials used to manufacture the beamline components and by deposition of carbon onto the optical components during the initial building, development, and commissioning of a beamline. Therefore special measures must be taken to ensure the lowest levels of carbon contamination. Any carbon contamination effectively absorbs photons emitted from the insertion device causing a decreased flux in the energy region where carbon absorbs. At best, the majority of the photon flux is not absorbed and at worst only a fraction $(<5 \%)$ of the photons are transmitted to the STXM. In this event, it is nearly impossible to obtain quantitative carbon spectra. Although some degree of carbon contamination is always present, selecting a beamline with low levels of contamination is critical for obtaining high quality (and quantitative) carbon spectra. Over time, within the STXM itself, carbon will deposit onto optical elements such as the zone plate. Examining the background absorption spectra (photons detected in the absence of a sample) is critical to ensure that absorption by carbon on beamline optical components does not compromise the measured NEXAFS spectra. 


\section{The STXM/NEXAFS Technique}

Soft x-ray scanning transmission microscopy, STXM, was developed by Kirz, Jacobsen, Ade and coworkers ${ }^{7}$ at the National Synchrotron Light Source, NSLS, (Brookhaven, USA) during the late 1980's. During the early years a number of developments were also underway at Daresbury (United Kingdom). ${ }^{8}$ In the following years, STXM instruments at the Advanced Light Source, ALS, (Berkeley, USA), went through several iterations. The Advanced Photon Source (Argonne National Laboratory, Argonne, USA) ${ }^{9}$ STXM operates in the higher energy region $(0.8 \mathrm{k} \mathrm{eV}-4 \mathrm{keV})$. To date, the majority of STXM experiments in the soft x-ray region $(\sim 100 \mathrm{eV}$ $-1000 \mathrm{eV}$ ) have been at the ALS or NSLS. Several new instruments are either operational or anticipated in the next few years: Diamond Light Source (United Kingdom), ${ }^{10}$ Canadian Light Source (Saskatoon, Canada), ${ }^{11}$ BESSY II (Berlin, Germany), ${ }^{12}$ Swiss Light Source (Paul Scherrer Institut, Villingen, Switzerland), ${ }^{13}$ Elettra (Trieste, Italy), ${ }^{14}$ European Synchrotron Radiation Source (France), ${ }^{15}$ SOLEIL II (France), Pohang Light Source (Korea), ${ }^{16}$ Shanghai (China), Stanford Synchrotron Radiation Laboratory (USA), as well as a third STXM at the ALS (USA).

\subsection{Scanning Transmission X-ray Microscope (STXM) Description}

The STXM spatial resolution is determined by the X-ray spot size at the focal point. For visual light microscopes, the diffraction limited spatial resolution is on the order of $200 \mathrm{~nm}$. As soft $\mathrm{x}$-rays have much shorter wavelengths $(1-10 \mathrm{~nm})$, they can be focused to a smaller spot size (Rayleigh criterion). Rather than focusing using refraction, zone plates focus monochromatic x-rays with a circular diffractive grating (called a Fresnel zone plate). As shown in Fig. 2, zone plates consist of variable width concentric gold rings (zones) on a thin transparent silicon nitride support. Zone plates are manufactured using lithography to create high-aspect ratio zones. The zone-width (width of the gold zone) decreases with increasing radial distance from the center of the zone plate. The width of the outermost zone determines the largest diffraction angle and plays a critical role in obtaining the best spatial resolution. The spatial resolution depends on the coherence of the x-ray radiation incident on the zone plate and the 
quality of the zone plate. Spot sizes of $25 \mathrm{~nm}$ are routinely achieved, although $15 \mathrm{~nm}$ spot sizes are reported. ${ }^{17}$ Future improvements in the quality of zone plates are expected to further decrease the spot size. Zone plates are designed such that diffracted light from each of the zones constructively interferes at the focal point. As shown in Fig. 2, STXM instruments employ zone plates with a central stop to prevent unfocussed incident x-rays from impinging on the sample. Typical zone plates have diameters of $\sim 120-240 \mu \mathrm{m}$, with 100's to 1,000's of zones, central stops with diameters of $50-90 \mu \mathrm{m}$, and the width of outermost zone ranges from $20-50 \mathrm{~nm}$. The zone plate focal length is a function of photon energy and varies from $\sim 1200 \mu \mathrm{m}$ at $280 \mathrm{eV}$ to $\sim 3000 \mu \mathrm{m}$ at $700 \mathrm{eV}$.

Light incident on the zone plate can contain significant levels of higher order diffracted light from the monochromator that can decrease the spatial resolution and contaminate spectra. To mitigate these effects, an order sorting aperture (OSA) is used. The OSA indicated in Fig. 2 is a pin hole 40 - $60 \mu \mathrm{m}$ in diameter. When placed at the proper distance between the sample and the zone plate, higher order diffracted light is eliminated and only first order diffracted light is transmitted to the sample. The correct alignment of this aperture both in distance between the sample and zone plate $(\mathrm{z})$ and in the $\mathrm{x}$, $\mathrm{y}$ plane is important for obtaining quantitative spectra. The importance of the OSA alignment is somewhat dependent upon the insertion device used at the beamline. Due to the larger energy spread produced by bending magnets, the possibility of focusing higher harmonics onto the sample is increased and the correct OSA alignment is more critical.

Typically, the sample is held on a set of piezo fine stages operating over a range of $\sim 60$ microns. These fine stages are mounted onto a set of coarse stages with a range of motion in 10's of millimeters. Hence, a plate containing multiple samples can be loaded and individual samples selected by positioning the coarse stages. The fine stages, used for the majority of data acquisition, are monitored using laser interferometers to accurately determine their position. Additional information and more detailed description of microscopes at the ALS and NSLS are provided elsewhere. ${ }^{18-20}$ 
Images are obtained at a given photon energy by raster scan the sample through the focal point while measuring the transmitted x-rays. To obtain spatially resolved spectral information, a sequence of images is measured as a function of photon energy. This sequence of images is referred to as a "stack". From this three dimensional data set a spectral image is obtained with the spatial resolution determined by the zone plate. As the zone plate focal length is proportional to the incident $\mathrm{x}$-ray photon energy, during acquisition of a "stack", each time the energy is changed, the distance between the zone plate and the sample $(\mathrm{z})$ changes to keep the sample in focus.

A variety of detection techniques are used in scanning transmission x-ray microscopy: gas flow proportional counters; ${ }^{21,22}$ diode detectors with segmentation; ${ }^{23}$ avalanche photodiodes run in pulse-counting mode $;{ }^{20}$ fluorescence detectors; ${ }^{15}$ charge-coupled-device (CCD) detectors $;{ }^{24}$ and differential phase contrast and dark field imaging. ${ }^{25}$ To date, most atmospheric aerosol STXM studies have used a detector consisting of a phosphor coated Lucite pipe coupled to a photomultiplier for single photon counting. ${ }^{18,26}$

\subsection{Background on NEXAFS Spectroscopy}

\subsubsection{Electronic Transitions Probed}

When inner (core) shell electrons absorb a soft x-ray photon several processes such as excitation to a bound or continuum state can occur. Depending upon the type of information desired, for example surface vs. bulk and elemental vs. chemical, different experiments measure absorbance, fluorescence, partial or total electron yields. For low atomic number (Z) elements, fluorescence yields are small (Stöhr pg 117). ${ }^{27}$ The amount of absorption depends upon photon energy, elemental composition, sample thickness and density. If an electron is completely removed from the atom, ionization occurs. At energies just below the ionization threshold, photon absorption excites inner shell electrons into unoccupied valence orbitals. For a specific element, the sudden increase in absorption is referred to as an absorption edge. Table 1 lists elements typically present in environmental samples with absorption edges lying in the soft xray region. 
Most STXMs operate in the soft x-ray region - an energy range exceptionally well suited for probing natural materials. ${ }^{28}$ Several STXMs have extended energy ranges approaching 2000 $\mathrm{eV}$. First row elements possess a single core level transition in the soft $\mathrm{x}$-ray region: the K-shell or $1 s$ orbital. \{Note: Chemists refer to electron orbitals as $\mathrm{s}, \mathrm{p}$, or $\mathrm{d}$ while $\mathrm{x}$-ray notation refers to them as K, L, and M, shells (or edges), respectively\}. Environmental samples typically contain carbon, nitrogen, and oxygen, for which the 1s electron binding energies are about $290 \mathrm{eV}, 400$ $\mathrm{eV}$, and $530 \mathrm{eV}$, respectively. Hence, in the water window (the region between $\sim 280 \mathrm{eV}$ to $\sim 525$ $\mathrm{eV}$ ) water is essentially transparent but carbon and nitrogen absorb. In this window, high contrast images can be obtained when probing systems containing carbon such as aerosols, soil samples, biofilms or biological systems without interference from water.

The transition metal L-edges are also accessible in the soft x-ray energy range. L-edge excitation probes $3 d$ valence orbitals that provide metal oxidation state information. ${ }^{28}$ They arise from the dipole-permitted transitions from the $2 p$ core level to the $3 d$ valence level. For transition metals, probing the L-edge is preferred over the core shell (K-edge) because the outermost (valence shell) electrons are most sensitive to the bonding environment.

Fortuitously, atmospheric aerosols have sizes ideal for STXM measurements. Soot and black carbon particulates are in the fine and accumulation modes. Hence, the most strongly absorbing (in the soft x-ray region) particulates are typically in a size range where they are partially transparent to the incident $\mathrm{x}$-ray photons. In addition, the penetration depth is a few microns at the carbon K-edge $(\sim 300 \mathrm{eV})$ allowing the soft $\mathrm{x}$-rays to penetrate the entire particle volume. Larger particles, mineral dusts, sulfates, and sea salts, typically contain less carbon and it is possible to measure carbon spectra on particles with diameters from $\sim 100 \mathrm{~nm}$ to 10 's of microns. In Fig. 3, the calculated mass absorption in the soft x-ray region is plotted for $100 \mathrm{~nm}$ thick samples of mineral dust, sea salt residue, and secondary aerosols. As seen in this figure, the soft $\mathrm{x}$-ray region is ideal for probing a variety of common atmospheric aerosol constituents. 


\subsubsection{Conversion to Optical Density}

Quantitative analysis is obtained by converting the transmitted intensity signal into absorbance (commonly referred to as optical density, OD, in the soft x-ray energy region), a dimensionless quantity, given by the Beer-Lambert's law:

$$
A=O D=-\ln \left(\frac{I(d)}{I_{0}}\right)=\rho \mu d=\sigma d
$$

where $I_{0}$ is the incident flux transmitted through a sample free region of the substrate, $I(d)$ is the flux transmitted through the sample, $\rho$ is the sample density, $\mu$ is the mass absorption coefficient, $d$ is the sample thickness, and $\sigma$ is the absorption cross section. The decrease in flux is due to absorption through the sample column and is a bulk measurement. However, STXM samples are typically thin $(80-200 \mathrm{~nm})$ and the surface contribution is significant. One advantage of the conversion into OD is that absorption from a uniform homogeneous substrate (carbon thin film or silicon nitride window) is eliminated. For a sample containing several different chemical components, the optical density is given by the sum of the optical densities of the individual compounds. A common assumption is that at energies sufficiently far from the ionization threshold, the material may be modeled as a collection of non-interacting atoms. The

mass absorption coefficient, $\mu(E)\left(\mathrm{cm}^{2} / \mathrm{g}\right)$, depends upon the incident photon energy, $E$, and atomic number, Z. For a material composed of a single element, A, the mass absorption coefficient is directly related to the total atomic absorption cross section, $\sigma_{A}\left(\mathrm{~cm}^{2} /\right.$ atom) by

$$
\mu(E)=\frac{N_{A}}{Z} \sigma_{A}
$$

were $N_{A}$ is Avogadro's number. Tabulations of atomic absorption cross sections are found in Henke et al. ${ }^{29}$ and in the X-ray Data Booklet. ${ }^{30}$ Transmission can be calculated from these or by using the website maintained by the Center for X-ray Optics (CXRO). ${ }^{31}$ Spectra of known elemental composition can be calculated to estimate an appropriate sample thickness. 
Alternatively, these spectra can be normalized to a specific thickness and used to quantify their contribution in an unknown sample ${ }^{32}$ or to derive quantitative composition maps. ${ }^{32-34}$

\subsubsection{Carbon NEXAFS}

Carbon NEXAFS spectra are rich in details and can provide insight into the molecular nature of the carbonaceous material present in aerosols. The book by Stöhr, a critical reference in this field, covers theoretical and experimental considerations related to carbon NEXAFS spectroscopy. ${ }^{27}$ Carbon NEXAFS spectra contain features dependent upon bonding and unoccupied molecular orbitals. Figure 4 schematically illustrates the core-level transitions producing the absorption spectrum. Energy levels of unoccupied valence orbitals provide information on the chemical bonding environment, for example, carbon functional group bonding and oxidation states.

Core-level spectroscopy is a powerful technique both because it is element specific and because the localized chemical bonding environment has a significant effect on spectral features. Spectra from carbon 1s electrons are in the energy region of $\sim 280-320 \mathrm{eV}$. At photon energies close to the absorption edge, sharp peaks can be observed in the NEXAFS spectra. These peaks arise from electronic resonance transitions of different functional groups and involve both $1 \mathrm{~s} \rightarrow$ $\pi^{*}$ and/or $1 \mathrm{~s} \rightarrow \sigma^{*}$ transitions (denoted as $\pi^{*}$ and $\sigma^{*}$ throughout this chapter). The transition peak width is governed by the Heisenberg uncertainty principle. Therefore, absorption features arising from excitation to short-lived states produce wider peaks in the absorption spectra and those to long-lived states result in sharp and narrow peaks such as the exciton peak observed in highly oriented graphite. Peaks arising from $\sigma^{*}$ transitions are usually broader than peaks from $\pi^{*}$ transitions and may be superimposed on the photoionization continuum. The peak positions can shift depending upon the local coordination environment around different atoms (electrondonating or electron-withdrawing groups). NEXAFS peak positions and intensities are used to determine functional groups and ultimately provide quantitative information on the functional groups present. Since the fine structure in the NEXAFS region above the ionization potential is broad with overlapping $\sigma^{*}$ transitions, usually only resonance transitions below the ionization 
potential are used to quantify chemical composition. Broad peaks can also arise from multiple electronic transitions that are close in energy and overlap with one another.

Specific peak positions are often noted in the literature; however, caution is necessary when assigning transitions based on specific positions. Urquhart and $\mathrm{Ade}^{35}$ examined carbonyl $\pi^{*}$ transition energies as a function of different bonding environments and observed that transition energies for a particular electronic transition can vary significantly. The transition energy depends upon a range of variables that affect the molecular orbital energies. These variables include neighboring electron withdrawing or donating groups, the presence of long range order or extensive bond conjugation or resonance. For complex environmental samples, an approach that assigns functional groups based on an energy range ${ }^{36,37}$ rather than a specific peak position is preferred. While not exhaustive, Fig. 5 provides guidance in assigning peaks to specific functional groups. Obtaining NEXAFS spectra at additional edges can provide further confirmation of peak assignments. For example, carbonyl $(\mathrm{C}=\mathrm{O})$ groups will exhibit a $\pi^{*}$ transition at both the carbon and oxygen K-edges (denoted by $\mathrm{C} 1 \mathrm{~s} \rightarrow \pi^{*} \mathrm{R}\left(\mathrm{C}^{*}=\mathrm{O}\right) \mathrm{R}$ and $\mathrm{O} 1 \mathrm{~s} \rightarrow \pi^{*}$ $\mathrm{R}\left(\mathrm{C}=\mathrm{O}^{*}\right) \mathrm{R}$, respectively). The presence of these two peaks can be spatially correlated with one another to confirm an assignment. ${ }^{38}$ Spectra from standards of known chemical composition can also aid in peak assignments.

\subsection{Polarization}

Although not discussed explicitly in the STXM/NEXAFS aerosol literature, polarization effects may be observed for crystalline and highly structured materials. While a detailed discussion is beyond the scope of this chapter, electronic transitions are polarization dependent and the reader is referred to Stöhr. ${ }^{27}$ The polarization dependence arises due to the directionality of chemical bonds and molecular orbitals. For K-shell excitation, the spatial orientation of the molecular orbital relative to the electric vector of the incident radiation determines the angular dependence. In a single bond, the $\sigma^{*}$ orbital is localized along the internuclear axis. Double bonded species, such as $\mathrm{C}=\mathrm{C}$ or $\mathrm{C}=\mathrm{O}$, have both the $\sigma^{*}$ as well as a $\pi^{*}$ orbital. NEXAFS spectra measured from highly oriented pyrolytic graphite display strong polarization dependence. 
Depending upon the insertion device employed, different polarizations may be produced; linear, circular or elliptically polarized.

If sample collection resulted in a preferential orientation of aerosols on the substrate, polarization dependence could be observed. In many atmospheric field campaigns the particleto-particle spectral variation would make it difficult to ascertain the presence of more subtle polarization effects. Soot, the atmospheric substance most likely to exhibit polarization dependence at the carbon edge is fortuitously constructed of spherically symmetric spherules. These are the spherules formed by graphitic soots and black carbons consisting of small sheets of graphite, stacked to create symmetric spherules on the order of 15-70 nm in diameter. These spherules then combine in fractal-like structures forming larger particles. Given the spherical symmetry, atmospheric black carbons and soots should not exhibit polarization dependence. However, if during combustion (or other processes) small sheets of oriented graphite are formed, they could exhibit polarization dependence. Evidence for this has been observed when examining changes in carbon bonding upon laser irradiation. ${ }^{39}$ Thus far, little evidence for polarization dependence has been observed in carbonaceous atmospheric aerosols.

\subsection{Aerosol Technique Comparison}

Figure 6 illustrates the different capabilities of a variety of electron, photon and ion imaging techniques used to study atmospheric aerosol particles. By far the most widely used techniques for aerosols are x-ray and electron microscopies; these offer the best combination of chemical information and spatial resolution. Transmission electron microscopy (TEM) offers high spatial resolution and a variety of different chemical detection schemes; however it is time consuming and not well-suited for analyzing organic species. Scanning electron microscopy (SEM) provides the advantage of high counting statistics but is limited to quantitative elemental

analysis of heavy elements $(Z>11)$ with a lower spatial resolution than TEM. Micro-Raman and Fourier transform infrared (FTIR) spectroscopy provide more bonding information, but at the expense of lower spatial resolution. Micro x-ray fluorescence (XRF), x-ray absorption (XAS) and proton induced x-ray emission (PIXE) are typically used for time-resolved bulk analysis of 
small amounts of particulate matter collected on filters. Secondary ion mass spectrometry coupled with a time-of-flight mass analyzer (TOF-SIMS) can perform elemental analysis while obtaining limited bonding information with a spatial resolution of $\sim 200 \mathrm{~nm}$.

While the spatial resolution of STXM is lower than TEM and SEM, it has several advantages over electron microscopy including: 1) chemical specificity, 2) higher energy resolution, 3) lower excitation energy (100-2000 eV versus 50-200 keV), 4) reduced radiation exposure (discussed in more detail in a following section), and 4) no ultra-high vacuum requirements. Therefore, STXM provides an enhanced chemical sensitivity for obtaining chemical bonding, speciation, and oxidation state information compared to electron microscopy.

Braun et al. examined SLX-25 graphite using STXM/NEXAFS and high resolution electron energy loss spectroscopy (EELS). ${ }^{40}$ As seen in Fig. 7, several carbon functional groups observed in STXM studies were not apparent in the EELS spectrum (dotted line). In the STXM/NEXAFS spectra shown in Fig. 7 (solid line), the $\mathrm{C} 1 \mathrm{~s} \rightarrow \pi^{*}{ }_{\mathrm{R}\left(\mathrm{C}^{*}=\mathrm{C}\right) \mathrm{R}}$ peak at $285 \mathrm{eV}$ is sharp and more intense than the $292 \mathrm{eV}\left(\mathrm{C} 1 \mathrm{~s} \rightarrow \sigma^{*}\right)$ peak. Whereas in the EELS spectra, the 285 $\mathrm{eV}$ peak is significantly broader and the $292 \mathrm{eV}$ peak is more intense. ${ }^{40}$ Katrinak et al. ${ }^{41}$ were also unable to observe oxygen functional groups in uncoated soot using EELS, while in contrast, Hopkins et al. ${ }^{42}$ observed oxygen in every uncoated soot/soot surrogate examined using STXM/NEXAFS. Hence, the EELS data is inconsistent with the STXM/NEXAFS studies. Braun et al. concluded that EELS was unable to detect carbonyl or carboxyl groups in soot. ${ }^{40}$ Hitchcock et al. showed that spectra obtained using TEM-EELS, partially due to the lower energy resolution, exhibit much less structural information than those obtained using STXM/NEXAFS. ${ }^{43}$

\subsection{Potential for Radiation Damage}

Detailed mechanisms of $\mathrm{x}$-ray damage are uncertain and the topic of current research; ${ }^{44-51}$ a journal issue was recently devoted to this topic. ${ }^{50}$ However, it is clear that exposure to radiation can change bonding within a sample. Soft x-ray photons are much lower in energy ( $\sim 300 \mathrm{eV}$ at the carbon K-edge) than the $50 \mathrm{keV}-100 \mathrm{keV}$ electrons used for TEM or SEM. 
Further, it is thought that a significant amount of sample damage results from dissipation of heat energy from energetic electrons and electron collisions. Generally, x-ray damage from STXM is considered to be at least two orders of magnitude lower than electron microscopy. ${ }^{52}$ This potential for less sample damage motivated some of the first STXM experiments on soft matter such as polymers. ${ }^{53}$ Several studies have been performed on radiation sensitive systems either by taking images at only a few key energies, ${ }^{32,54}$ or with the intention of patterning a sample. ${ }^{51,55}$

Radiation damage is often manifested as a decrease or increase in the intensity of a peak as a function of radiation exposure. For example, Braun et al. examined soot extracts with increasing $\mathrm{x}$-ray exposure and noted an increase in the $\mathrm{C} 1 \mathrm{~s} \rightarrow \pi{ }^{*}{ }^{*}{ }^{*} \mathrm{O}(\sim 290.2 \mathrm{eV})$ peak and a corresponding decrease in the $\mathrm{C} 1 \mathrm{~s} \rightarrow \pi^{*}{ }_{\mathrm{R}\left(\mathrm{C}^{*}=\mathrm{O}\right) \mathrm{OH}} 288.5 \mathrm{eV}$ peak. ${ }^{46}$ The radiation dose employed, $10^{6} \mathrm{~Gy}$ (Gy or Gray is the unit of the absorbed radiation dose of ionizing radiation), lies within a normal range for STXM experiments. The authors speculated that atmospheric oxygen present in their STXM experiments (not within a sealed chamber) could have contributed to the spectral changes observed. ${ }^{46}$ Attempts by our group to induce bonding changes in the carbon K-edge NEXAFS spectra from mixed composition aerosols containing soot (Mexico City samples), were unsuccessful. This could be due to the fact that the ALS STXMs are contained within an evacuated chamber and backfilled with helium. This is in contrast to the open STXM used by Braun et al. which was purged by a helium flow. ${ }^{46}$ Nevertheless, systematic examination for changes in bonding with radiation dose is a critical component in obtaining quantitative data. Because each electron absorbs x-ray photons, the absorption cross section increases with increasing atomic number. Hence, absorption increases across a row in the periodic table as well as down. ${ }^{50}$ This is consistent with experimental observations that sulfur containing aerosols were more sensitive to radiation exposure than carbonaceous aerosols. ${ }^{56}$ If a sample is radiation sensitive, images can be taken at a few chemically selective energies, ${ }^{32,54}$ short dwell times used, or spectra measured using a defocused mode. 


\subsection{Practical Sample Considerations}

\subsubsection{Sample Preparation and Collection}

While the broad categories of STXM aerosol experiments are deferred to section III, here a few brief remarks are made about samples and substrates. Although STXM measurements require only a single particle, most studies examine a large number of particles. Typically, samples are collected throughout a field campaign. Depending upon the research group's preference, samples are sealed and either stored at ambient temperatures or frozen. Atmospheric aerosols are often collected via impaction onto substrates. For maximum time resolution, impaction can be done using a time-resolved aerosol collector (TRAC) ${ }^{57}$ or multi-sample impactor. $^{58}$ Time resolved samples are collected for 2-20 minutes depending upon location of collection (ground based site or during flight) and local aerosol concentration. Regardless of lower aerosol concentrations, shorter collection times are often used during flights due to the rapid change in location and local conditions. For studies on cloud drop residuals, TRAC samplers can be located downstream of a counterflow virtual impactor (CVI), followed by a heater to selectively collect particles that formed droplets. Occasionally STXM substrates are taped to filters in a MOUDI cascade impactor (Micro Orifice Uniform Deposit Impactor, Applied Physics Co., Niwot, CO, USA).

Obtaining samples with good particle coverage (for example 6 or more particles in an 8 micron square region) with distinct individual particles is critical to optimize data acquisition. In the initial stages of a campaign a few samples are collected and inspected with a visual light microscope (VLM) or an SEM coupled with energy-dispersive x-ray spectroscopy (SEM/EDX) to ensure an appropriate level of sample loading on the substrates and alignment of the impactor nozzle. This pre-screening aids in developing protocols for collection under different aerosol loading conditions. Ideal impaction includes a region of the sample, where particles are distinct and separated (non-overlapping), yet closely spaced so time spent acquiring data on regions that are sparsely loaded is minimized. 
The VLM is also used prior to STXM data acquisition. Samples are photographed, the images calibrated to the STXM coordinates and read into the STXM data acquisition program to directly guide data acquisition. As time allocated on the STXM microscopes is normally limited, this step saves significant time in locating sample regions for potential data acquisition.

A variety of artifacts can influence the measured chemical composition and morphology of collected aerosols. For example, liquid droplets containing salts could dry upon collection and the relative solubility of each salt present will affect the final particle morphology. When using the TRAC or MOUDI impactor, impacted particles are exposed to reduced pressure conditions for up to 6 hours during collection with the MOUDI, or 48 hours with the TRAC sampler. Hence, a basic assumption is that all semi-volatile organics evaporate during collection. In addition, the STXM instrument is routinely either flushed with helium or partially evacuated to $\sim 80$ mTorr and backfilled with helium, both of which could result in additional losses of semi-volatile components. Therefore, STXM measurements provide a lower limit for organics.

For comparison with atmospheric samples, standards are prepared by a variety of impaction techniques or by a gentle contact of the silicon nitride membrane to a fine powder. Liquid standard samples are prepared by micro-pipetting a dilute solution onto the corner of the membrane and allowing the liquid to dry on the membrane. If wet samples are desired a sandwich surrounding the liquid can be formed by attaching a second silicon nitride window. Although not generally used for atmospheric aerosols, samples prepared by focused ion beam

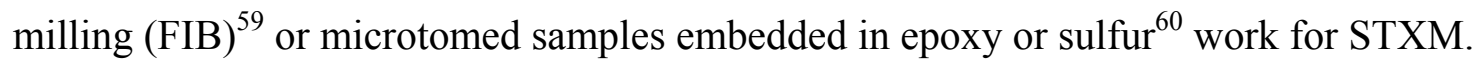

Generally, samples suitable for SEM or TEM also work well for STXM experiments. The most fundamental requirement for STXM measurements is that the absorption lies within the linear regime of Beer Lambert's law (approximately $30-80 \%$ absorption or OD 0.4 to 1.5 on a natural logarithmic scale).

\subsubsection{Substrates}

Several types of substrates are frequently used to collect atmospheric aerosols (or for standards) for STXM experiments. Silicon nitride windows $\left(\mathrm{Si}_{3} \mathrm{~N}_{4}\right)$ have a thin membrane $(50-$ 
$100 \mathrm{~nm}$ thick) placed on a silicon wafer. The wafer is then etched away to reveal an area containing only the thin membrane film. These have advantages of being relatively optically transparent in the soft $\mathrm{x}$-ray region as well as being a uniform film. One major disadvantage is that they are quite fragile and easily broken. Hence, the failure rate is high due to particle impaction when sampling in a region with large, dense particles with a relatively high inertia. Carbon coated TEM grids have a higher survival rate under these conditions. However, these films are composed of carbon and some oxygen and absorb in the energy range of interest. In our experience, these films are relatively uniform and with careful normalization can be used successfully in studies on carbonaceous aerosols. Silicon monoxide coated TEM grids are occasionally used when trying to minimize nitrogen absorption from $\mathrm{Si}_{3} \mathrm{~N}_{4}$ windows. Holey carbon films are another type of coated TEM grid; however, they are probably the least desirable. Often aerosols appear to spread along the holey carbon web and the non-homogenous thickness of the carbon web may result in a larger uncertainty in the spectral analysis.

2.7. Data Analysis

Several software programs are commonly used to analyze STXM data: AXIS $2000,{ }^{61}$ singular value decomposition analysis, ${ }^{62}$ a cluster analysis program, ${ }^{63-65}$ and MATLAB based scripts. As aerosol studies examine a large number of spectra from individual particles, or statistically examine specific spectral components within particles, Moffet et al.${ }^{66}$ developed a series of openly available MATLAB scripts ${ }^{67}$ In practice, data analysis often combines several of these methods and software. Regardless of which analysis program is used, several basic steps are required: image alignment, selection of a background region for $\mathrm{I}_{0}$, and conversion of the transmitted flux data into optical density, OD. Beyond these basic steps a range of techniques are used to extract, map, and quantify spectra from individual pixels as well as individual particles. A detailed description of the analysis is beyond the scope of this chapter and is provided both in individual publications, as well as in references to the software programs. 


\section{STXM/NEXAFS Aerosol Studies}

The primary advantages of STXM/NEXAFS over electron microscopies are: the ability to distinguish between carbon functional groups, the higher spectral energy resolution of STXM/NEXAFS, the reduced radiation exposure and subsequent sample damage, and (depending upon the insertion device) the capacity to change the polarization of the incident photons. Disadvantages include limited access to the STXM, fewer samples can be studied than automated microscopies, and obtaining the full elemental composition is impractical. Soil scientists, marine biologists, astrophysicists, and atmospheric scientists share common interests in naturally occurring carbon, minerals and their chemical processing. Hence, results from other environmental fields on humic and fulvic acids, ${ }^{34,68-76}$ soils and clays, ${ }^{45,77-85}$, marine and aquatic samples, ${ }^{86}$ natural organic matter, ${ }^{45,73,87}$ black carbons, ${ }^{81,88,89}$ char, ${ }^{36}$ minerals, ${ }^{77,90}$ biofilms, ${ }^{34,91-}$ 102 interstellar dust and particles, ${ }^{60,103-108}$ and meteorites ${ }^{105-107,109,110}$ may be of interest to atmospheric scientists.

Aerosols may be studied on a single particle basis or results combined with data from larger numbers of particles to provide statistical evidence to support broader conclusions. Typical atmospheric field campaigns employ a suite of measurements examining particle concentrations, size distributions, light absorption and scattering, composition, and meteorology. Results from these measurements can guide sample selection and help focus the scientific questions for STXM investigation. Research on atmospheric aerosols using STXM is currently limited and falls into a few categories; characterizing black carbons and light absorbing components within aerosols, characterizing organic carbons and chemical speciation of a variety of elements other than carbon (S, Fe, $\mathrm{Zn})$.

This section begins with research on black carbons/soots, light absorbing carbon, and biomass burn particulates. These studies provide the foundation for evaluating changes in carbonaceous aerosol mixing states and atmospheric processing of black carbons. In this section, details on analysis are provided that further illustrate the development (and limitations) of current analysis techniques. The progression has been to probe aerosols in a statistically 
representative manner by connecting STXM/NEXAFS results with collocated measurements and complementary spectromicroscopy measurements. It also reflects the growth in STXM research from more well-defined laboratory samples (polymers and magnetic samples) to complex and often poorly characterized environmental samples. The next section emphasizes research focused on the organic composition of aerosols and their processing. Both of these sections begin with studies on a handful of particles and grow to encompassing much larger numbers of samples and incorporate STXM measurements more fully within a larger picture. This organization allows the reader to develop an understanding of the method as well as the development of the analysis from a single sample to a statistical analysis. Next, we explore the more limited studies on chemical speciation of sulfur containing aerosols, and the identification and quantification of oxidation states for elements such as Fe, S and Zn. Finally, we survey recent studies on cloud droplet residuals and interstitial aerosols. The chapter closes with a brief discussion of recent and future developments of interest to the atmospheric community.

\subsection{Soot/Black Carbons/Brown Carbons}

Although its definition differs across fields, black carbon plays a critical role in nearly every environmental field. STXM work on black carbons explore the chemical inhomogeneities of carbonaceous samples including coals, ${ }^{111-115}$ soils, ${ }^{80,83-85}$ absorption of chemical species, ${ }^{88}$ carbon bonding changes from charring plant biomass, ${ }^{36}$ interplanetary dust particles, ${ }^{105-108,110,116}$ stardust comet samples, ${ }^{60,103,104}$ and marine sediments, ${ }^{86,89}$ as well as aerosol studies presented here. Many of the early STXM studies on soot, diesel exhaust, and black carbons focused on non-atmospheric samples. Early work on coal ${ }^{111-115}$ showed the potential for using STXM/NEXAFS to examine diesel exhaust particulate. Braun et al. examined diesel exhaust particulates for the purpose of source apportionment. ${ }^{117}$ Building on the concept of source apportionment, Vernooij et al. studied wood combustion and diesel combustion samples. ${ }^{37}$ However, they concluded that unequivocal source assignment based on NEXAFS spectra was unlikely due to the influence of atmospheric processing. With the eventual goal of monitoring changes in mixing states of aerosols containing black carbons (and light absorbing carbons), 
their atmospheric evolution, and in situ reactivity, Hopkins et al. ${ }^{42}$ sought to identify the ranges in bonding and composition of atmospheric black carbons and the variation in laboratory black carbon surrogates. They observed a significant range in the carbon bonding of these surrogates, but determined that it was much less than that in atmospheric light absorbing aerosols. This large variation in carbon bonding for light absorbing atmospheric aerosols was also seen in a study focused on aged tar balls. ${ }^{38}$ Laboratory generated biomass burn particulates were examined for carbon bonding, which was then correlated with measured optical properties. ${ }^{118}$ These studies provided the foundation to distinguish soot/black carbons from organic carbons and to monitor changes in mixing state with particle growth and age. ${ }^{119}$ Current, unpublished work on black carbons includes the influence of charring cellulose (with and without added salts) on carbon bonding as well as field studies on atmospheric processing.

The early STXM study of Braun et al. on diesel soot initially pursued source identification, ${ }^{117}$ it clearly indicated the potential of STXM for distinguishing graphitic carbon from hydrocarbons, organic or inorganic carbon, and indirectly motivated studies monitoring the evolution of the mixing states of carbonaceous aerosols. Diesel exhaust was collected onto filters, dispersed in acetone, ultrasonicated and deposited onto silicon nitride membranes. ${ }^{117}$ STXM images taken below the carbon absorption edge $(<283 \mathrm{eV})$ showed much lower absorption than images acquired at the peak of the $\mathrm{C} 1 \mathrm{~s} \rightarrow \pi^{*}{ }_{\mathrm{R}\left(\mathrm{C}^{*}=\mathrm{C}\right) \mathrm{R}}$ peak $(\sim 285 \mathrm{eV})$. In higher energy images $(>288 \mathrm{eV})$ more diffuse particle edges were observed. Although these particulate samples had been mixed in acetone, they clearly illustrated the ability of STXM to distinguish between graphitic and non-graphitic regions of carbonaceous particles with a spatial resolution of $\sim 50$ nm. ${ }^{117}$ Comparing flame soots and field collected biomass particles, Gilles et al. ${ }^{120}$ reported enhanced oxygenated peaks and decreasing graphitic content for some biomass samples. Subsequent STXM work by Braun examined NEXAFS spectra from a range of deposited combustion products: creosote (wood smoke deposits) from chimneys and wood burners, particulates from engines, and a NIST standard reference material (SRM 1648 Urban PM). ${ }^{121}$ Spectra from the wood smoke deposits and the NIST Urban particulate matter exhibited minor C 
$1 \mathrm{~s} \rightarrow \pi^{*}{ }_{\mathrm{R}\left(\mathrm{C}^{*}=\mathrm{C}\right) \mathrm{R}}$ peaks and were dominated by $\mathrm{C} 1 \mathrm{~s} \rightarrow \pi^{*} \mathrm{R}_{\mathrm{R}\left(\mathrm{C}^{*}-\mathrm{OH}\right)}$ and $\mathrm{C} 1 \mathrm{~s} \rightarrow \pi^{*} \mathrm{R}\left(\mathrm{C}^{*}=\mathrm{O}\right) \mathrm{OH}$ peaks. These initial studies by Gilles and Braun indicated that biomass burn particulates could have significantly different chemical bonding than fossil fuel combustion.

\subsubsection{Black Carbon/Soot Single Energy Images and Spectra}

With an ultimate objective of identifying black carbons/soots/light absorbing carbons in atmospheric aerosols using STXM/NEXAFS, Hopkins et al. ${ }^{42}$ examined a variety of laboratory surrogates for black carbons. For the black carbon surrogates, specifically flame generated soots, particles were not visible in images taken at the carbon pre-edge $(280 \mathrm{eV})$. This is in contrast to the pre-edge images of diesel soot, where absorbance (possibly due to the sample preparation or from non-carbonaceous components in the original sample) was observed. ${ }^{117}$ The lack of absorbance at energies below the carbon pre-edge $(<280 \mathrm{eV})$ and strong absorbance around $285.4 \mathrm{eV}$ is one of the identifying features for black carbon. Fig. 8 displays single energy images of particles collected during the MILAGRO field campaign. ${ }^{119}$ These images were recorded at the A) $278 \mathrm{eV}$ (carbon pre-edge), B) $\left.285.4 \mathrm{eV} \mathrm{C} 1 \mathrm{~s} \rightarrow \pi^{*}{ }_{\mathrm{R}\left(\mathrm{C}^{*}=\mathrm{C}\right) \mathrm{R}}, \mathrm{C}\right) 288.5 \mathrm{eV}$ carboxyl C $1 \mathrm{~s} \rightarrow \pi^{*}{ }_{\mathrm{R}\left(\mathrm{C}^{*}=\mathrm{O}\right) \mathrm{OH}}$, and D) $320 \mathrm{eV}$ at the carbon post-edge region. A subtraction map of total carbon shown in Fig. 8E is obtained by subtracting the pre-edge image (A) from the post-edge image (D). The component map shown in (F), discussed in a later section, identifies regions containing soot (EC), organic carbon (OC) and non-carbonaceous inorganic (IN) material. The particle indicted with a an arrow in (A) shows a stronger absorbance (relative to other particles) at the pre-edge indicating the presence of an element other than carbon, such as metals, mineral dust, salts and/or sulfur. In (C) this particle displays its strongest absorbance in the $288.5 \mathrm{eV}$ image, indicating a large carboxyl peak. In the total carbon map (E), the same particle indicated in (A) and (C) appears dark in the center with a brighter surrounding region. Hence, this particle appears to contain a crystalline inorganic inclusion surrounded by organic carbon.

The particle indicated with an arrow in Fig. 8B does not appear in Fig. 8A. The image recorded at $320 \mathrm{eV}$ shows a stronger absorbance for this particle compared to the image at 280 $\mathrm{eV}$ as a result of high carbon content in the particle. This pattern is consistent with carbonaceous 
particles containing considerable $\mathrm{C}=\mathrm{C}$ bonds, and may be an indicator of soot. The difference map in (E) represents the total amount of carbon in the sample. This proves to be a useful tool for a preliminary identification of a particle as soot/black carbon particles or as a soot/black carbon inclusion. Black carbon has a density of $\sim 1.8 \mathrm{~g} \mathrm{~cm}^{-3}$ whereas organic compound densities are closer to $\sim 1 \mathrm{~g} \mathrm{~cm}^{-3}$. Hence, at the carbon $\mathrm{K}$-edge, a $100 \mathrm{~nm}$ thick black carbon particle will absorb nearly a factor of two more strongly than organic carbon simply due to the difference in carbon density. Thus, even without examining the NEXAFS spectra, the first indications that a particle contains soot/black carbon are single energy images at 280, 285.4, and $320 \mathrm{eV}$. Particles should have little or no absorbance in the $280 \mathrm{eV}$ image and the $285.4 \mathrm{eV}$ and $320 \mathrm{eV}$ images should have strong absorbance (of similar values). For soots/black carbons, absorbance should increase more strongly as a function of particle size than organics.

\subsubsection{C:O Atomic Ratios}

Figure 9 displays representative carbon and oxygen K-edge spectra for diffuse flame generated soot using methane for the fuel. The most prominent peaks in the carbon spectrum, C $1 \mathrm{~s} \rightarrow \pi^{*}{ }_{\mathrm{R}\left(\mathrm{C}^{*}=\mathrm{C}\right) \mathrm{R}}$ and $1 \mathrm{~s} \rightarrow \sigma^{*} \mathrm{C}^{*}-\mathrm{C}$ are indicated. The pre-edge backgrounds $(280 \mathrm{eV}$ for carbon and $525 \mathrm{eV}$ for oxygen) arise from the photoionization of valence electrons and the weak, but finite, absorption and scattering of other elements present in the sample. The difference between the post-edge and pre-edge absorbance represents the total amount of a particular element in a sample. For a two component carbonaceous system, calculating the $\mathrm{C}: \mathrm{O}$ ratio is relatively straightforward. ${ }^{38}$ These calculations neglect interactions between atoms and assume that at energies sufficiently far away from valence transitions, tabulated atomic cross sections are valid. Absorption edges for other elements are far away and neglected for these calculations as they would contribute only minor amounts to the observed difference between post-edge and preedge absorbance. Therefore, the total number of carbon, $x_{c}$, and oxygen, $x_{0}$, atoms in the sample is calculated using: ${ }^{38,42}$

$$
\frac{x_{O}}{x_{C}}=\frac{O D_{O} \mu_{C} Z_{C}}{O D_{C} \mu_{O} Z_{O}}
$$


where $\mu_{\mathrm{O}}, Z_{\mathrm{O}}$ and $\mu_{\mathrm{C}}, Z_{\mathrm{C}}$ are the mass absorption coefficients and atomic masses for oxygen and carbon atoms, respectively. The difference in optical density, $320 \mathrm{eV}-280 \mathrm{eV}$, is used to calculate the total carbon. Similarly the total oxygen can be calculated using pre and post-edge energies of $525 \mathrm{eV}$ and $550 \mathrm{eV}$, respectively. The values of $\mathrm{OD}_{\mathrm{O}}$ and $\mathrm{OD}_{\mathrm{C}}$ are obtained from the difference in the post-edge and pre-edge absorbance in the oxygen and carbon NEXAFS spectra measured over the same particle region. For the flame soots, n-hexane, ethylene and methane, C:O ratios were $\sim 85: 15$, which compares well with the elemental compositions of Akhter et al. ${ }^{122}$

To further evaluate the approximations used for calculating $\mathrm{C}: \mathrm{O}$ atomic ratios, aerosols of azelaic acid, isophthalic acid, glucose, ascorbic acid and malic acid were generated and impacted onto silicon nitride substrates. The NEXAFS spectra were measured at the carbon and oxygen $\mathrm{K}$-edges and the $\mathrm{C}: \mathrm{O}$ atomic ratios calculated from the spectra in a blind study. The resulting $\mathrm{C}: \mathrm{O}$ atomic ratios, as well as that calculated from the chemical formulas, are shown in Fig. 10. The difference between the measured $\mathrm{C}: \mathrm{O}$ and calculated atomic ratios was largest for malic acid (-36\%) and smallest for glucose $(6 \%)$. This method is useful for determining the relative amount of oxygen in single particles and in different types of particles within a sample. This method differs from mass spectrometric methods that can determine $\mathrm{C}: \mathrm{O}$ for organic, inorganic or both species, but not for soots/black carbons. ${ }^{123}$ STXM/NEXAFS determines C:O for the total particle (inorganic + organic + soot/black carbon). For samples containing significant amounts of other elements determining the $\mathrm{C}: \mathrm{O}$ ratio is further complicated as their often non-linear pre-edge and post-edge absorbance in the energy region where carbon and oxygen absorb, must be considered.

\subsubsection{Identifying Black Carbon/Soot via NEXAFS Spectra}

The carbon NEXAFS spectra of surrogate soots shown in Fig. 11 are scaled to a thickness of $100 \mathrm{~nm}$ and density of $1.8 \mathrm{~g} \mathrm{~cm}^{-3}$ using carbon mass absorption coefficients. ${ }^{29}$ This normalizes the spectra to the same total carbon and allows a more meaningful comparison. (The maximum OD measured for these samples was 1.2; clearly in the linear regime of Beer 
Lambert's law.) A magic angle spectrum of highly oriented pyrolytic graphite (HOPG) is included for comparison. All of these spectra display a strong peak at $\sim 285.3 \mathrm{eV}$, arising from the $\mathrm{C} 1 \mathrm{~s} \rightarrow \pi^{*}{ }_{\mathrm{R}\left(\mathrm{C}^{*}=\mathrm{C}\right) \mathrm{R}}$ transition, and a broader peak at $292 \mathrm{eV}$ corresponding to the $\mathrm{C} 1 \mathrm{~s} \rightarrow \sigma^{*} \mathrm{C}^{*}-\mathrm{C}$ transition. A valley is observed between these two peaks. This valley varies substantially due to overlapping peaks from multiple transitions and differences in bonding. As seen in Fig. 5, typical transitions in this energy region include aliphatic $\mathrm{C}-\mathrm{H}$ groups, ketones or carboxylic acid carbonyl peaks, ethers, and alcohols. Aside from hydrogen, a primary component of black carbon is oxygen. The flame generated methane soot oxygen K-edge spectra (Fig. 9) has a preedge $\mathrm{OD}$ at $525 \mathrm{eV}$, about a factor of two larger than observed in the carbon pre-edge. This enhanced absorbance arises from the extended tail of the carbon absorption spectrum as well as atomic scattering. The oxygen spectra contains a distinct peak at $\sim 531 \mathrm{eV}$ due to the $\mathrm{O}$ $1 \mathrm{~s} \rightarrow \pi^{*} \mathrm{C}=\mathrm{O}^{*}$ carbonyl transition. The presence of this peak in the oxygen spectra confirms that the carbonyl group should be present in the carbon spectrum, even if too weak to be resolved. Measuring spectra at multiple edges provides confirmation for spectral peak assignments. Although there are differences in the absorption spectra shown in Fig. 11, all of these (except perhaps the amorphous carbon) would be suspected of a black carbon/soot origin rather than organic or inorganic species in atmospheric aerosols. The dominant peak, $\mathrm{C} 1 \mathrm{~s} \rightarrow \pi^{*}{ }_{\mathrm{R}\left(\mathrm{C}^{*}=\mathrm{C}\right) \mathrm{R} \text {, with }}$ an intensity approximately equal to or greater than the absorbance at $320 \mathrm{eV}$, the disappearance of the particle in the pre-edges images with a strong absorbance at the post-edge, all indicate the possibility of a black carbon or soot.

\subsubsection{Spectral Deconvolution}

More quantitative information is obtained by spectral fitting of the NEXAFS spectra. Fitting routines employ an arctangent function for the ionization step at $\sim 290.3 \mathrm{eV}$ combined with the minimum number of Gaussian, Lorentzian, or Voigt, ${ }^{124}$ functions required to fit the observed spectra. Peak energies are set at the peak maxima of distinct spectral features and additional non-resolved peaks may be required to fit the measured spectrum. Spectral fitting

programs typically minimize the $\chi^{2}$ value by adjusting peak positions and peak widths are either 
fixed, or allowed to vary. For environmental samples, these fits provide a semi-quantitative method to compare samples of complex compositions. To ensure that changes in peak intensity are not a function of sample thickness, peak areas are normalized to the integral of the spectrum over the energy range for the particular edge. Studies may employ the approximation that the area under the peak for a particular functional group is representative of the number of bonds. For example, the percentage that a particular functional group contributes to the total carbon in the sample is estimated from the ratio of the integral of an individual peak ( $\pi^{*}$ or $\left.\sigma^{*}\right)$ to the integral of the spectrum over the energy range $280-320 \mathrm{eV}$ (some researchers integrate over smaller energy ranges). Additional uncertainty arises due to ambiguous peak assignments in the carbon NEXAFS spectra. As indicated in Fig. 4, multiple transitions can occur in a similar energy region resulting in poorly resolved spectral features. Comparison of transitions occurring in both the $\mathrm{C}$ and $\mathrm{O}$ (or $\mathrm{C}$ and $\mathrm{N}$ ) NEXAFS spectra can confirm the presence of specific functional groups. While not a rigorous treatment, given the chemical complexity of aerosol and of environmental samples in general, this may be the most reasonable method to compare relative compositions and provide additional insight into the nature of these samples.

\subsubsection{Quantifying the Graphitic Nature: $s p^{2}$ Hybridization}

The relative amount of graphitic $s p^{2}$ carbon can be estimated from the ratio of the area under the $\mathrm{C} 1 \mathrm{~s} \rightarrow \pi^{*}{ }_{\mathrm{R}\left(\mathrm{C}^{*}=\mathrm{C}\right) \mathrm{R}}$ peak $\left(A_{C=C}\right)$ to the overall area of the spectrum, for example in the region between 280 and $310 \mathrm{eV}\left(A_{280-310}\right)$ according to:

$$
f_{s p^{2}}=\frac{A_{C=C}}{A_{280-310}} .
$$

Similar to Lenardi et al. ${ }^{125}$ this can be referenced to the corresponding ratio for the HOPG magic angle spectrum, assuming a $100 \%$ abundance of $s p^{2}$ carbon using:

$$
f_{s p^{2}}^{\text {soot }}=\frac{A_{C=C}}{A_{280-310}} \frac{A_{280-310}^{H O P G}}{A_{C=C}^{H O P G}} .
$$

The area under the spectrum $A_{280-310}$ is obtained by numerical integration of the experimental data, and the area under the $\pi^{*}$ peak $A_{C=C}$ can be calculated by fitting this transition to a 
Gaussian function and integrating the area under the peak. ${ }^{38,39,42,118}$ The black carbons and soots in Fig. 11 are ordered by their graphitic content; highly ordered pyrolytic graphite (top) has the highest amount (100\%) and amorphous carbon (bottom) has the least (41\%). As noted above, if these spectra were observed in atmospheric samples, with perhaps the exception of amorphous carbon, they would all be identified as black carbon/soot.

This determination of the $s p^{2}$ hybridization is considered relative and semi-quantitative.

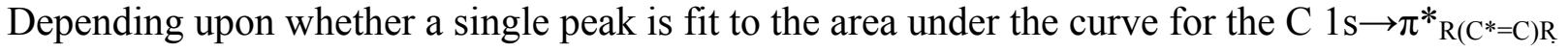
peak, or if the entire spectrum is deconvoluted, the $s p^{2}$ value may differ by as much as $15 \%$. Some additional uncertainties could arise due to possible polarization effects. Other methods for determining variations in carbon bonding include examining intensity variations ${ }^{41}$ in the $\pi^{*}$ peak versus the $\sigma^{*}$ in EELS spectra or by examining the $s p^{2} / s p^{3}$ ratios by fitting the region below 287 $\mathrm{eV}$ as $\pi^{*}$ and those between 294 and $301 \mathrm{eV}$ as $\sigma^{*} .{ }^{126}$ Each of these methods contains its own set of problems; none is perfect. A study combining Raman spectroscopy, another method used to estimate the graphitic nature of carbon, with STXM/NEXAFS could provide insight into systematic uncertainties in determining carbon bonding.

\subsubsection{Biomass Burn Aerosols}

Aerosols containing biomass burn particulate matter show a wider range in their carbon K-edge spectra than that observed for the black carbon/ soot surrogates. ${ }^{42}$ Anthropogenic combustion sources often exhibit a higher percentage of $s p^{2}$ bonded carbon compared to biomass burn particles. ${ }^{37,42}$ They also often exhibit a shoulder at $\sim 284.2 \mathrm{eV}$ attributed to a $\mathrm{C}=\mathrm{C}$ bond in the ring of quinone $\left(\mathrm{C} 1 \mathrm{~s} \rightarrow \pi^{*}{ }_{\text {quinone }\left(\mathrm{C}^{*}=\mathrm{C}\right)}\right)$. Occasionally the sharp exciton peak is observed in the carbon spectrum. Several studies report biomass burn influenced samples with a higher proportion of oxygen containing functional groups than those produced via anthropogenic combustion or even similarities between biomass burn particulates with humic-like substances or fulvic acids. Keiluweit et al. also recently observed significant changes in carbon bonding upon charring plant biomass. ${ }^{36}$ 
Hopkins et al. examined biomass burn particulate matter combining SEM/EDX and STXM/NEXAFS measurements produced from about a dozen fuels. ${ }^{118}$ The SEM images, elemental composition, and carbon K-edge NEXAFS spectra showed surprising variability. These range from fuels from semi-arid regions that contain salts and produce spectra, $s p^{2}$ hybridization, and $\mathrm{C}: \mathrm{O}$ ratios nearly indistinguishable (aside from the $\mathrm{K}$ doublet) from methane flame soots. Other samples were dominated by the presence of mixed carbonaceous and inorganic salts or produced a liquid/oily organic carbon with fractal inclusions. Hopkins et al. showed that the $s p^{2}$ hybridization was correlated with the measured optical absorbance at visible wavelengths. As Bond ${ }^{127}$ has shown, these types of correlations are clearly expected.

Vernooij et al. examined particulates from a village where ambient particulate matter is dominated by wood stove emissions and a sampling site dominated by traffic using TEM and STXM/NEXAFS. ${ }^{37}$ Diesel soot contained a C $1 \mathrm{~s} \rightarrow \pi^{*}{ }_{\text {quinone }\left(\mathrm{C}^{*}=\mathrm{C}\right)}$ peak $(\sim 284 \mathrm{eV})$, the $\mathrm{C} 1 \mathrm{~s} \rightarrow$ $\pi^{*}{ }_{\mathrm{R}\left(\mathrm{C}^{*}=\mathrm{C}\right) \mathrm{R}}$ peak $(\sim 285 \mathrm{eV})$ and a shoulder at $\sim 291 \mathrm{eV}$ resulting from the corresponding $\sigma^{*}$ transitions. The wood smoke particulates had a signature phenolic peak at $\sim 287 \mathrm{eV}$ with a smaller contribution from the $\mathrm{C} 1 \mathrm{~s} \rightarrow \pi^{*}{ }_{\mathrm{R}\left(\mathrm{C}^{*}=\mathrm{C}\right) \mathrm{R}}$ peak, however only $\sim 60 \%$ of the particulates were identified as wood smoke soot. The range and variation in particulates produced from biomass burning, the dependency on flaming versus smoldering conditions, and the propensity of specific fuels to flame or smolder are all poorly understood and ripe for additional studies.

\subsubsection{Tar balls}

Tar balls are amorphous carbonaceous spheres, with a structure distinctly different from soot, and have been observed in numerous field campaigns. ${ }^{128-130}$ Hand et al. performed extensive single particle analysis on samples collected at the base of Yosemite National Park during transport of an air mass impacted by forest fires in Oregon. ${ }^{131}$ The highest concentrations of light absorbing carbon were correlated with periods when SEM/EDX analysis indicated that tar balls dominated the particle samples. Tivanski et al. employed the results from the detailed particle analysis of Hand et al. to guide selection of samples from specific collection times for STXM experiments. The goal of STXM/NEXAFS in these experiments was to examine the 
carbon bonding and determine if there were any similarities with soots/black carbons that would account for their absorption of solar radiation in the atmosphere.

In Fig. 12, three different types of particles observed in this study are shown: the particles within circles are tar balls, the solid-line square surrounds an organic particle, and a dotted-line square indicates an agglomerate. Although not shown in this image, occasionally, particles were observed with a fractal structure of soot (and corresponding NEXAFS spectra). In this image, the organic particle, although larger in diameter, is lighter in color (less absorbing) than the smaller tar balls. To determine if the particles identified as tar balls were spherical, Tivanski et al. combined the 2-dimensional STXM/NEXAFS measurements with a model that allowed determination of a 3-dimensional particle shape. ${ }^{38}$ The averaged absorbance signal $<\mathrm{OD}(\mathrm{d})>$ through a spherical particle of uniform density $\rho$ and diameter $\mathrm{d}$ was determined from the following equation:

$$
\langle O D(d)\rangle=\frac{2}{d} \int_{0}^{d / 2} 2 \mu \rho \sqrt{(d / 2)^{2}-x^{2}} d x=\frac{\rho \mu d}{2 \sin (1)}=A \rho \mu d
$$

where $\mathrm{x}$ was the radius variable and $A=1 / 2 \sin (1) \approx 0.59$ for a perfect sphere. The maximum optical density, $O D_{\max }(d)=\rho \mu d$, corresponds to the absorption through the center of the sphere. Thus for a spherical particle, a plot of the particle's average absorbance versus its maximum absorbance yields a line with slope $A=0.59$ and an intercept of zero. Figure 13 displays the measured averaged absorbance versus the maximum absorbance for the $\mathrm{C}$ edge at $320 \mathrm{eV}$. The mean absorbance value for $\sim 7$ particles in $\sim 50 \mathrm{~nm}$ wide bins (based on their diameters) is represented by each cross. A fit to the data yielded a slope of $0.59 \pm 0.03$. Although not shown here, the analogous plot at the $\mathrm{O}$ edge at $550 \mathrm{eV}$ yielded a slope of $0.6 \pm 0.05$. Both of these slopes are in excellent agreement with the predicted slope of 0.59 , implying that tar balls are essentially perfect spheres of uniform densities, and that the majority of $\mathrm{C}$ and $\mathrm{O}$ atoms are homogeneously distributed throughout the tar ball. (A discussion below considers an inhomogeneous surface coating with a thickness similar to the spatial resolution of the STXM/NEXAFS experiments.) If the particles had been shaped like a flat disc (pancake), the 
maximum optical density would be equal to the averaged optical density. Hence, although STXM/NEXAFS is strictly a 2-dimensional imaging technique some information on the $3^{\text {rd }}$ dimension is obtained.

The fact that tar balls are perfect spheres of uniform densities with homogeneous distribution of $\mathrm{C}$ and $\mathrm{O}$ atoms uniquely allows a quantitative determination of their elemental composition and particle density. Tivanski et al. ${ }^{38}$ developed an analytical model that predicts linear relationship between the averaged total carbon (oxygen) absorbance and tar ball diameter with the slope that depends on atomic carbon to oxygen ratio and the particle density. Using the model and measured size-dependent total carbon and oxygen absorbencies, the atomic ratio of $\mathrm{C}$ to $\mathrm{O}$ was determined to be $1.2(55 \% \mathrm{C}, 45 \% \mathrm{O})$, with a total density of $0.75 \mathrm{~g} / \mathrm{cm}^{3}{ }^{38}$

One of the primary interests in tar balls is that they are correlated with the absorption of long wavelength solar radiation. Typically soots and graphitic carbons are the most strongly absorbing species at long wavelengths in the visible spectrum. NEXAFS spectra of $\sim 150$ tar balls were measured and compared to spectra of black carbons and humic-like substances. Figure 14 displays a representative tar ball spectrum as well as spectra for soot (measured in the same samples as the tar balls), humic and fulvic acids. Tar ball spectra were unique in that unlike most atmospheric samples, there was almost no particle to particle variation in the spectra. As previously reported, ${ }^{130,131}$ tar balls were extremely insensitive to radiation exposure. Spectra measured on samples that had been examined via SEM analysis were identical to those measured using very low radiation STXM scans. A single particle was scanned repeatedly, for a total of $\sim 5$ times at normal radiation exposure and the spectra did not vary. Tar ball spectra measured on samples from African biomass burn were identical to those reported by Tivanski et al. ${ }^{38}$ Vernooji et al. report tar ball spectra with greatly reduced carboxyl carbonyl intensity. ${ }^{37}$ While this discrepancy could be due to the different types of fuel (dried wood versus live biomass) it is unclear if they rigorously determined that the particles they observed were spherical. 
The tar ball $\mathrm{C}$ edge spectrum contains four sharp resonance transitions at 285.1 (C $1 \mathrm{~s} \rightarrow$ $\pi^{*}{ }_{\mathrm{R}\left(\mathrm{C}^{*}=\mathrm{C}\right) \mathrm{R}}, 286.7$ (possible transitions: $\mathrm{C} 1 \mathrm{~s} \rightarrow \pi_{\mathrm{R}\left(\mathrm{C}^{*}=\mathrm{O}\right) \mathrm{R}}, \mathrm{C} 1 \mathrm{~s} \rightarrow \pi^{*}{ }_{\text {quinone }\left(\mathrm{C}^{*}=\mathrm{O}\right)}, \mathrm{C} 1 \mathrm{~s} \rightarrow$ $\left.\pi^{*}{ }_{\text {phenolic( }\left(\mathrm{C}^{*}-\mathrm{OH}\right)}\right), 288.5 \mathrm{eV} \mathrm{C} \mathrm{1s} \rightarrow \pi^{*}{ }_{\mathrm{R}\left(\mathrm{C}^{*}=\mathrm{O}\right) \mathrm{OH}}$ and $289.5 \mathrm{eV}$ (possible functional groups; $\mathrm{C} 1 \mathrm{~s}$

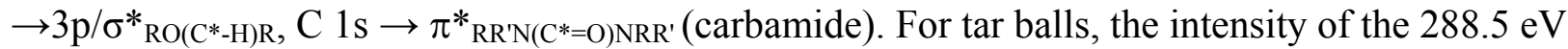
and $289.5 \mathrm{eV}$ peaks were strongly correlated. A weak $\left(\mathrm{R}^{2} \approx 0.4\right)$ correlation between the peak at 286.7 and the $531.8 \mathrm{eV}$ peak $\left(\mathrm{O} 1 \mathrm{~s} \rightarrow \pi^{*}{ }_{\mathrm{R}\left(\mathrm{C}=\mathrm{O}^{*}\right) \mathrm{R}}\right)$ in the oxygen spectra indicates at least a partial contribution from a ketonic carbonyl. However, comparison of the spectra shown in Fig. 14 indicates that tar ball bonding is different from soot and more similar to humic and fulvic acids. The spectra from these acids and the tar balls all contain relatively small contributions from aromatic carbon $(\mathrm{C}=\mathrm{C})$, ketonic carbonyl and a large contribution from carboxylic carbonyl. Additional insight into the nature of tar balls was obtained by normalizing the functional group intensities to the total carbon and plotting this as a function of diameter. An example of this is shown for the carboxylic carbon in Fig. 15. If a specific functional group is more concentrated at the surface at smaller particle diameters, its contribution will be enhanced, similar to the surface limited oxidation described in Maria et al., ${ }^{132}$ described in a following section. While the carboxylic and O-alkyl-C functional groups display a dependence on particle diameter, the aromatic and ketonic carbonyls showed no dependence on particle diameter. These results indicate the presence of an oxygenated layer at the surface of the tar balls that is thinner than the STXM spatial resolution (35 $\mathrm{nm}$ for this study).

\subsubsection{Evolution of Aerosol Mixing States}

Applying the soot identification method of Hopkins et al., ${ }^{42}$ Moffet et al. performed an analysis of particles collected from three sampling sites located progressively farther from the Mexico City center: T0, T1, and T2. ${ }^{119}$ The sample date was selected to coincide with a time of air-mass transport from the city center toward the peripheral sites. Soot was identified by identifying particles that contained regions with $\geq 35 \% s p^{2}$ hybridized carbon. Figure 16 demonstrates how C K-edge NEXAFS spectra change by selecting only regions having a $\% s p^{2}$ above a specific value. From Fig. 16, it is clear that organic coatings are visible below 35\% $s p^{2}$; 
at and above $35 \% s p^{2}$ only particle cores are visible. In Fig. 11, all soots had $\mathrm{C} 1 \mathrm{~s} \rightarrow \pi^{*}{ }_{\mathrm{R}\left(\mathrm{C}^{*}=\mathrm{C}\right) \mathrm{R}}$ peak intensities greater than the absorbance due to total carbon at $320 \mathrm{eV}$. In Fig. 16, below a threshold of $35 \% s p^{2}$, the absorbance at $285 \mathrm{eV}\left(\mathrm{C} 1 \mathrm{~s} \rightarrow \pi^{*}{ }_{\mathrm{R}\left(\mathrm{C}^{*}=\mathrm{C}\right) \mathrm{R}}\right)$ is less than that at $320 \mathrm{eV}$. Additionally, both the total carbon and the intensity of the $\mathrm{C} 1 \mathrm{~s} \rightarrow \pi^{*}{ }_{\mathrm{R}\left(\mathrm{C}^{*}=\mathrm{C}\right) \mathrm{R}}$ peak rapidly increase above $35 \% s p^{2}$, consistent with previous measurements of soot spectra. Inorganic, predominantly non-carbonaceous, regions within particles were identified by a pre-edge (278$280 \mathrm{eV})$ to post-edge $(320 \mathrm{eV})$ ratio of 0.6 . Organic regions were identified by absorption at the energy of the $\mathrm{C} 1 \mathrm{~s} \rightarrow \pi^{*}{ }_{\mathrm{R}\left(\mathrm{C}^{*}=\mathrm{O}\right) \mathrm{OH}}$ peak. ${ }^{66}$ The assignment of inorganic regions was confirmed with CCSEM/EDX; as in samples from other sites, the large pre-edge absorbance could be attributed to salts and mineral dust. ${ }^{86}$ Each of the identifying components - soot (EC-elemental carbon), inorganic (IN), and organic (OC) - were used to label particles in order to quantify trends in particle type number fractions. These components were used to derive singular value decomposition maps of particles from the three sampling sites as shown in Fig. 17 (T0, T1 and T2 are shown in panels $\mathrm{A}, \mathrm{B}$ and $\mathrm{C}$, respectively).

Fig. 17 demonstrates the complex, internal heterogeneous mixtures of components within particles at T0. Farther from the city center, the number fraction of homogenous organic particles (OC) lacking both soot and inorganic inclusions (Fig. 17) increased. Although these particles lacked organic inclusions, by examining the sulfur edge it was determined that inorganic sulfate was homogenously mixed with the organic material.

As shown in Fig. 17, NEXAFS spectra for the organic carbon indicated a relative increase in all carbon functionalities (increased spectral congestion) with the exception of $s p^{2}$ hybridized carbon. The decrease in $s p^{2}$ with distance from the city center was determined to be either from condensation and/or oxidation processes. All of the soot inclusions identified in Mexico City had a strong contribution from $\mathrm{COOH}$ groups, indicating possible surface reactions or rapid photochemical oxidation and condensation of gas phase species. As with the organic carbon, the $\% s p^{2}$ of the soot inclusions decreased with increasing time and distance from the 
urban center. However, these heterogeneous processes could not be decoupled from the condensation of gas phase organics.

Fig. 18 presents number fractions of particles containing combinations (or absenceNOID) of these three components, EC, OC, and IN, at each sampling site. The increase in organic carbon particles without inorganic or soot inclusions as a function of distance from the city center was attributed to the growth of ultrafine particles by secondary aerosol condensation. This observation was confirmed by demonstrating that the average size of the homogeneous OC particles increased with distance from the urban center. This study from Mexico City is the first STXM investigation to account for multi-component particles containing soot, noncarbonaceous inorganic species, and organic carbon. These results clearly indicate that the mixing state of the particles changed with plume age. Such changes are expected to strongly influence chemical and physical properties such as hygroscopicity and optical properties.

Knopf et al. used samples collected at the same locations and similar times as those analyzed by Moffet et al. ${ }^{119}$ to examine their ice nucleation activity. ${ }^{133}$ The particles collected from Mexico City nucleated ice under cirrus cloud temperatures and relative humidities. This finding is notable because the STXM/NEXAFS showed they have a large organic content. Presumably even dust particles, which normally make efficient ice nuclei, would be coated with organics and thought to be rendered inactive with respect to ice nucleation. Previous ice nucleation studies have suggested that organic dominated particles would not serve as ice nuclei under cirrus cloud conditions.

\subsection{Organic Carbon}

Russell et al. ${ }^{58}$ were the first to use STXM to map a variety of organic functional groups on individual aerosol particles. Ratios of carboxylic to aliphatic compounds on individual particles indicated surface coatings of shorter chains or more oxygenated groups. This observation indicated that the particles underwent heterogeneous surface oxidation. This study provided a first glimpse of the variable nature of organics in single particles at an unprecedented spatial resolution. Maria et al. ${ }^{132}$ demonstrated the utility of STXM/NEXAFS for determining 
organic aerosol growth processes by exploiting particle size resolved organic composition. The size dependence of the functional group mass ratio with respect to either total mass or total carbonaceous mass was used to infer organic growth mechanisms. Total mass was assumed to be proportional to the optical density of the region between $278-280 \mathrm{eV}$. Carbon mass was taken to be proportional to the difference between the absorption at $303-305 \mathrm{eV}$ and $278-280 \mathrm{eV}$. As illustrated in Fig. 19, if particles undergo surface limited oxidation, the ratio of oxidized functional group to total carbon will be enhanced for smaller particles due to their larger surface to volume ratio. Conversely, if particles undergo volume limited oxidation, the spatial distribution of carbonyl groups should be uniform due to fast diffusion of reactants compared to the kinetics of reaction. In the case of a volume limited reaction, the oxidized functional group to total carbon mass ratio would not be size dependent. Using this approach for atmospheric samples, surface limited reactions were found to occur for particles sampled in low relative humidity environments and for particles that likely contained insoluble compounds. Volume limited reactions were found to occur for particles sampled under high relative humidity conditions. By combining the STXM/NEXAFS results with additional information provided by FTIR and air-mass back trajectories, it was concluded that the oxidation rate used in current models was three times faster than the observations.

Incorporating data from several field campaigns, Takahama et al. ${ }^{134}$ demonstrated the first use of spectral cluster analysis to identify individual particle types using the carbon K-edge NEXAFS spectrum. Particle cluster analysis performs an automated grouping of similar spectra based on mathematical criteria. Individual particles were grouped into fourteen different particle types, shown in Fig. 20. The most abundant particle type (a), presumably secondary organic aerosol (SOA), was dominated by the carboxylic peak. This observation highlighted the ubiquity of carboxylic acids in particles sampled over different geographical regions. Furthermore, organic classes indicated in Fig. 20 (panel 2) had little contribution from the $\mathrm{C} 1 \mathrm{~s} \rightarrow \pi^{*}{ }_{\mathrm{R}\left(\mathrm{C}^{*}=\mathrm{C}\right) \mathrm{R}}$ peak. Other particle types were defined based on the abundance of $\mathrm{C}=\mathrm{C}\left(\mathrm{C} 1 \mathrm{~s} \rightarrow \pi^{*} \mathrm{R}\left(\mathrm{C}^{*}=\mathrm{C}\right) \mathrm{R}\right)$, $\mathrm{CO}_{3}\left(\mathrm{C} 1 \mathrm{~s} \rightarrow \pi^{*}{ }^{*}{ }{ }_{03}\right)$, and $\mathrm{K}\left(\mathrm{L}_{2} 2 \mathrm{p}_{1 / 2,3 / 2} \rightarrow \sigma^{*}\right)$. Particle types with large contributions from 
$\mathrm{C}=\mathrm{C}$ most likely contain soot (Fig. 20, panel 1); within soot particle types, there are different amounts of oxidized functional groups presumably due to differences in atmospheric processing. The presence of $\mathrm{K}$ in the particles (Fig. 20, panel 2) may be indicative of either dust or biomass burning. If particles contained both $\mathrm{K}$ and $\mathrm{CO}_{3}$ (Fig. 20, panel 3) they were classified as dust based on their similarity with the pine ultisol soil NEXAFS spectrum. ${ }^{2}$

The approaches of Maria et al. ${ }^{132}$ and Takahama et al. ${ }^{134}$ were combined in the analysis of airborne samples taken as part of the INTEX-B field campaign. ${ }^{135}$ INTEX-B covered the western Pacific Ocean as well as California, Oregon and Washington. ${ }^{132,134,135}$ The majority of particles observed during INTEX-B were attributed to SOA formation processes based on the submicron size and dominant contribution from carboxylic acid. The methods of Maria et al. ${ }^{132}$ were employed to show that growth of organic aerosol occurs via both condensation and surface limited processes. ${ }^{135}$

As part of the INTEX-B campaign, a separate study focused on the analysis of dust transported from Asia. ${ }^{136}$ Dust plumes observed at Whistler, British Columbia were associated with an increase in sulfate, indicating anthropogenic influences. These plumes occurred with a very low concentration of accumulation mode organics. Half of the NEXAFS spectra sampled during the Asian dust event indicated characteristic peaks for dust $\left(\mathrm{K}\right.$ and $\left.\mathrm{CO}_{3}\right)$ in addition to a well defined carboxyl peak. This finding was corroborated by ion chromatography of water extracted filters, which showed significant concentrations of coarse mode formate $\left(\mathrm{CHO}_{2}{ }^{-}\right)$. The mixing of carboxylic acids and dust within a particle indicates that the mineral dust acts as a condensable surface for organics. The authors concluded that the condensation of organics on large dust particles may diminish their indirect radiative forcing while potentially enhancing direct forcing.

To analyze particles from Mexico City, Liu et al. ${ }^{137}$ followed a method similar to Takahama et al., ${ }^{134}$ but used positive matrix factorization in addition to k-means clustering. Samples were collected aboard an aircraft on a high altitude mountain and at an urban site. Three main aerosol types were classified based on their carbon K-edge spectra. By number, soot 
particles were most abundant (70\% of the total number) followed by biomass burning and processed/secondary particles. Biomass burning particles had spectra similar to those of fulvic acid and tar balls. ${ }^{38}$ The secondary/processed particle type had a dominant carboxylic acid contribution, consistent with the studies outlined previously. Although distinct differences were seen in the number fractions of different particle types, the positive matrix factorization (PMF) factors exhibited approximately equal contributions from three factors, biomass, secondary/processed, and soot. This difference may arise because while there were more soot particles than organic particles, the organic particles contained more mass.

\subsection{Inorganic Species}

The potential to explore chemical bonding and oxidation states of sulfur and transition metals is of interest to atmospheric and environmental scientists because they provide insight into branching ratios and chemical processing. Ultimately, aerosol toxicity may be related to specific oxidation states, hence, such studies could be important to understand health affects of aerosols. To date, only a few studies have focused on speciation of metals, such as manganese, iron, or sulfur, in environmental samples. ${ }^{77,94,96,138}$ This section discusses STXM/NEXAFS studies characterizing the bonding and oxidation states of metals ( $\mathrm{Zn}$ and $\mathrm{Fe}$ ) and sulfur partitioning in the marine boundary layer.

\subsubsection{Speciation of Zn containing aerosols}

Historically, ambient aerosol measurements in Mexico City have indicated elevated $\mathrm{Pb}$, $\mathrm{Zn}$ and $\mathrm{Cl}$ levels in some neighborhoods. During the MILAGRO campaign, single particle mass spectrometry measurements indicated a daily cycle of internally mixed $\mathrm{Pb}, \mathrm{Zn}$, and $\mathrm{Cl}^{139}$ Combining the chemical evidence with the observation that the daily cycle was suppressed over weekends and holidays, it was concluded that their source was likely to be either industrial smelting and/or garbage burning. Because of the widespread nature of these particles and the increased blood lead levels in children residing in these neighborhoods, ${ }^{140}$ the speciation and morphology was pursued using STXM/NEXAFS and CCSEM/EDX. Microscopic information is important since particle morphology and speciation controls uptake by the human body. 
$\mathrm{CCSEM} / \mathrm{EDX}$ measurements indicated that particles containing the characteristic mixture of $\mathrm{Pb}$, $\mathrm{Zn}$, and $\mathrm{Cl}$ generally had two morphologies: compact structures and needle like structures. Based on their tetrahedral morphology and chemical composition some needle-like particles were hypothesized to be ZnO. As shown in Fig. 21, STXM/NEXAFS measurements at the Zn Ledge confirmed the presence of needle-like $\mathrm{ZnO}$ particles. An additional particle type composed of $\mathrm{Zn}\left(\mathrm{NO}_{3}\right)_{2}$ was also observed. Representative $\mathrm{Zn}$ L-edge NEXAFS spectra for both ambient particle classes along with standards $\left(\mathrm{Zn}\left(\mathrm{NO}_{3}\right)_{2} \cdot 6 \mathrm{H}_{2} \mathrm{O}\right.$ and $\left.\mathrm{ZnO}\right)$ are shown in Fig. 21 . The comparison with the ambient particle spectra with the standard spectra in Fig 21 provide clear chemical identification. $\mathrm{Zn}\left(\mathrm{NO}_{3}\right)_{2}$ may be formed from the reaction of $\mathrm{ZnCl}_{2}$ with $\mathrm{HNO}_{3}$. Mass spectrometry measurements showed the replacement of $\mathrm{Cl}$ by $\mathrm{NO}_{3}$ on particles containing $\mathrm{Zn}$, $\mathrm{Pb}$ and $\mathrm{Cl}$. Presumably, $\mathrm{PbCl}_{2}$ undergoes a similar reaction to form $\mathrm{Pb}\left(\mathrm{NO}_{3}\right)_{2}$. Measurements at the carbon K-edge confirmed the single particle mass spectrometry observation that metals were internally mixed with soot, indicating a combustion source. This study illustrates the capacity for transition metal speciation using STXM/NEXAFS, as well as the benefits of combining STXM with other micro-spectroscopic (CCSEM/EDSX) and mass spectrometric techniques.

\subsubsection{Fe Speciation}

It is estimated that the majority of bioavailable iron in the ocean comes from aerosols. Hence, understanding the origins, transport, and eventual fate of iron is of interest in several environmental fields. Several groups have explored iron speciation in oceans, ${ }^{101,141}$ biofilms, ${ }^{91,93,96,99,142-145}$ and aerosols, ${ }^{146}$ using STXM. Although dust dominates Fe containing aerosol, anthropogenic/industrial sources can also be important. As demonstrated in Fig. 22, using the methods of Dynes et al. ${ }^{96}$ and Takahama et al. ${ }^{146}$ using STXM at the Fe L edge, spatially resolved Fe speciation for nanometer to micron sized particles are obtained. Takahama et al. ${ }^{146}$ determined Fe oxidation states using analysis methods established by Dynes et al. ${ }^{96}$ and references therein. In Takahama et al., ${ }^{146} 63$ particles (from a variety of samples) indicated Fe (II) fractions from $0-0.73$. The absence of a strong correlation between Fe (II) fraction and distance from the particle surface indicated that surface reactions did not control Fe speciation. 
Furthermore, no correlation between organic carbon and Fe (II) fraction was observed, implying that organic ligands did not play a noticeable role in determining Fe speciation. However, a group of spherical particles (collected during the ACE Asia campaign) had both high Fe(II) fraction and organic carbon content; it was hypothesized that these particles were associated with biomass burning.

\subsubsection{Marine Boundary Layer Sulfur Speciation}

Although more bonding information is obtained at the L-edge, there are only a few studies at this edge ${ }^{147,148}$ and most sulfur NEXAFS spectra have been measured at the K-edge. ${ }^{1}$ During the Marine Stratus Experiment (MASE), dry residue particles from individual cloud droplets and interstitial aerosol were analyzed using an array of complementary microspectroscopic techniques at the Environmental Molecular Science Laboratory (collaboration with A. Laskin) combined with sulfur L-edge STXM/NEXAFS from the ALS. This study was aimed at chemical speciation of particulate sulfur. ${ }^{56}$

CCSEM/EDX provided microscopic particle imaging and quantitative elemental compositions. Analysis of $\sim 10,000$ particles indicated two prominent particle classes: sea salt or sulfur-rich (S-rich) particles. S-rich particles were submicron in diameter and spherical. Sea salt particles were cubic-shaped crystals, with diameters larger than $1 \mu \mathrm{m}$, surrounded by irregularly shaped residues. TOF-SIMS showed that sea salt particles contained both $\mathrm{CH}_{3} \mathrm{SO}_{3}{ }^{-}$and $\mathrm{SO}_{4}{ }^{2-}$ while S-rich particles were composed of a mixture of $\mathrm{H}_{2} \mathrm{SO}_{4}$ and $\left(\mathrm{NH}_{4}\right)_{2} \mathrm{SO}_{4}$.

STXM/NEXAFS analysis sought to quantify $\mathrm{CH}_{3} \mathrm{SO}_{3}{ }^{-} / \mathrm{SO}_{4}{ }^{2-}$ ratios within individual sea salt particles because this ratio is indicative of different chemical processes in the marine boundary layer. (Note: the STXM/NEXAFS measurements list only the anion as several cationic species could be paired with these species.) Figure 23 shows a representative STXM carbon Kedge image $(290.8 \mathrm{eV})$ indicating two particle classes: circles for S-rich and squares for sea salt. Maps generated by principle component analysis (PCA) of STXM/NEXAFS spectra taken at the carbon (B), nitrogen (C), and sulfur edges (D) are shown. These maps indicate that particles may contain carbon or nitrogen, but do not contain both. The PCA maps indicate two different types 
of sulfur; one component associated with carbon (grey) and a different component associated with nitrogen (black). This is consistent with particle compositions of either mixed sea salt $/ \mathrm{CH}_{3} \mathrm{SO}_{3}{ }^{-} / \mathrm{SO}_{4}{ }^{2-}$ (grey) or mixed $\mathrm{H}_{2} \mathrm{SO}_{4} /\left(\mathrm{NH}_{4}\right)_{2} \mathrm{SO}_{4}$ (black). For comparison, reference sulfur L-edge NEXAFS spectra of $\mathrm{Na}_{2} \mathrm{SO}_{4},\left(\mathrm{NH}_{4}\right)_{2} \mathrm{SO}_{4}$, and $\mathrm{CH}_{3} \mathrm{SO}_{3} \mathrm{Na}$ were measured. Sulfur spectra recorded from $\left(\mathrm{NH}_{4}\right)_{2} \mathrm{SO}_{4}$ and $\mathrm{Na}_{2} \mathrm{SO}_{4}$, were identical to one another with three distinct peaks. However, the $\mathrm{CH}_{3} \mathrm{SO}_{3} \mathrm{Na}$ spectrum had no resolvable peaks. Particles containing nitrogen (black) display a sulfur L-edge NEXAFS spectrum indicative of $\mathrm{SO}_{4}{ }^{2-}$ (consistent with mixed $\mathrm{H}_{2} \mathrm{SO}_{4} /\left(\mathrm{NH}_{4}\right)_{2} \mathrm{SO}_{4}$ composition). Particles indicated with grey had sulfur L-edge spectra that were intermediate between $\mathrm{CH}_{3} \mathrm{SO}_{3}{ }^{-}$and $\mathrm{SO}_{4}{ }^{2-} \mathrm{NEXAFS}$ spectra (consistent with a mixed sea salt $/ \mathrm{CH}_{3} \mathrm{SO}_{3}{ }^{-} / \mathrm{SO}_{4}{ }^{2-}$ composition). Combining the $\mathrm{Na}_{2} \mathrm{SO}_{4}$ and $\mathrm{CH}_{3} \mathrm{SO}_{3} \mathrm{Na}$ spectra would both broaden the resolved peaks and alter relative peak intensities. Using linear combinations of the $\mathrm{Na}_{2} \mathrm{SO}_{4}$, and $\mathrm{CH}_{3} \mathrm{SO}_{3} \mathrm{Na}$ reference spectra, a calibration curve was generated for the peak heights. Spectra from $\sim 100$ individual mixed sea salt $/ \mathrm{CH}_{3} \mathrm{SO}_{3}{ }^{-} /$non-sea salt- $\mathrm{SO}_{4}{ }^{2-}$ particles were measured and their $\mathrm{CH}_{3} \mathrm{SO}_{3}{ }^{-}$/total- $\mathrm{SO}_{4}{ }^{2-}$ ratio determined using the calibration curve. The CCSEM/EDX, TOF-SIMS and STXM/NEXAFS data are all consistent with one another and indicate enhanced formation of particulate $\mathrm{CH}_{3} \mathrm{SO}_{3}{ }^{-}$in sea salt droplets and particles. This unique combination of single-particle measurements enables quantitative assessment of $\mathrm{CH}_{3} \mathrm{SO}_{3}{ }^{-}$/non sea salt-SO ${ }_{4}{ }^{2-}$ ratios in individual particles. On the basis of particle morphology, chemical composition and chemical bonding, two types of sulfur containing particles were identified: chemically modified or aged sea salt particles and sulfate particles. Previously, only bulk measurements, which are an average over all particle types, had examined sulfur partitioning of methanesulfonate and sulfate.

\subsection{Other Studies}

\subsubsection{Power Plant Plume Processing: Presence of Organosulfates?}

Particles collected downwind of a power plant plume were examined using STXM/NEXAFS combined with CCSEM/EDX. ${ }^{149}$ NEXAFS spectra of particles at the three locations chosen progressively further from the power plant, $\mathrm{P} 0, \mathrm{P} 1$, and $\mathrm{P} 2$, were recorded at 
the carbon, nitrogen, oxygen, and sulfur edges. Unlike most field collected aerosol samples, spectra (within each specific location) were extremely homogeneous both within individual particles and from particle to particle. Therefore, at each location, spectra were averaged over $\sim 50$ individual particles. All carbon K-edge spectra exhibited a weak peak at $285.15 \mathrm{eV}$ arising from the $\mathrm{C} 1 \mathrm{~s} \rightarrow \pi^{*}{ }_{\mathrm{R}\left(\mathrm{C}^{*}=\mathrm{C}\right) \mathrm{R}}$ transition. Three distinct peaks were observed in the sulfur L-edge spectra. STXM/NEXAFS indicated that both carbon and sulfur were homogeneously distributed within individual particles and were not inclusions (for example $\left.\left(\mathrm{NH}_{4}\right)_{2} \mathrm{SO}_{4}\right)$ within the particles. Hopkins et al. observed that spectra from $\left(\mathrm{NH}_{4}\right)_{2} \mathrm{SO}_{4}$ and $\mathrm{Na}_{2} \mathrm{SO}_{4}$, were indistinguishable at the sulfur L-edge. ${ }^{56}$ However, ammonium sulfate is widely known to be very sensitive to x-ray exposure (as indicated by the growth of a peak at $401 \mathrm{eV}$ or evaporation in a TEM). However, the nitrogen spectra from the power plant plume samples did not vary with exposure to x-ray radiation. Based on the homogenous distribution of carbon and sulfur and the insensitivity to $\mathrm{x}$ ray exposure, the observed sulfate bonding was tentatively assigned to organosulfates. Organosulfates could be produced via secondary chemistry with organics. ${ }^{150}$ While the exact formation mechanisms are currently being investigated, some laboratory evidence exists for the formation of organosulfates and nitroxy organosulfates from reaction of acidic sulfate particles with isoprene, as well as photooxidation products such as pinonaldehyde and dihydroxyepoxides, under conditions similar to those found in the nocturnal power plant plume investigated in this study.

Using the carbon spectra, the $s p^{2}$ hybridization at each location downwind of the power plant plume was estimated using the $\mathrm{C} 1 \mathrm{~s} \rightarrow \pi^{*}{ }_{\mathrm{R}\left(\mathrm{C}^{*}=\mathrm{C}\right) \mathrm{R}}$ peak intensity (as discussed previously). The calculated $\% s p^{2}$ hybridizations were approximately $8 \%, 4 \%$ and $1.6 \%$, respectively, for the locations $\mathrm{P} 0, \mathrm{P} 1$ and $\mathrm{P} 2$. The decrease from $8 \%$ to less than $2 \%$ indicates a loss of $\mathrm{C}=\mathrm{C}$ bonds along the plume trajectory. One possible explanation is that heterogeneous reaction between elevated levels of the $\mathrm{NO}_{3}$ radicals present in the power plant plume with the $\mathrm{C}=\mathrm{C}$ bonds leads to the observed loss. 


\subsubsection{Ice Nucleation and Cloud Condensation Nuclei}

Many recent aerosol studies have examined how aerosols affect clouds, i.e. the aerosol indirect effect on climate. Aerosol indirect effects have a potentially large, but extremely uncertain effect on climate. STXM/NEXAFS was used to analyze particles collected using a counterflow virtual impactor (CVI) in several field campaigns. CVI impactors are designed to sample only cloud droplets or crystals while excluding interstitial aerosol. By sampling cloud droplet residues and comparing their chemical composition with interstitial aerosols, links between particle composition and cloud nucleating ability are studied.

During the ice in clouds experiment - layer clouds (ICE-L), the impact of playa (dry lakebed) dust as ice nuclei was explored in wave clouds consisting primarily of ice. ${ }^{151}$ A CVI sampled cloud drops which were subsequently heated and collected. Single particle mass spectrometers indicated the presence of playa dust in ice clouds while bulk aerosol mass spectrometers indicated highly oxygenated organics were present. These measurements of clouds over Wyoming implied that desert playa dust advected over the western United States made efficient ice nuclei. Based on the characteristic markers of $\mathrm{Na}, \mathrm{Ca}, \mathrm{K}, \mathrm{Cl}$ and $\mathrm{Mg}$, the single particle mass spectrometer identified periods of high playa dust ice nuclei. Although the single particle mass spectrometer measured some minor peaks for organics the presence of organics within the playa dust remained uncertain due to possible matrix effects. Based on STXM/NEXAFS measurements of $\mathrm{C}, \mathrm{K}$ and $\mathrm{Ca}$ edge spectra that identified internally mixed $\mathrm{CO}_{3}, \mathrm{~K}, \mathrm{Ca}$ and $\mathrm{COOH}, \mathrm{STXM} / \mathrm{NEXAFS}$ confirmed that organics were present within single cloud particle residuals. These findings indicate that the mixture of both dust and organics may contribute to ice nuclei. These results are in contrast with the hypothesis that organics inhibit ice nucleation by occupying active sites where ice nucleation would occur.

CCSEM/EDX and STXM were combined to study mixed phase (ice and liquid) clouds during the indirect and semi direct aerosol campaign (ISDAC) conducted over Barrow, AK. Interstitial aerosol and cloud drop residuals were characterized. ${ }^{152}$ Based on the carbon STXM/NEXAFS analysis, samples taken from a period of high ice nucleation contained 
enhanced fractions of coated carbonate and elemental carbon particles (compared to interstitial aerosol). STXM measurements indicated that $\mathrm{COOH}$ and $\mathrm{CO}_{3}$ were internally mixed (consistent with ICE-L and INTEX-B findings). By examining the pre-edge to post-edge ratio at the carbon K-edge, it was concluded that non-carbonaceous species were enhanced during the CVI sampling periods. SEM/EDX measurements showed enhanced $\mathrm{Mg}$ in cloud drop residuals (relative to interstitial aerosols), thus confirming the STXM/NEXAFS results. NEXAFS spectra of interstitial aerosol showed two types of organic carbon: one with a relatively high carboxylic acid content, and the other with a larger contribution in the region specific to $\mathrm{R}-\mathrm{OCH}_{2}-\mathrm{R}$ (the carbon adjacent to the oxygen in an ether) groups. Organic carbon containing more $\mathrm{ROCH}_{2} \mathrm{R}$ was also found in a Siberian biomass burning plume sampled during the same campaign. The enhanced organics in the interstitial aerosol and enhanced $\mathrm{Mg}$ in the cloud drop residuals indicate that inorganic species are more efficient condensation nuclei / ice nuclei than organic species.

\section{Opportunities for Future Applications and Developments}

\subsection{Combining Complementary Microscopic and Spectroscopic Techniques}

One of the most difficult aspects of studying natural samples is defining the scientific problem narrowly enough for focused experiments. Focusing on a specific scientific problem is simplified when the chemical composition is known, such as polymer or magnetic systems. In contrast natural samples are incredibly complex with poorly characterized chemical compositions. As only a limited number of samples can be examined using STXM they must be chosen carefully, often based upon data and insight obtained from other methods. For example, X-ray fluorescence, ${ }^{119}$ SEM, ${ }^{38}$ and mass spectrometry, ${ }^{139}$ can guide STXM measurements. In addition, atmospheric samples should be statistically representative. Using CCSEM/EDX or single particle mass spectrometry, to sample thousands to millions of particles provides a

statistical analysis for development of a classification scheme for particle types. ${ }^{38,56,118,119,139,149}$ The particle types can then be examined in greater detail using STXM/NEXAFS. These results 
can then be linked back to SEM/EDX and mass spectrometry data to provide more representative results.

In environmental science, STXM/NEXAFS can be combined with other microscopy and spectroscopy methods to exploit the strengths of each method. As the number of STXM instruments increases, more investigations will combine multiple techniques. Transmission electron microscopy (TEM) has been used in combination with STXM/NEXAFS to examine environmental samples including biofilms, ${ }^{92}$ fossil spores, ${ }^{153}$ marine sediments, ${ }^{98}$ meteorites, ${ }^{154}$ biomineralization, ${ }^{143,155}$ and nanoparticles in drinking water. ${ }^{156}$ Numerous investigations have employed other complementary techniques such as micro-FTIR, ${ }^{98}$ Raman imaging, ${ }^{154}$ Atomic Force Microscopy (AFM), ${ }^{54,69,156-158}$ and TOF-SIMS. ${ }^{158}$

Although very few studies have employed multiple techniques in combination with STXM/NEXAFS on atmospheric aerosol samples, ${ }^{38,56,118,119,139}$ a variety of applications are apparent. One limitation of STXM/NEXAFS is that the measured absorbance is the product of particle density times its thickness. Separating these two requires knowledge of the particle shape. For understanding chemical and physical properties knowing the aerosol density and morphology is useful. By performing AFM and STXM measurements on identical particles, their 3-D shape, size, height, density, and total atomic absorbance (mass) can be quantified. The Tivanski research group has used this approach to determine, for the first time, single particle densities for various atmospherically-relevant organic compounds, such as low molecular weight dicarboxylic acids and natural fulvic acid. ${ }^{159}$

\subsection{Development of in situ Techniques}

Controlled in situ studies relevant to aerosols, such as those reported in catalysis ${ }^{160-162}$ are certain to develop in the coming years. Ideally, aside from temperature control (heating and cooling), and reactive gas flow, reliable humidity control is desired. This would allow the reactivity of a single particle to be monitored for changes in chemical bonding and oxidation states using STXM/NEXAFS. 
Several research groups have been exploring STXM/NEXAFS for studies on water vapor uptake. Ghorai and Tivanski have developed a novel approach based on STXM/NEXAFS for in situ studies of the hygroscopic properties of individual submicron aerosols. ${ }^{163}$ In particular, several inorganic aerosols $\left(\mathrm{NaCl}, \mathrm{NaBr}, \mathrm{NaI}\right.$ and $\left.\mathrm{NaNO}_{3}\right)$ deposited on silicon nitride membranes were characterized using STXM/NEXAFS at varying relative humidities, up to $90 \%$. The amount of water absorbed by a single particle during hydration/dehydration cycle was measured as a function of relative humidity and the measured hygroscopic properties were in excellent agreement with results determined by established techniques. Zelenay et al. recently incorporated an in situ reactor to examine the variations in oxygen NEXAFS spectra and changing particle morphology of individual mixed particles of adipic acid/ammonium sulfate as a function of relative humidity. ${ }^{164}$ Hence, future studies are expected to include atmospherically relevant aerosols, ambient aerosols, and organic/inorganic mixtures as well as improvements in controlling and measuring the relative humidity. The ability to probe organic/inorganic mixtures is particularly important due to the extremely limited knowledge of how the type and degree of mixing, and aerosol microstructure influence their hygroscopic properties.

Other potential in situ experiments could combine irradiation (with UV or laser light) with STXM to monitor chemical changes or the extent of progression of a reaction with time. Depending on experimental settings, STXM can be used to follow time-resolved chemical changes with a temporal resolution of several milliseconds. Several groups have combined STXM with UV/Visible light irradiation to examine chemical changes upon light exposure ${ }^{112}$ or to provide experimental confirmation of the sample heterogeneity and spatial distribution of different components within the sample. ${ }^{75}$

Although the NSLS cryo-STXM has been in existence for years, ${ }^{20}$ and Tzvetkov and Fink recently examined the temperature dependent phase changes in polymers, ${ }^{165}$ cooling techniques for STXM are not fully developed. Thibault et al. imaged a zone plate buried beneath layers of gold by combining elements of scanning microscopy with coherent diffraction resulting in reconstructed images with higher resolution than the focused spot size. ${ }^{166}$ Several groups are 
developing techniques of contrast imaging, fluorescence detection, and tomography for STXM. These techniques along with improved in situ capabilities will ultimately enhance the ability to probe environmental samples.

Although a relatively new technique for atmospheric research and environmental science, STXM/NEXAFS applications have grown from examining laboratory samples of soots and mapping functional groups on just a few particles to detailed experiments on hundreds of particles. Initially, a very limited number of STXM instruments were available and the data acquisition and analysis were labor intensive. However, the number of instruments available worldwide is increasing rapidly, and top-off mode has significantly improved data acquisition. The development of software focused on statistical analysis has decreased the time required for data analysis. Combined with other imaging techniques (SEM/EDX, TEM, EELS, AFM), spectroscopic techniques (FTIR, Raman, TOF-SIMS) and technological advances (in situ cells, improved temperature and humidity control and measurement) we anticipate a rapid increase both in the number and type of scientific investigations in atmospheric and environmental sciences that employ STXM/NEXAFS.

\section{Acknowledgements}

The authors wish to acknowledge financial support provided by the Atmospheric System Research Program, Office of Biological and Environmental Research (OBER) of the U.S. Department of Energy (DOE). R. C. Moffet acknowledges additional financial support from a Lawrence Berkeley National Laboratory Glenn T. Seaborg Fellowship. A. V. Tivanksi acknowledges The University of Iowa for the financial support. A significant portion of the STXM/NEXAFS particle analysis was performed at beamlines 5.3.2 and 11.0.2 at the Advanced

Light Source at Lawrence Berkeley National Laboratory. The work at the Advanced Light Source was supported by the Director, Office of Science, Office of Basic Energy Sciences, of the U.S. Department of Energy under Contract No. DE-AC02-05CH11231. Supporting CCSEM/EDX particle analysis was performed in the Environmental Molecular Sciences Laboratory, a national scientific user facility sponsored by the Department of Energy's Office of 
Biological and Environmental Research at Pacific Northwest National Laboratory. PNNL is operated by the U.S. Department of Energy by Battelle Memorial Institute under contract DEAC06-76RL0. The authors would also acknowledge collaborators that have provided their expertise and insights, as well as samples: P. Ziemann, R. A. Zaveri, S. Wirick, K. R. Wilson, Z. Wang, C. H. Twohy, S. Takahama, P. O. Sprau, J. Smith, V, Shutthanandan, D. K. Shuh, L. M. Russell, K. A. Pratt, K. A. Prather, S. Prakash, L. Muntean, L. T. Molina, H. A. Michelsen, B. D. Marten, D. A. Knopf, T. Kirchstetter, A. Laskin, R. J. Hopkins, T. R. Henn, J. L. Hand, R. Gonzalez, J. Fast, I. J. Drake, and Y. Desyaterik. Additionally, the authors would like to personally acknowledge the spirit of generosity extended by A. P. Hitchcock, C. Jacobsen, A. D. Kilcoyne, G. Mitchell, and T. Tyliszczak in encouraging new users and in advancing the technique. 


\section{Tables}

Table 1. Core absorption edges typically used in the soft x-ray region

\begin{tabular}{|c|c|}
\hline Binding Energy & Edge \\
\hline \multicolumn{2}{|l|}{$150-500 \mathrm{eV}$} \\
\hline $\mathrm{B}, \mathrm{C}, \mathrm{N}, \mathrm{Mg}, \mathrm{Al}, \mathrm{Si}$ & K 1s \\
\hline $\mathrm{S}, \mathrm{Cl}, \mathrm{Ar}, \mathrm{K}, \mathrm{Ca}, \mathrm{Sc}, \mathrm{Ti}$ & $L_{2} 2 p_{1 / 2} \& L_{2} 2 p_{3 / 2}$ \\
\hline $\mathrm{Y}, \mathrm{Zr}, \mathrm{Nb}, \mathrm{Mo}, \mathrm{Tc}, \mathrm{Ru}, \mathrm{Rh}, \mathrm{Pd}, \mathrm{Ag}, \mathrm{In}, \mathrm{Sn}$ & $M_{4} 3 d_{3 / 2} \& M_{5} 3 d_{5 / 2}$ \\
\hline \multicolumn{2}{|l|}{$500-1000 \mathrm{eV}$} \\
\hline $\mathrm{O}, \mathrm{F}, \mathrm{Ne}$ & $\mathrm{K} 1 \mathrm{~s}$ \\
\hline $\mathrm{V}, \mathrm{Cr}, \mathrm{Mn}, \mathrm{Fe}, \mathrm{Co}, \mathrm{Ni}, \mathrm{Cu}$ & $L_{2} 2 p_{1 / 2} \& L_{2} 2 p_{3 / 2}$ \\
\hline $\mathrm{Sb}, \mathrm{Te}, \mathrm{I}, \mathrm{Xe}, \mathrm{Cs}, \mathrm{Ba}, \mathrm{La}, \mathrm{Ce}, \mathrm{Pr}$ & $M_{4} 3 d_{3 / 2} \& M_{5} 3 d_{5 / 2}$ \\
\hline \multicolumn{2}{|l|}{$1000-1500 \mathrm{eV}$} \\
\hline $\mathrm{Na}, \mathrm{Mg}$ & $\mathrm{K} 1 \mathrm{~s}$ \\
\hline $\mathrm{Zn}, \mathrm{Ga}, \mathrm{Ge}, \mathrm{As}, \mathrm{Se}$ & $L_{2} 2 p_{1 / 2} \& L_{2} 2 p_{3 / 2}$ \\
\hline $\begin{array}{l}\text { Nd, Pm, Sm, Eu, Gd, Tb, Dy, Ho, Er, } \\
\text { Tm, Yb }\end{array}$ & $\mathrm{M}_{4} 3 \mathrm{~d}_{3 / 2} \& \mathrm{M}_{5} 3 \mathrm{~d}_{5 / 2}$ \\
\hline \multicolumn{2}{|l|}{$1500-2000 \mathrm{eV}$} \\
\hline Al, Si & $\mathrm{K} 1 \mathrm{~s}$ \\
\hline $\mathrm{Br}, \mathrm{Kr}, \mathrm{Rb}, \mathrm{Sr}$ & $L_{2} 2 p_{1 / 2} \& L_{2} 2 p_{3 / 2}$ \\
\hline Lu, Hf, Ta, W, Re, Os & $M_{4} 3 d_{3 / 2} \& M_{5} 3 d_{5 / 2}$ \\
\hline
\end{tabular}




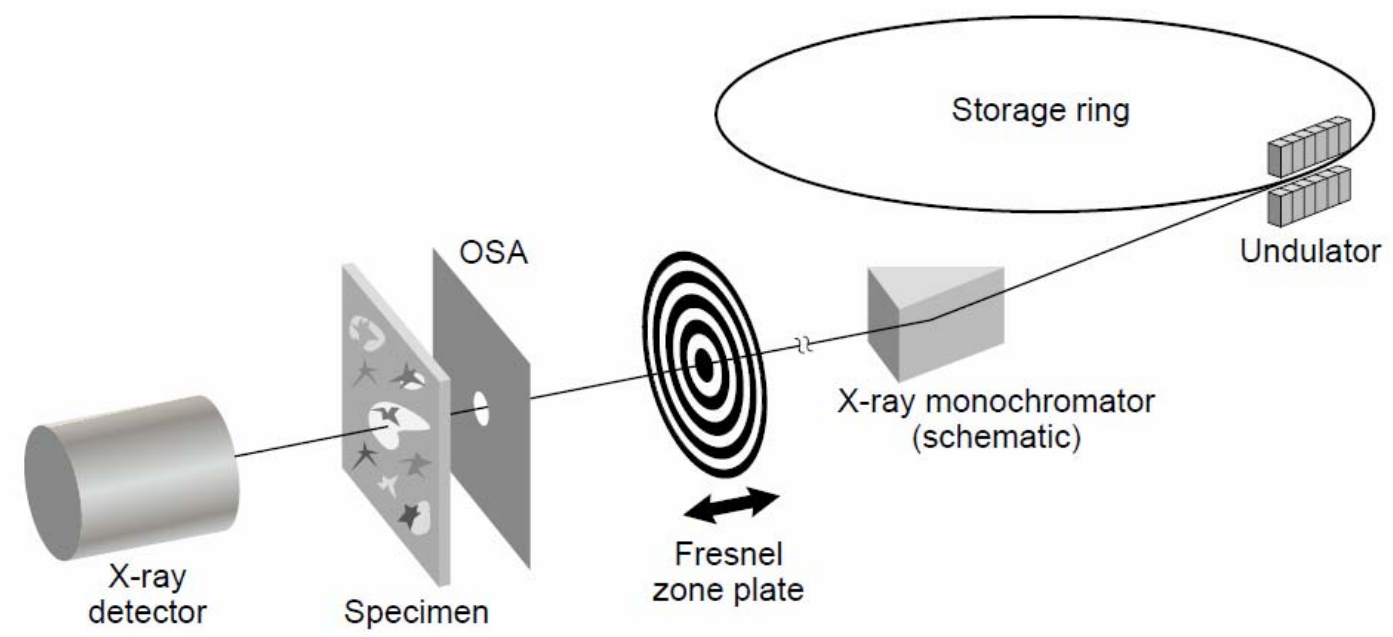

Figure 1. Schematic of a synchrotron (not to scale) showing a single insertion device (undulator) and beamline with an x-ray monochromator for energy selection. The STXM instrument includes the Fresnel zone plate for focusing, an order sorting aperture (OSA) to eliminate unfocused and higher-order focused x-rays, a sample, and the detector. The sample is located at the focal point and raster scanned to obtain an image. Figure adapted from Maser et al. ${ }^{20}$

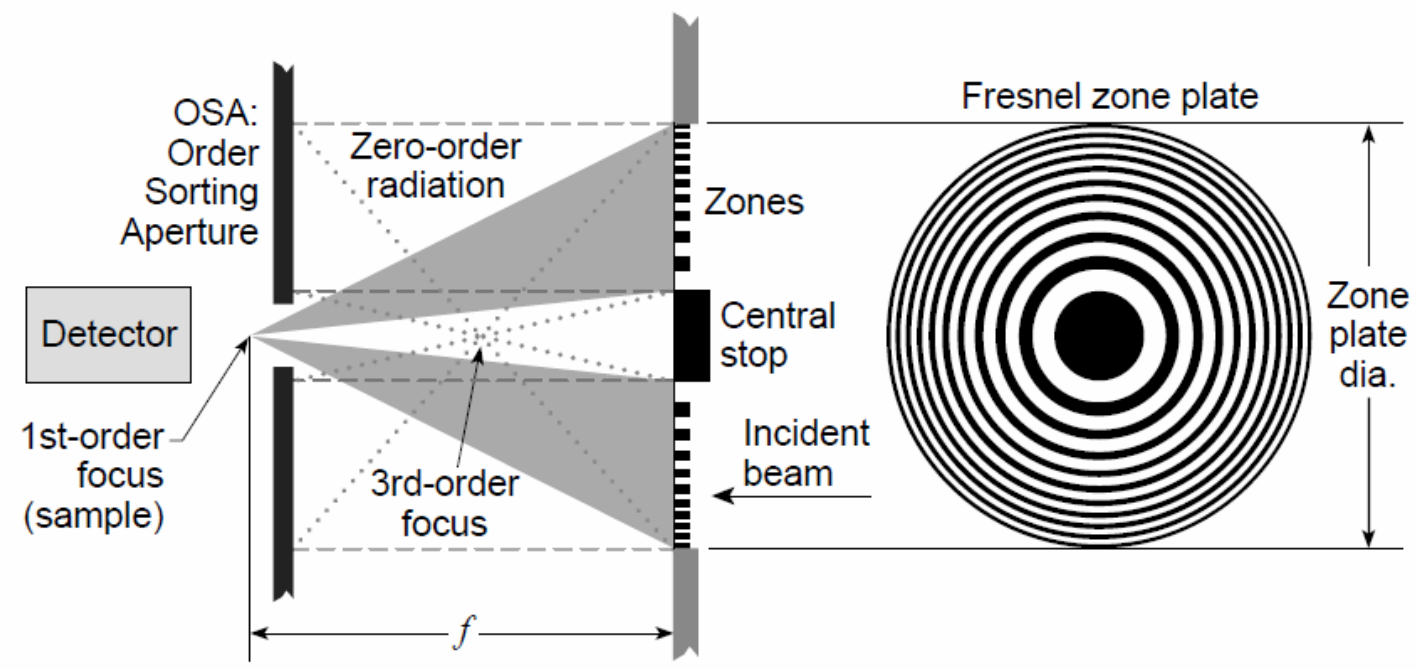

Figure 2. Right) Schematic of a Fresnel zone plate showing the central stop and the series of zones having decreasing width with increasing distance from the center. Left) Schematic of a zone plate (rotated $90^{\circ}$ ) with the proper positioning of the order sorting aperture (OSA) to prevent $3^{\text {rd }}$ order diffracted light from impinging on the sample. The sample lies in the focal plane for $1^{\text {st }}$ order diffracted light. The zero-order (non-diffracted) light is eliminated by the zone plate central stop. 


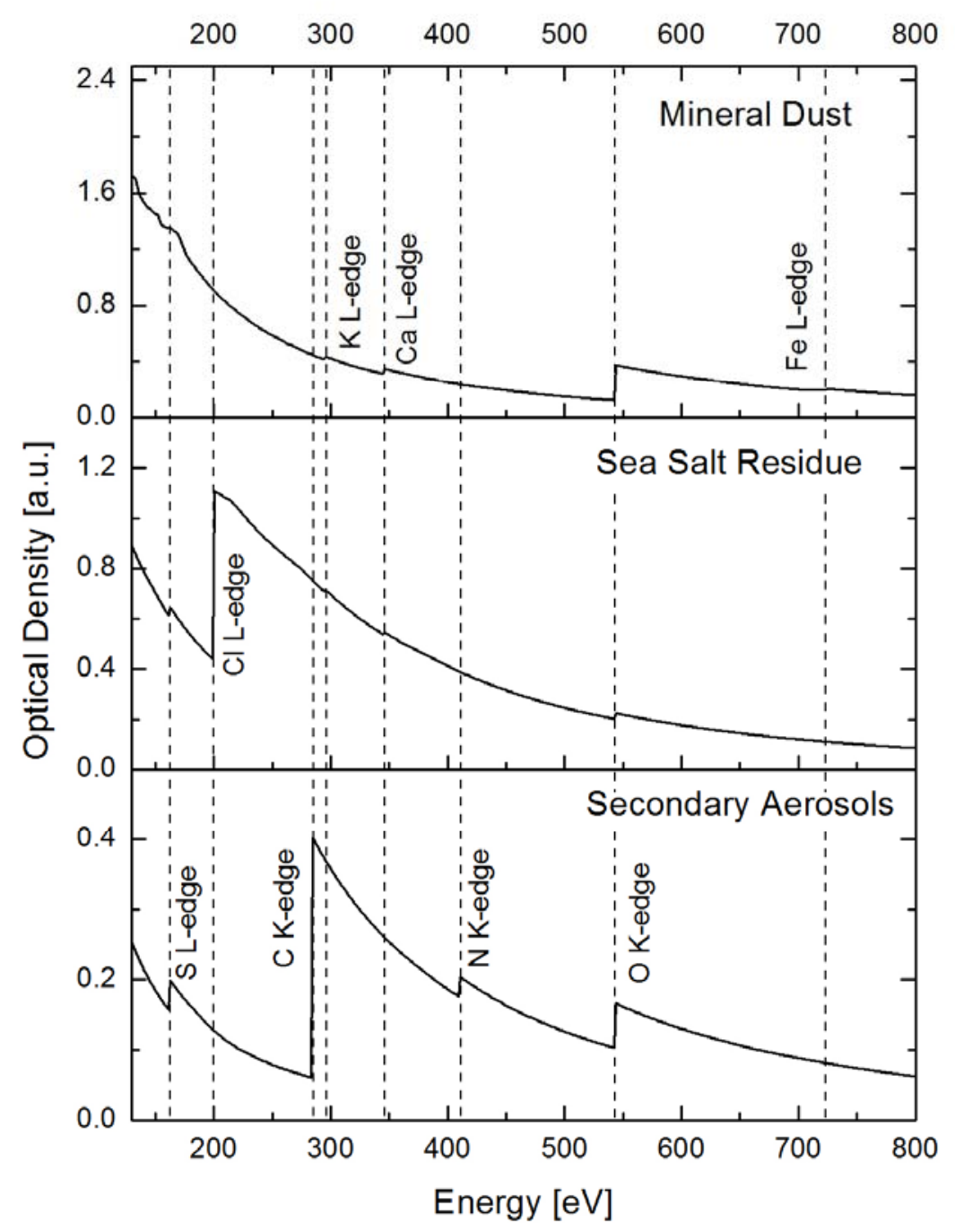

Figure 3. Calculated mass absorption for a $100 \mathrm{~nm}$ thick sample of common atmospheric aerosols: mineral dust (calculated using the elemental abundance of the earth's crust, $\mathrm{O}_{63} \mathrm{Si}_{21} \mathrm{Al}_{6} \mathrm{Fe}_{2} \mathrm{Mg}_{2} \mathrm{Ca}_{2} \mathrm{Na}_{3} \mathrm{~K}$, and the density of $\mathrm{SiO}_{2}, 2.6 \mathrm{~g} / \mathrm{cm}^{3}$ ), sea salt residue (calculated using the formula $\mathrm{Na}_{420} \mathrm{Cl}_{490} \mathrm{Mg}_{50} \mathrm{Ca}_{10} \mathrm{~K}_{10}\left(\mathrm{SO}_{4}\right)_{25}\left(\mathrm{HCO}_{3}\right)_{2}$ and the density of $\left.\mathrm{NaCl}, 2.2 \mathrm{~g} / \mathrm{cm}^{3}\right)$ and secondary aerosols consisting of a mixture of 0.25 mole $\left(\mathrm{NH}_{4}\right)_{2} \mathrm{SO}_{4}, 0.25$ mole $\left(\mathrm{NH}_{4}\right) \mathrm{NO}_{3}$, and 0.5 mole palmitic acid, $\mathrm{CH}_{3}\left(\mathrm{CH}_{2}\right)_{14} \mathrm{CO}_{2} \mathrm{H}$ (where the density was determined from their respective mole fractions). 


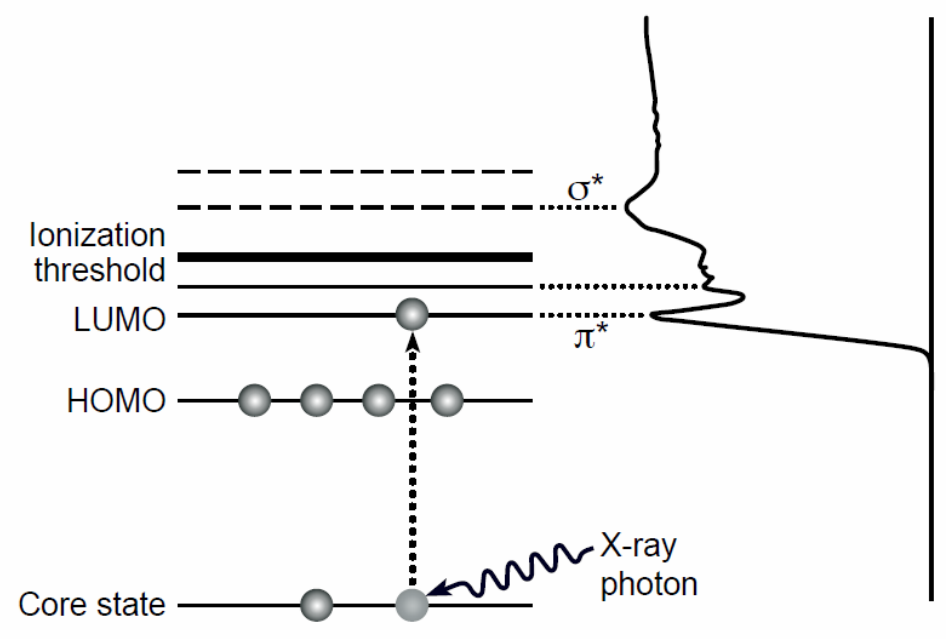

Figure 4. Left) Schematic energy level diagram showing the highest occupied molecular orbital (HOMO), the lowest unoccupied molecular orbital (LUMO), and the ionization potential. Typically, for unsaturated compounds the LUMO is a $\pi^{*}$ molecular orbital, such a transition is indicated. Right) Example of a resulting NEXAFS spectrum.

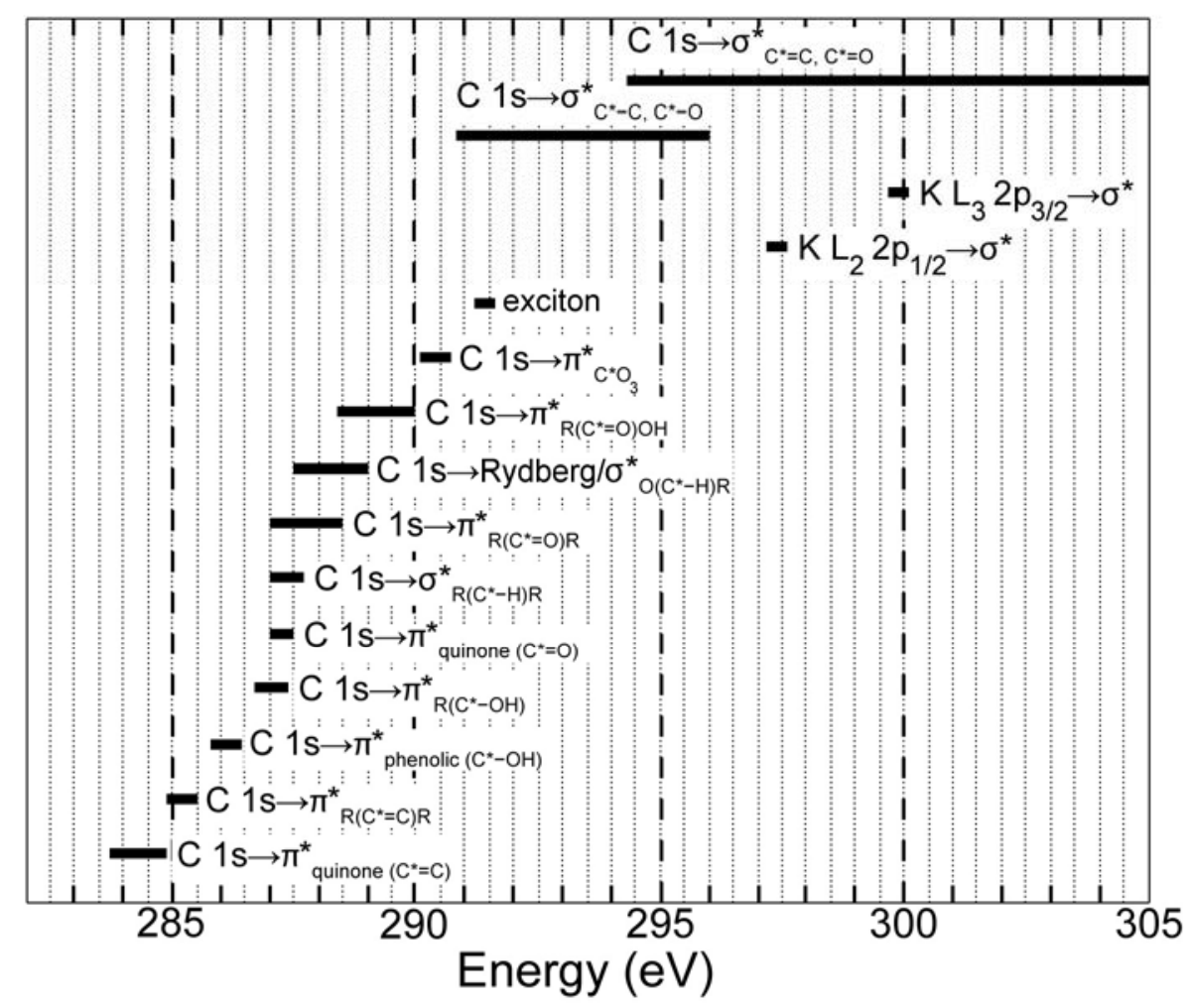

Figure 5. Approximate range of transition energies for organic functional groups in the carbon K-edge NEXAFS spectra. Potassium L-edge transitions are also indicated. 


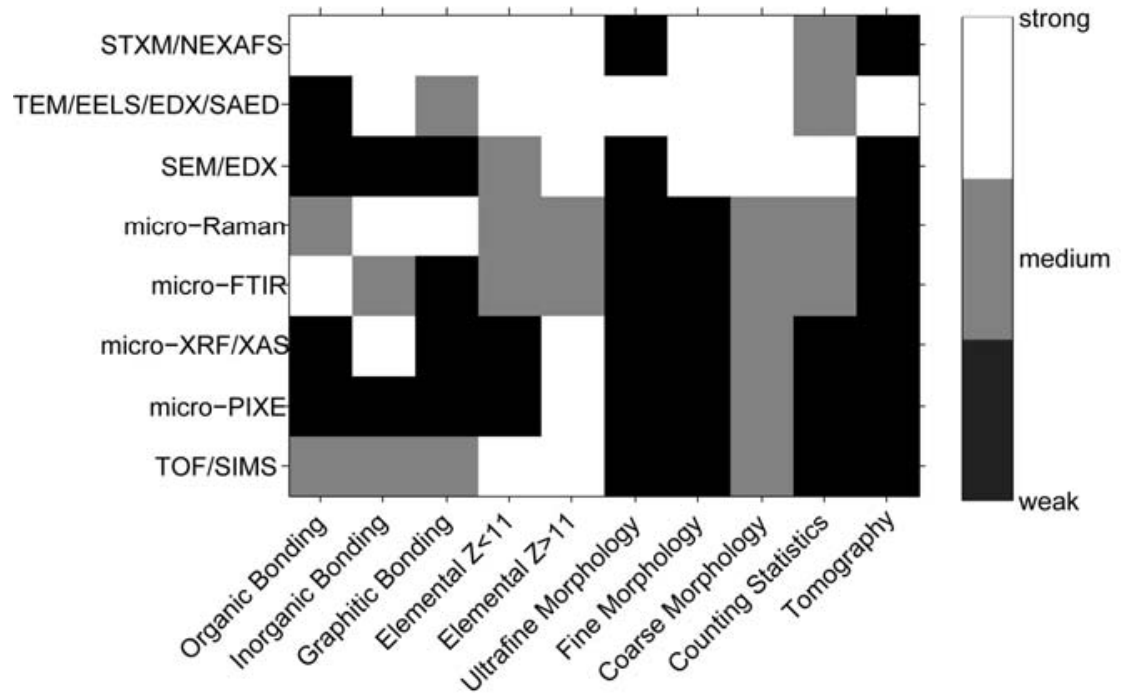

Figure 6. Analysis of capabilities (x-axis) of imaging techniques (y-axis) used to analyze atmospheric aerosol. The grey scale corresponds to analysis capability which is classified as strong, medium or weak. Acronyms are as follows: TEM/EELS/EDX/SAED: Transmission Electron Microscopy/Electron Energy Loss Spectroscopy/Energy Dispersive X-ray/Selected Area Electron Diffraction, SEM: Scanning Electron Microscopy, FTIR: Fourier Transform Infrared Spectroscopy, XRF/XAS: X-ray Fluorescence/X-ray Absorption Spectroscopy, PIXE: Proton Induced X-ray Emission and TOF-SIMS: Time-of-Flight Secondary Ion Mass Spectrometry.

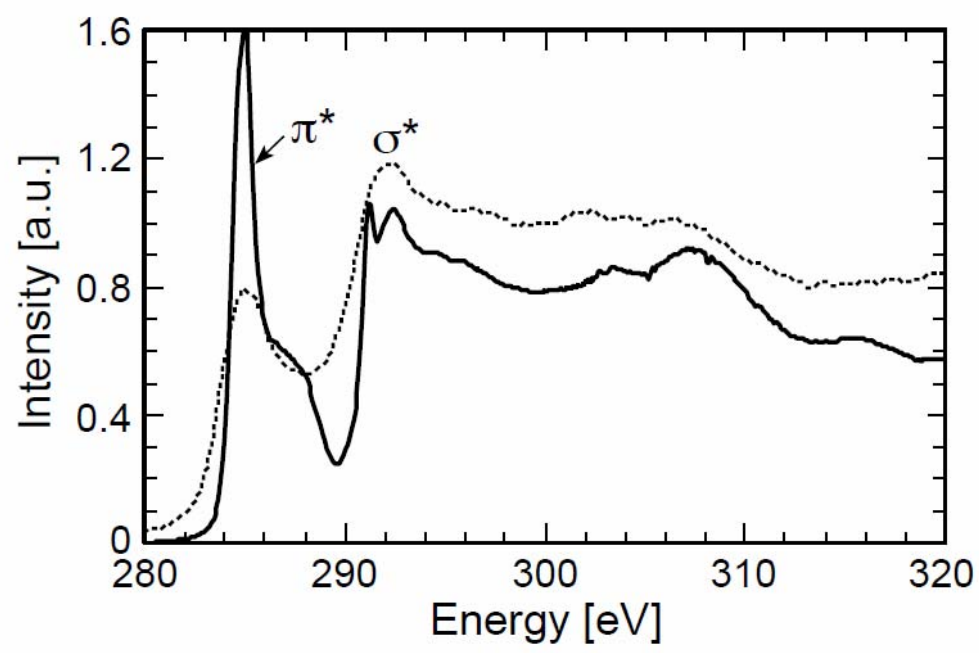

Figure 7. Spectra of SLX-25 graphite taken using electron energy loss spectroscopy, EELS, (dotted line) and STXM/NEXAFS (solid line). The $\pi^{*}$ peak at $285 \mathrm{eV}$ is much broader and less intense in the EELS spectra than observed in the NEXAFS spectra. The improved energy resolution of STXM/NEXAFS results in structural features that are not observed in EELS spectra. Figure adapted from Braun et al. ${ }^{40}$ 
Figure 8. Single energy STXM images $(6 \mu \mathrm{m} \times 6 \mu \mathrm{m})$ shown on the same optical density scale (0-1.8): A) $278 \mathrm{eV}$, B) $285.4 \mathrm{eV}$, C) $288.5 \mathrm{eV}$, and D) $320 \mathrm{eV}$. The difference image, E), obtained by subtracting the pre-edge $(278 \mathrm{eV})$ from the post-edge $(320 \mathrm{eV})$ where each is first converted into optical density (shown on OD scale $-0.2-1.4$ ). The particle indicated in (A) absorbs at $278 \mathrm{eV}$ (the carbon pre-edge), indicating the presence of non-carbonaceous species (such as inorganic salts); the area surrounding this region shows stronger absorption at 288.5 (C) than at 285.4 (B), indicating an organic coating. The particle indicated in (B) has little or no absorption at the carbon pre-edge (A) and strong absorption at $320 \mathrm{eV}(\mathrm{D}), 285.4 \mathrm{eV}$, and in the difference map (E), indicating a carbonaceous (potentially soot) particle. Panel (F) is a map showing the components, elemental carbon or soot (EC), inorganic carbon (IN) and organic carbon (OC).

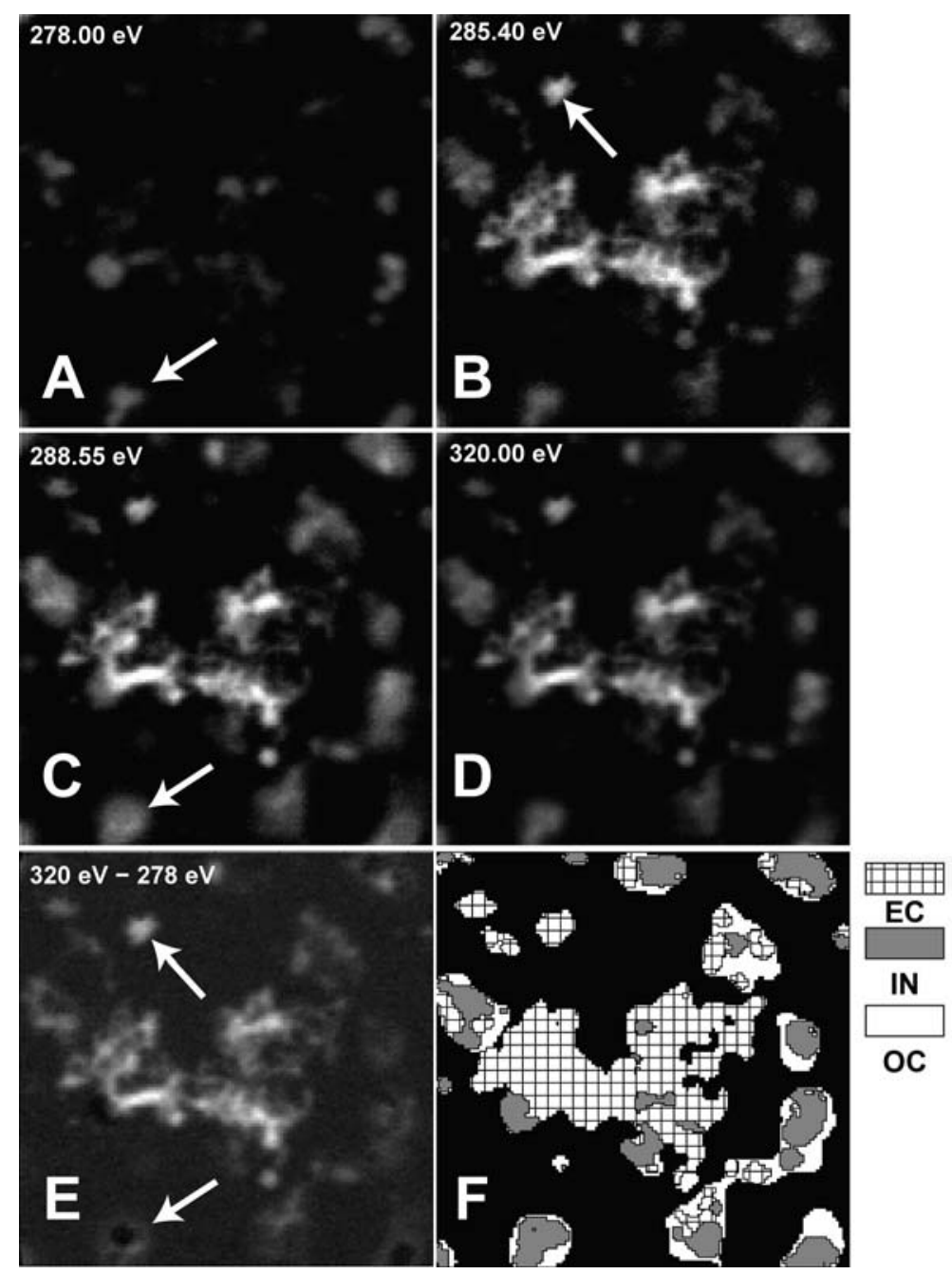




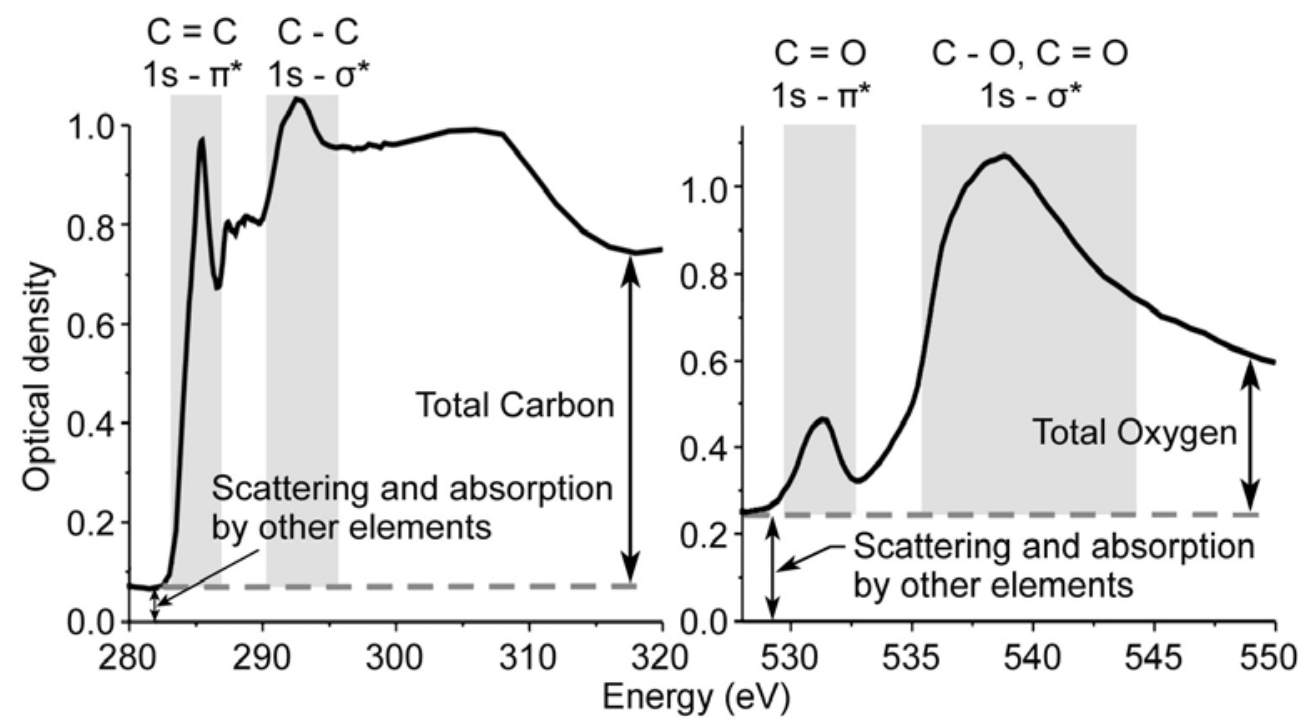

Figure 9. NEXAFS spectra for flame generated methane soot taken at the carbon and oxygen Kedges. Spectra are raw data without any pre-edge subtractions or scaling. The small pre-edge absorbance for carbon $(\mathrm{OD}<0.1)$ and strong total carbon absorption (absorption at $320 \mathrm{eV}$ absorption at $280 \mathrm{eV}$ ) is often observed for aerosols consisting primarily of carbon and oxygen. Note the higher pre-edge at the oxygen edge $(\sim 0.25$ OD) arises from absorption and scattering of atoms other than oxygen (including carbon).

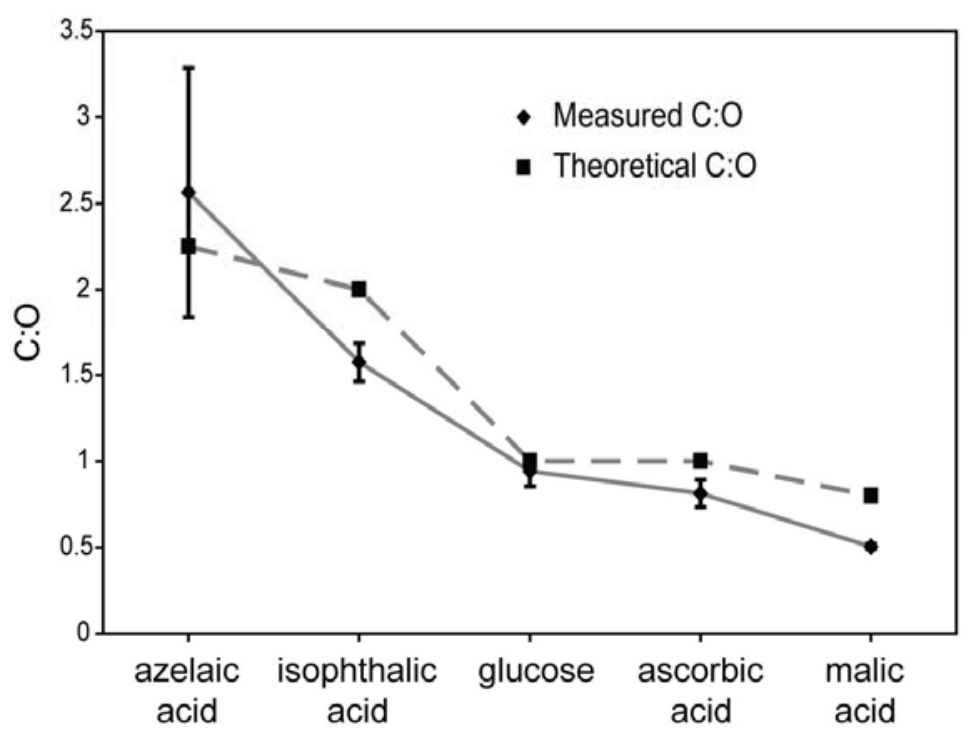

Figure 10. $\mathrm{C}$ : $\mathrm{O}$ atomic ratios determined (see text) from NEXAFS spectra of compounds containing carbon and oxygen (neglecting hydrogen). Compounds measured include: azelaic acid $\left.\left(\mathrm{HO}_{2} \mathrm{C}\left(\mathrm{CH}_{2}\right)_{7}\right) \mathrm{CO}_{2} \mathrm{H}\right)$, isophthalic acid $\left(\mathrm{C}_{8} \mathrm{H}_{6} \mathrm{O}_{4}\right)$, glucose $\left(\mathrm{C}_{6} \mathrm{H}_{12} \mathrm{O}_{6}\right)$, ascorbic acid $\left(\mathrm{C}_{6} \mathrm{H}_{8} \mathrm{O}_{6}\right)$ and malic acid $\left(\mathrm{C}_{4} \mathrm{H}_{6} \mathrm{O}_{5}\right)$. $\mathrm{C}: \mathrm{O}$ atomic ratios determined from the molecular formula are indicated as theoretical values. Error bars represent the standard deviation taken from four independent measurements. 


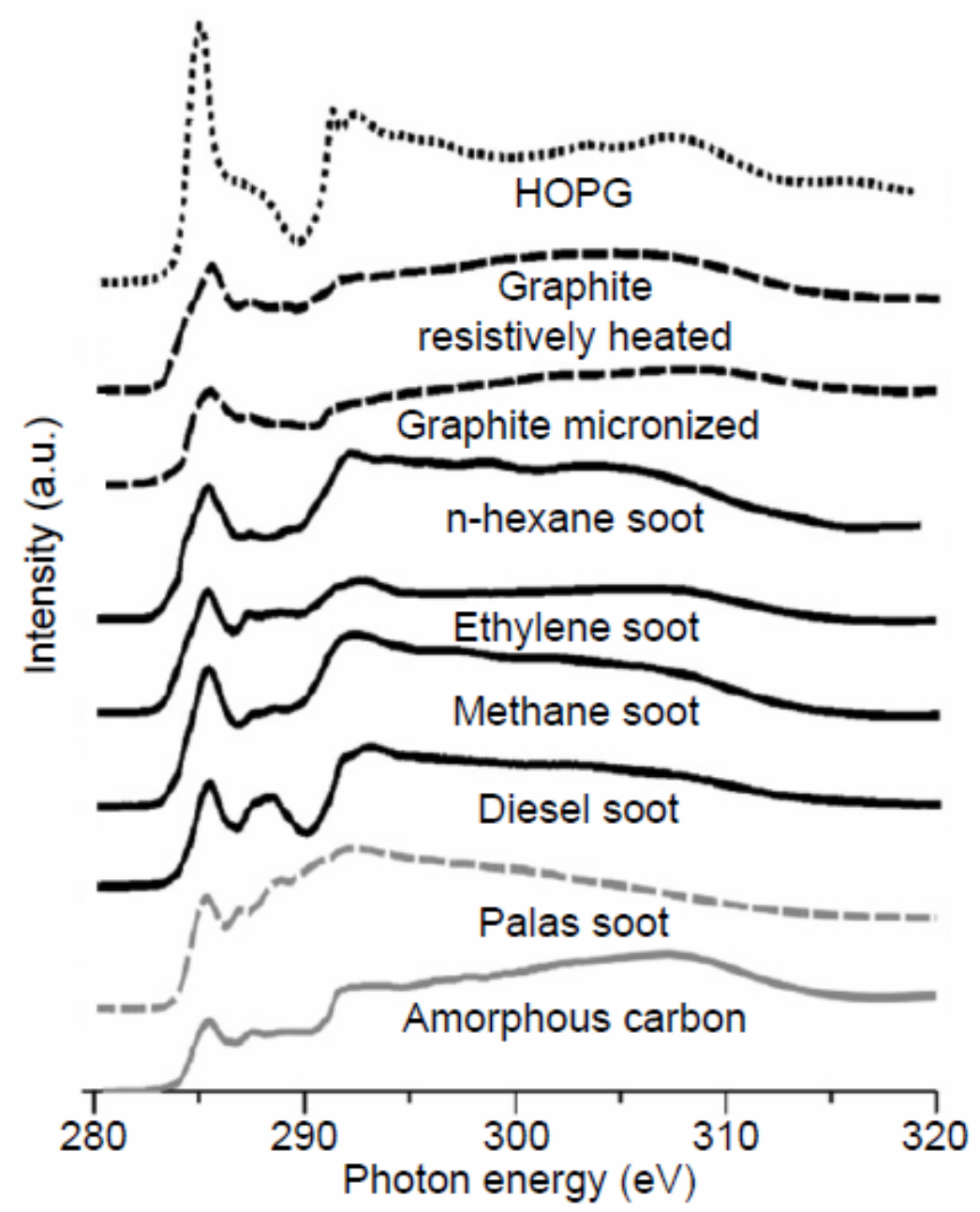

Figure 11. Carbon K-edge NEXAFS spectra from a variety of laboratory generated black carbons (soots) and purchased carbonaceous materials. Indications of black carbon are the intense $\pi^{*}$ peak with a peak intensity similar to the post-edge absorbance, a high absorption for the particle size (due to the increased density of carbon), and a valley in the energy region $\sim 286$ $290 \mathrm{eV}$. Except for amorphous carbon, all of these spectra would indicate the presence of black carbon in atmospheric samples. 


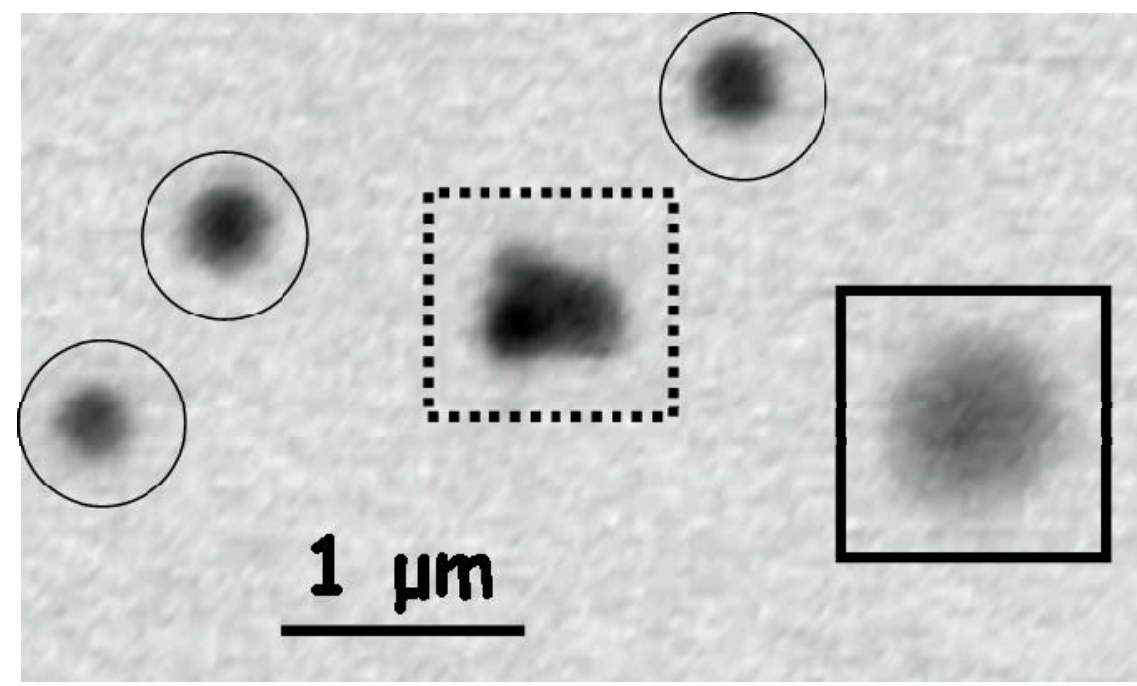

Figure 12. Single energy ( $320 \mathrm{eV})$ STXM image of representative particles from an aged biomass burning event. Circles indicate tar balls, the solid square is an organic particle, and an agglomerate is indicated by the dotted square. The tar ball appears darker than the organic particle, indicating increased x-ray absorption.

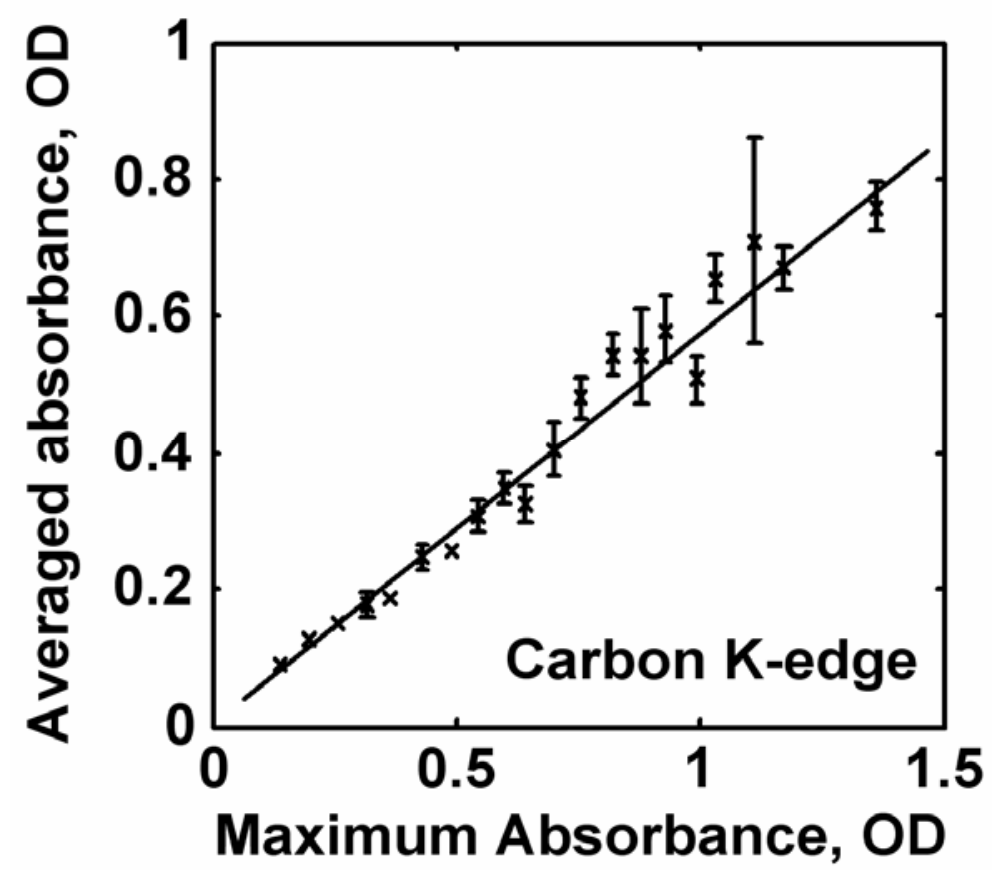

Figure 13. Averaged absorbance versus the maximum absorbance from the $\mathrm{C} \mathrm{K}$-edge spectra at the post-edge $(320 \mathrm{eV})$ for tar balls. Each data point represents the mean absorbance value for $\sim 7$ particles in $\sim 50 \mathrm{~nm}$ wide bins (based on their diameters). A fit to the data yields a slope of $0.59 \pm 0.03$. Although not shown here, the analogous plot at the $\mathrm{O}$ edge at $550 \mathrm{eV}$ yields a slope of $0.6 \pm 0.05$. These slopes are in excellent agreement with slope of 0.59 calculated for perfect spheres. 


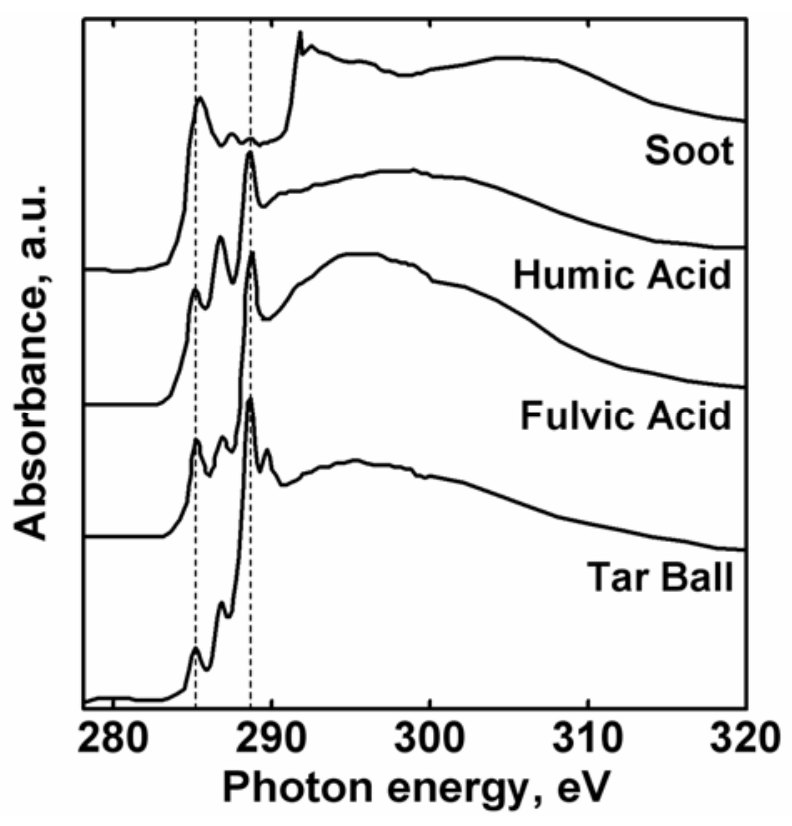

Figure 14. Spectra of tar balls, soot (measured in the same sample as the tar balls), humic, and fulvic acids. Although tar bars are correlated with long wavelength absorption in the visible region, these spectra show that the carbon bonding in tar balls is much more similar to humic and fulvic acids than soots or black carbons.

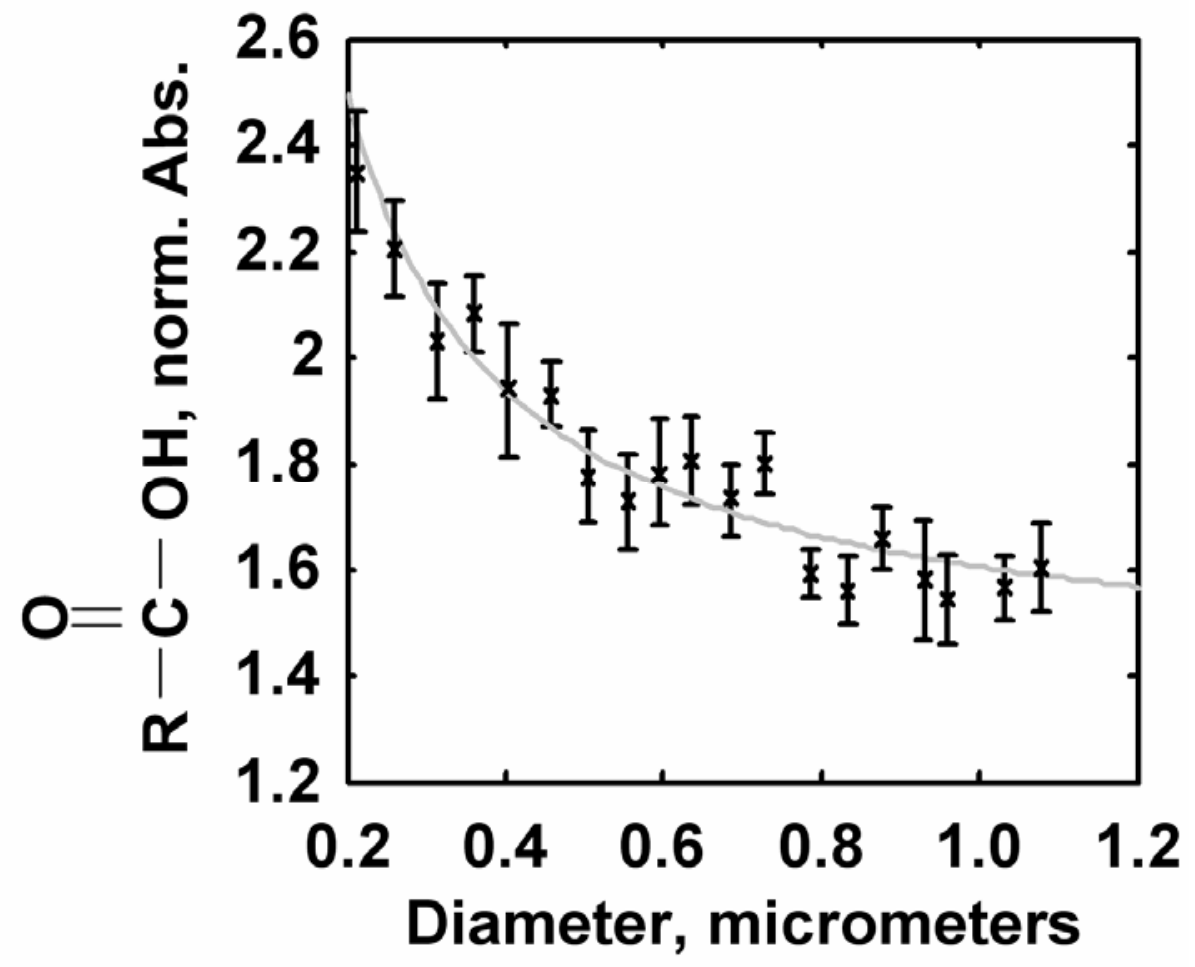

Figure 15. Carboxylic carbonyl absorbance (normalized to the total carbon) plotted as a function of tar ball diameter. The increased contribution of the carboxyl group at smaller particle sizes indicates a surface enhancement. 


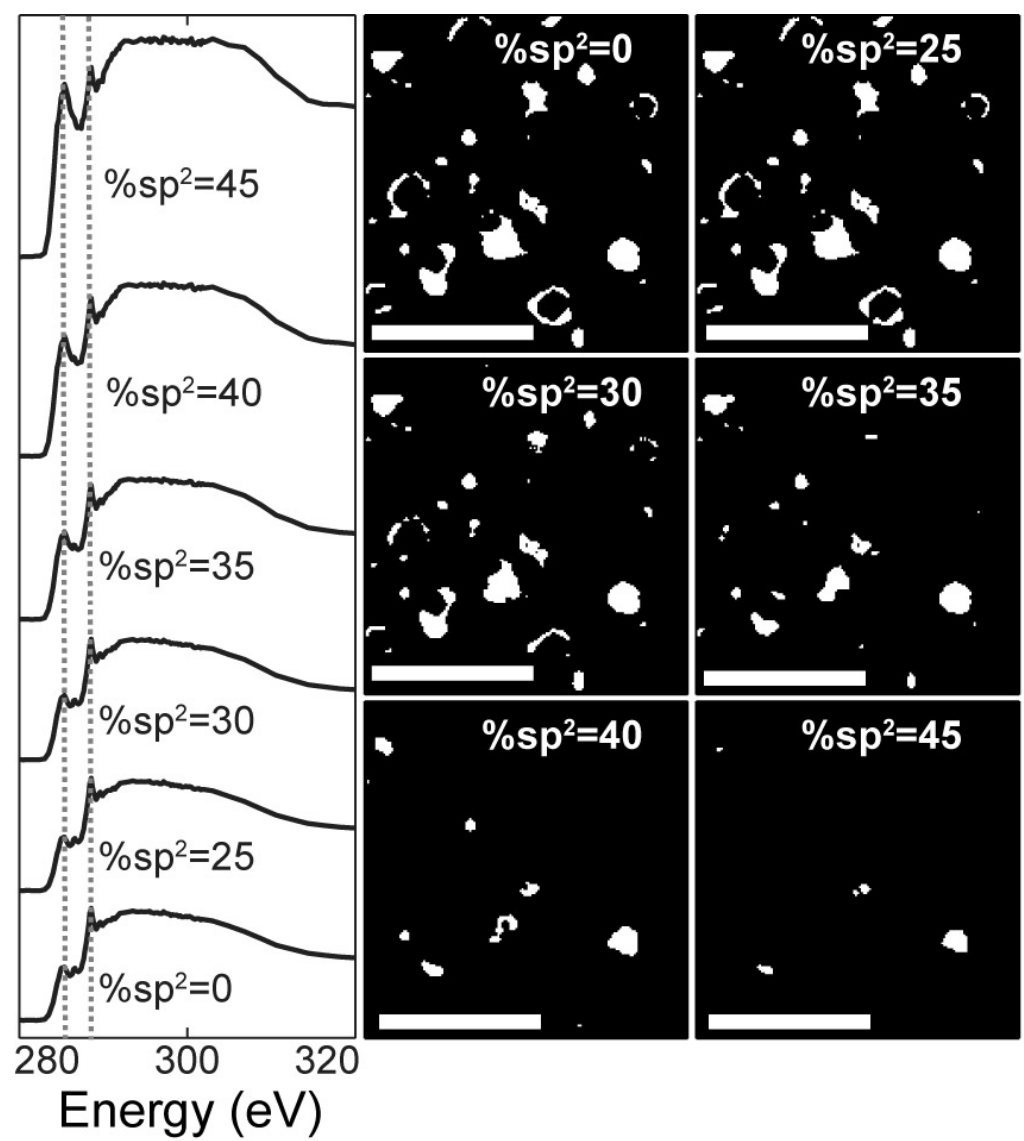

Figure 16 Left) Carbon NEXAFS spectra from a Mexico City sample obtained by setting different threshold values for $s p^{2}$ hybridization. Vertical gray dotted lines at 285.4 (C $1 \mathrm{~s} \rightarrow$

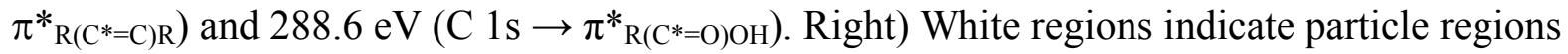
above the threshold value. Non-carbonaceous, inorganic regions are masked to highlight organic coatings. At $\geq 35 \% s p^{2}$ the intensity of the 285.4 peak is equal to or greater than the total absorbance at $320 \mathrm{eV}$, similar to soots/black carbon samples previously reported. White scale bar is $3.2 \mu \mathrm{m}$. 

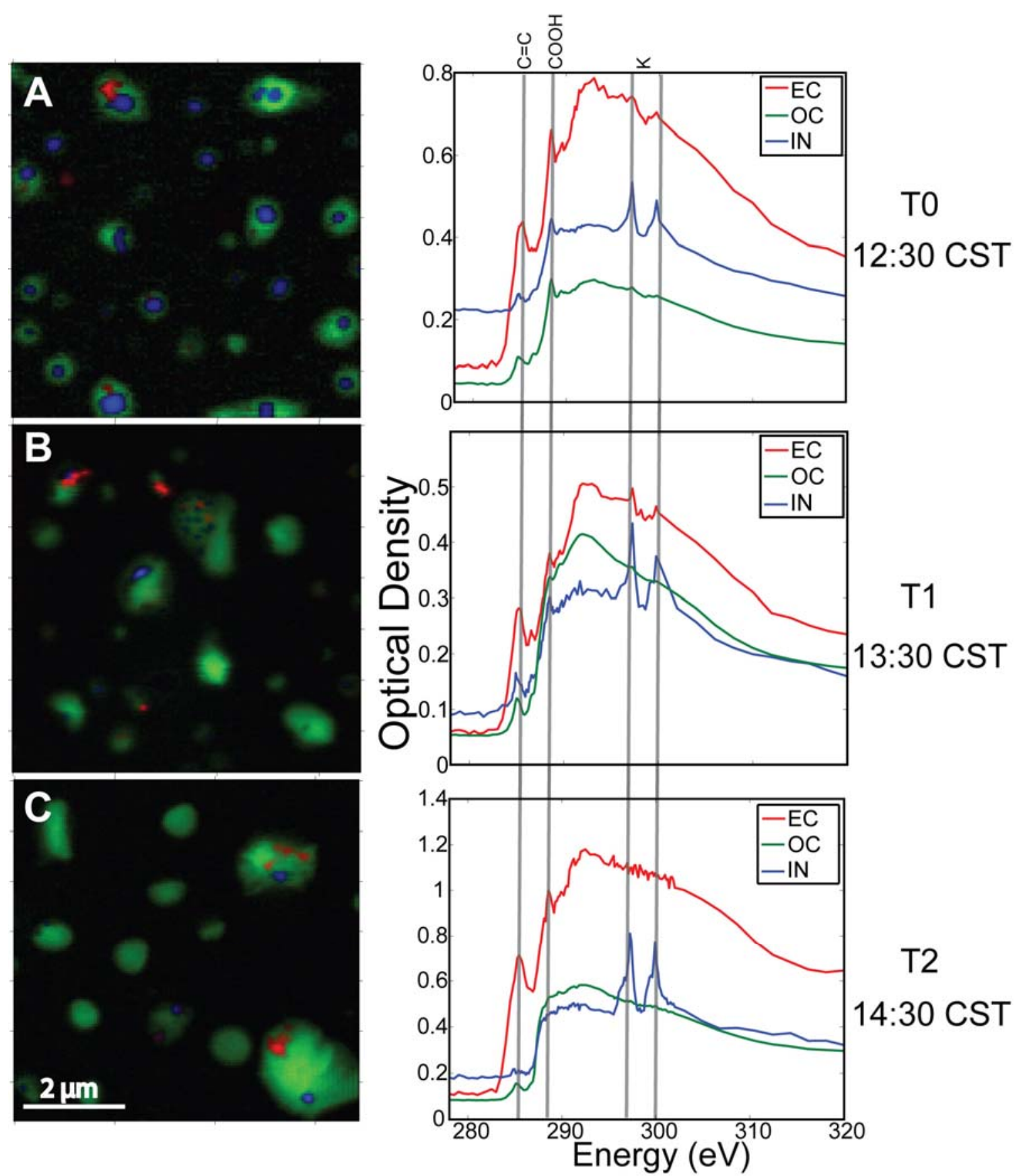

Figure 17. Left) Singular value decomposition (SVD) maps of particles from the three sampling sites showing soot (red), inorganic regions (blue) and organic regions (green). Panels A, B and C refer to sampling sites T0, T1, and T2 located progressively farther from the urban center of Mexico City. Soot was defined as regions with $\geq 35 \% s p^{2}$ hybridized carbon, inorganic regions were defined as having a pre-edge $(278-280 \mathrm{eV})$ to post-edge $(320 \mathrm{eV})$ ratio of 0.6 and organic regions contained absorption at the $\mathrm{COOH}$ peak. Right) Spectra used to produce SVD maps shown on the left. 


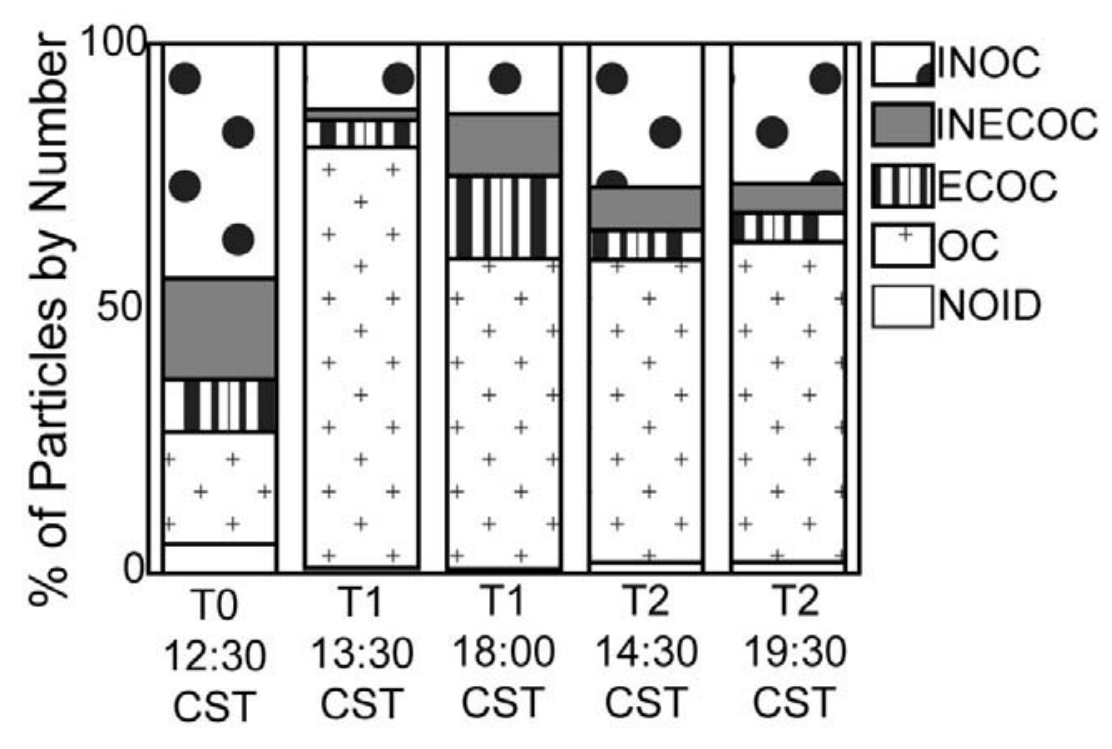

Figure 18. Percentage of particle types, by number, for samples from the three sites, T0, T1, and T2 located progressively farther from the Mexico City urban center. Particle types are indicated with labels: IN for inorganic, EC for elemental (soot) carbon, OC for organic carbon. Combinations of these are used to indicate particle mixing state. Particles that did not fit into any of these classifications are denoted NOID (not identified). Farther from the city center, the number fraction of homogenous organic particles (OC) lacking both soot and inorganic inclusions increased.

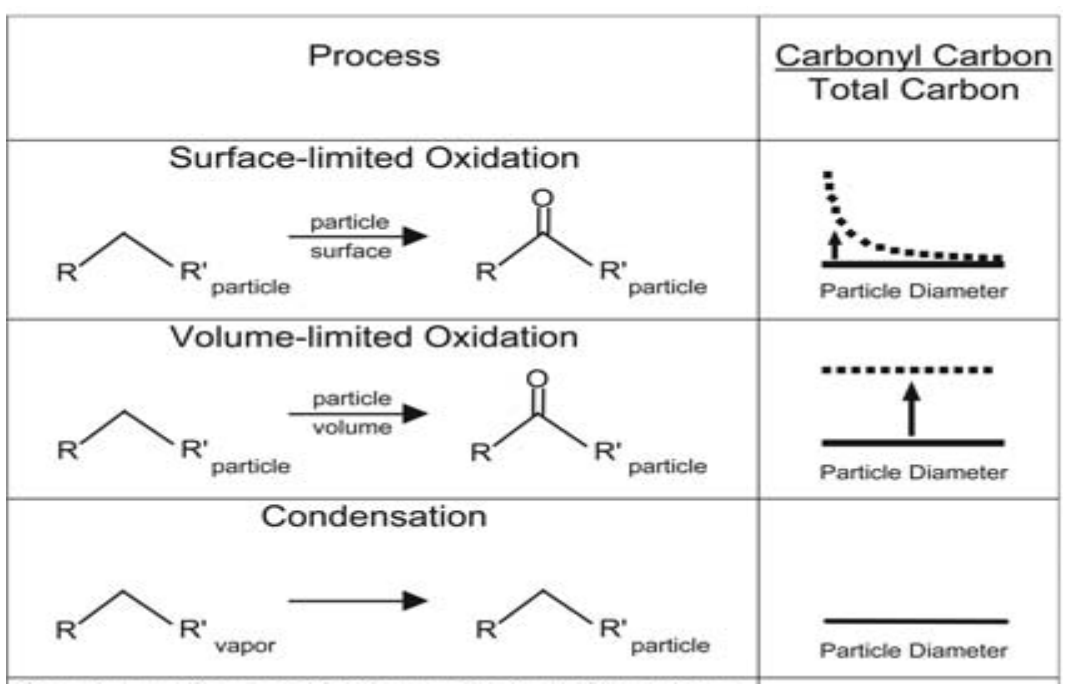

Figure 19. Particles undergoing surface limited oxidation contain an oxidized functional group ratio to total carbon that would be enhanced for small particles due to their larger surface to volume ratio. If particles underwent volume limited oxidation, the spatial distribution of carbonyl groups would be uniform due to fast diffusion of reactants compared to the kinetics of reaction. In the case of a volume limited reaction, the oxidized functional group to total carbon mass ratio would not exhibit a size dependence. Particles formed via condensation would also not exhibit a size dependence for organic functional groups. Figure adapted from Maria et al. ${ }^{132}$ 


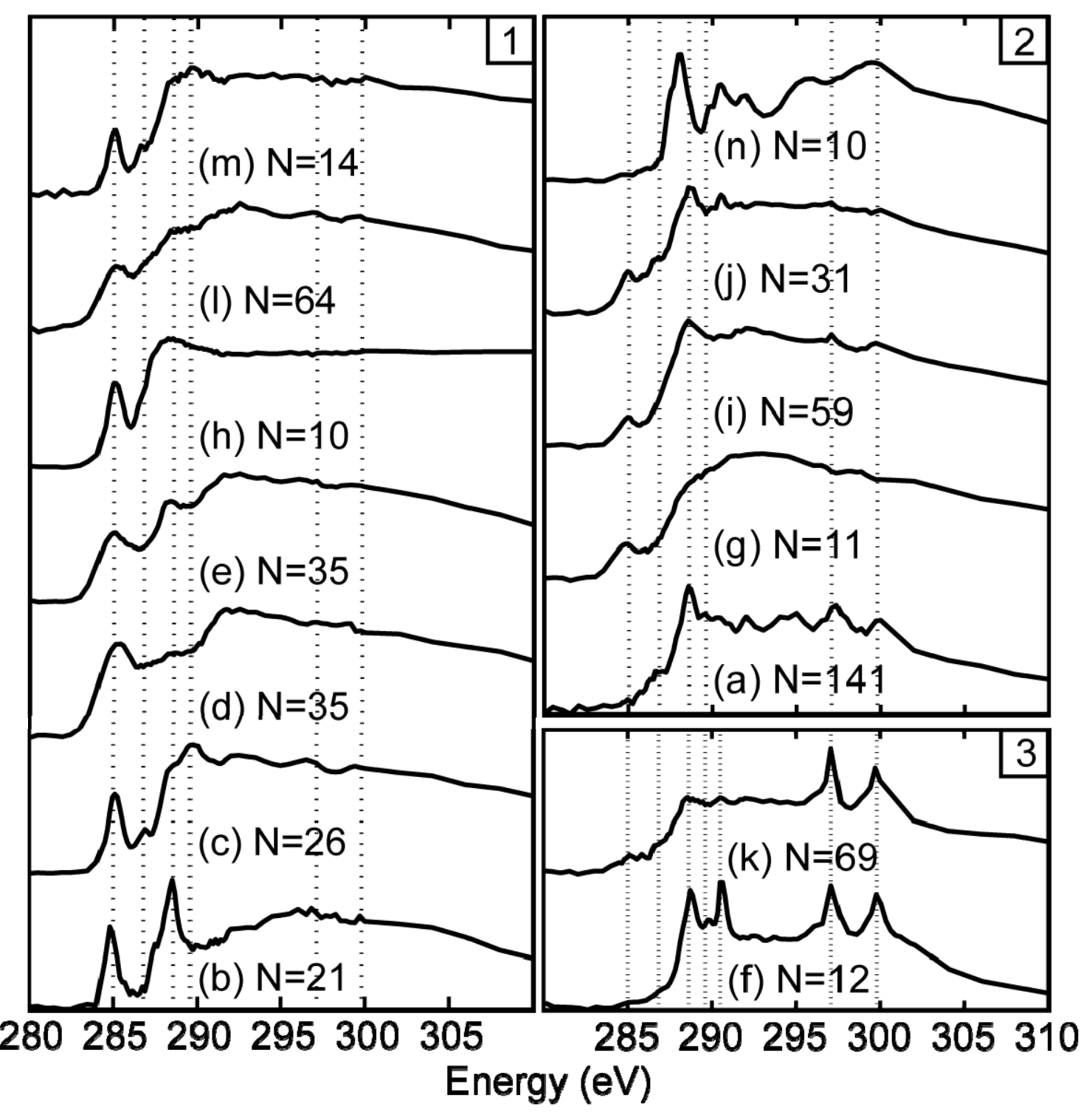

Figure 20. Spectra derived from k-means clustering of ambient-collected particles from Takahama et al. ${ }^{134}$ Clusters are organized into panels as follows: 1) soot, 2) organic, and 3) inorganic. Dotted lines indicate: $285 \mathrm{eV}\left(\mathrm{C} 1 \mathrm{~s} \rightarrow \pi^{*}{ }_{\mathrm{R}\left(\mathrm{C}^{*}=\mathrm{C}\right) \mathrm{R}}\right), 286.8 \mathrm{eV}\left(\mathrm{C} 1 \mathrm{~s} \rightarrow \pi^{*}{ }_{\mathrm{R}\left(\mathrm{C}^{*}=\mathrm{O}\right) \mathrm{R}}\right)$, $288.6 \mathrm{eV}\left(\mathrm{C} 1 \mathrm{~s} \rightarrow \pi^{*}{ }_{\mathrm{R}\left(\mathrm{C}^{*}=\mathrm{O}\right) \mathrm{OH}}\right), 289.6 \mathrm{eV}$ (unassigned), $297.1 \mathrm{eV}\left(\mathrm{K} \mathrm{L}_{2} 2 \mathrm{p}_{1 / 2} \rightarrow \sigma^{*}\right)$, and 299.8 $\mathrm{eV}\left(\mathrm{K} \mathrm{L}_{2} 2 \mathrm{p}_{3 / 2} \rightarrow \sigma^{*}\right) \mathrm{eV}$. For dust, a line at $290.5 \mathrm{eV}$ was added for the $\mathrm{C} 1 \mathrm{~s} \rightarrow \pi^{*}{ }_{\mathrm{C}^{*} \mathrm{O}}$ transition. 

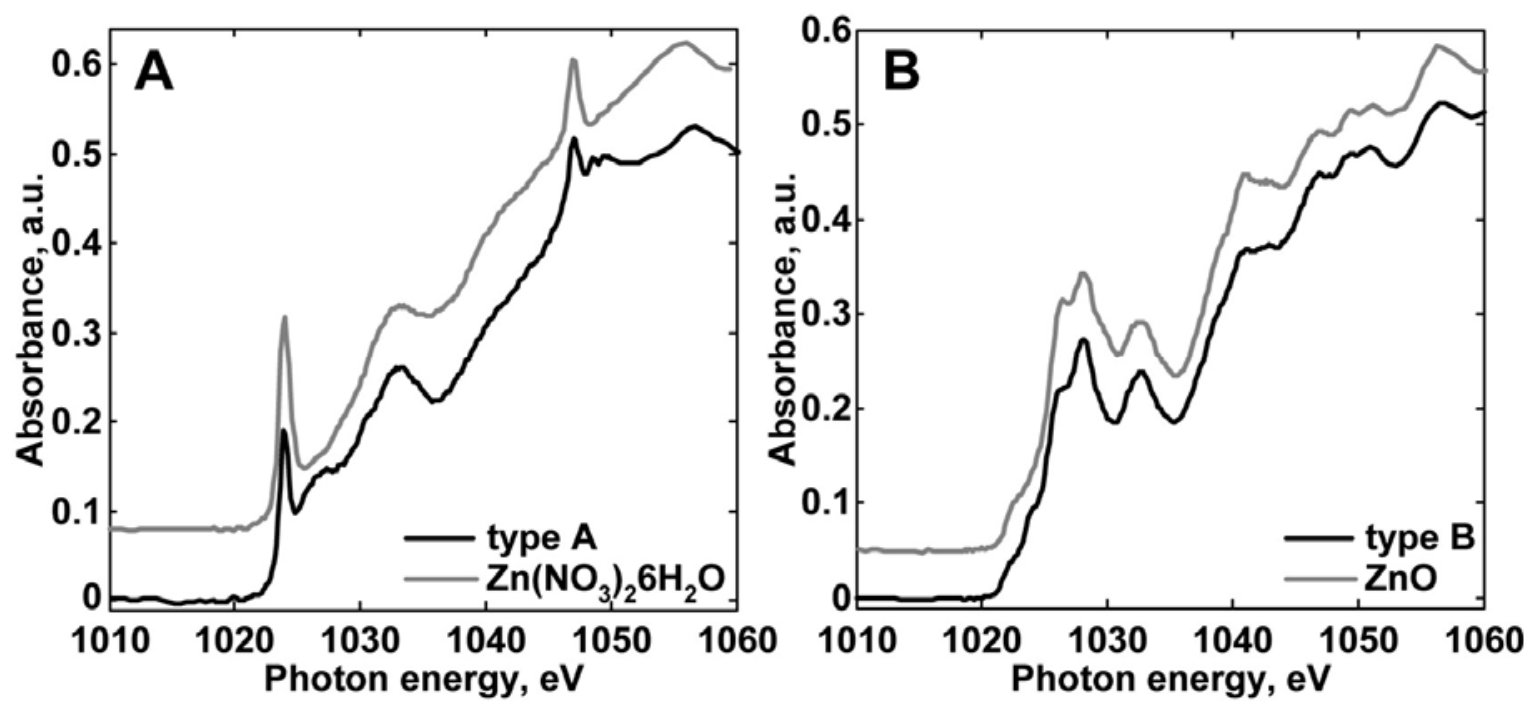

Figure 21. $\mathrm{Zn}$ spectra from ambient particle from Mexico City compared with standard spectra. A) representative $\mathrm{Zn}$ L-edge NEXAFS spectra for particle type A and $\mathrm{Zn}\left(\mathrm{NO}_{3}\right)_{2} 6 \mathrm{H}_{2} \mathrm{O}$ standard and $\mathrm{B}$ ) spectra from a second particle type, $\mathrm{B}$, and spectra from $\mathrm{ZnO}$ standard. Spectra measured for $\mathrm{ZnS}, \mathrm{ZnSO}_{4}$ and $\mathrm{ZnCl}_{2}$ did not match either type A or B.
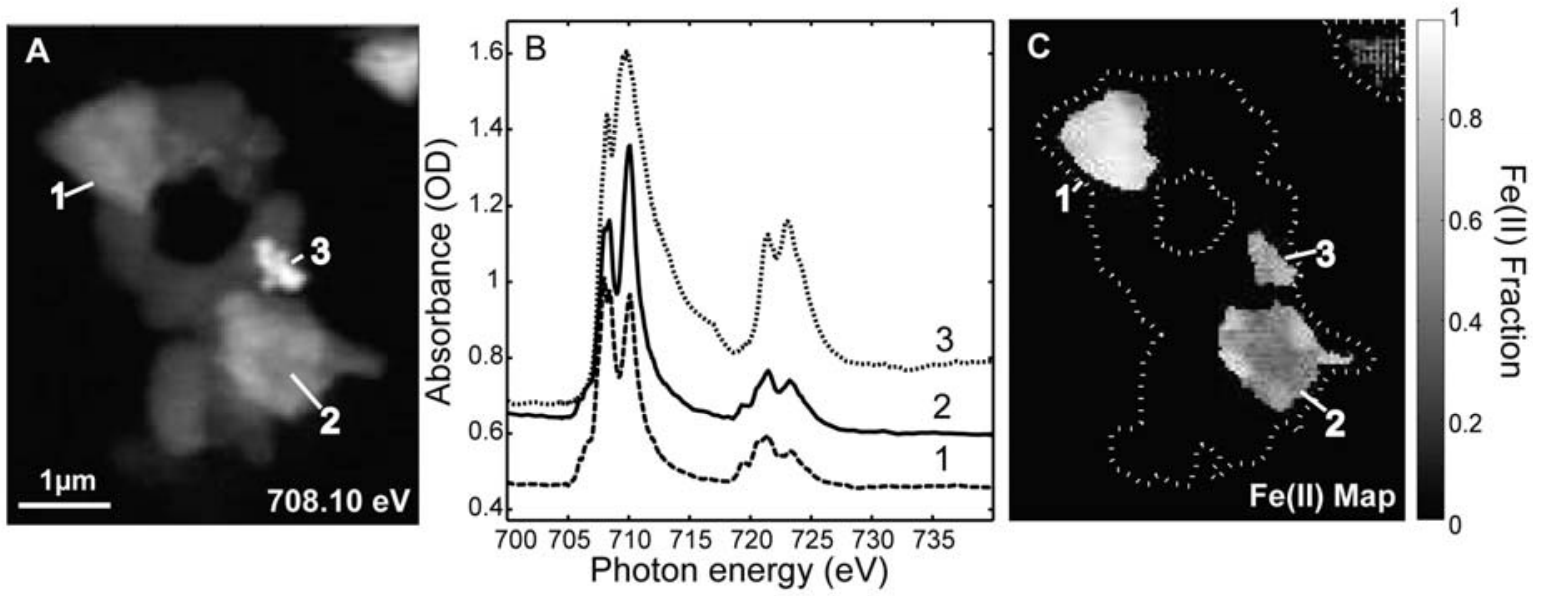

Figure 22. A) a single energy STXM image taken at $708.1 \mathrm{eV}$ (at the peak of the Fe $\mathrm{L}_{3}$ edge), with numbers indicating bright regions containing Fe. B) Spectra taken from regions indicated in A and C. Differences in Fe(II) fraction is indicated by changes in the relative heights of the peaks occurring between 705 and $710 \mathrm{eV}$. C) Fe(II) fraction indicated by the grayscale with nonFe containing regions masked in black and the particle perimeter indicated by the dotted line. Region 1 is Fe(II) rich while regions 2 and 3 contain less Fe(II). 


\section{STXM image}
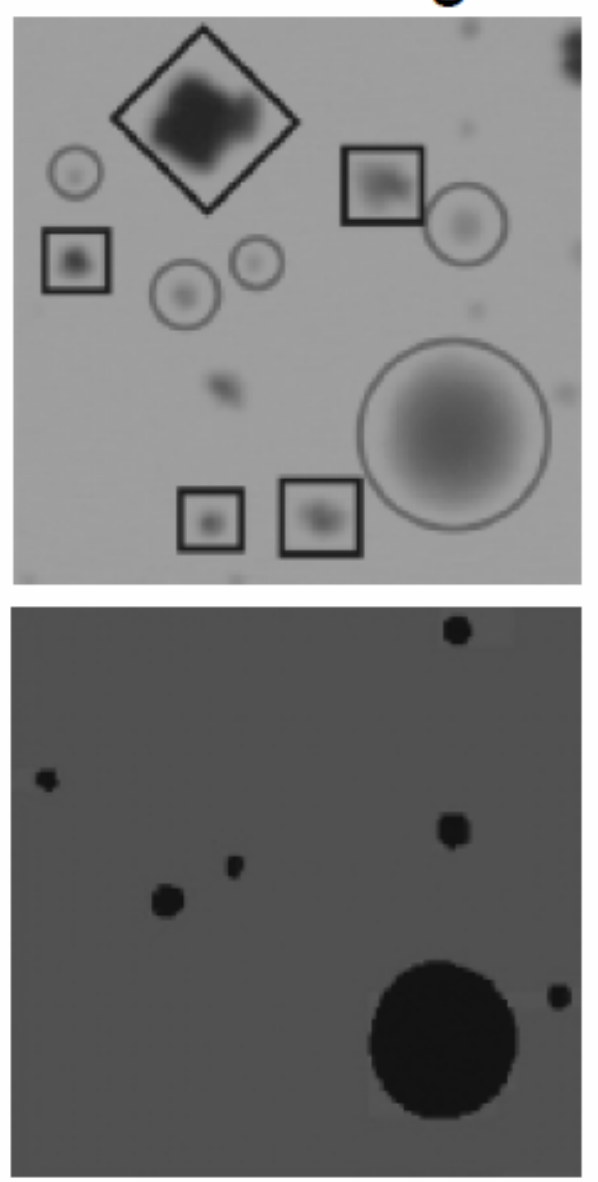

Nitrogen map
Carbon map
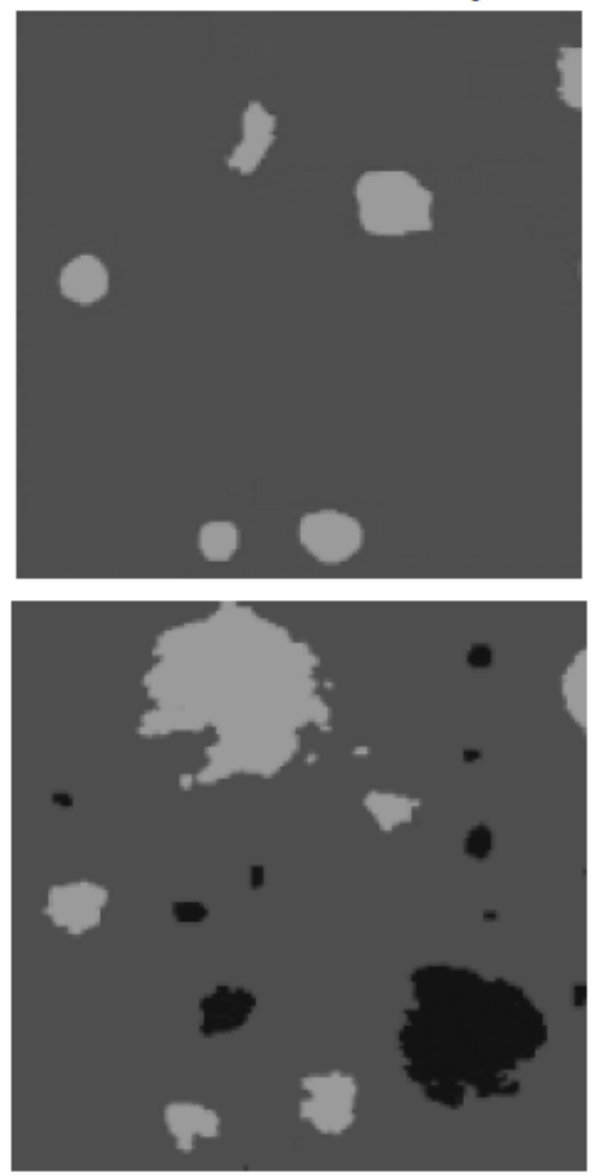

Sulfur map

Figure 23. Single energy $(290.8 \mathrm{eV}) \mathrm{STXM}$ image $(12 \mu \mathrm{m} \times 12 \mu \mathrm{m})$ of externally mixed sea salt $/ \mathrm{CH}_{3} \mathrm{SO}_{3}{ }^{-} / \mathrm{SO}_{4}{ }^{2-}$ (squares) and $\mathrm{H}_{2} \mathrm{SO}_{4} /\left(\mathrm{NH}_{4}\right)_{2} \mathrm{SO}_{4}$ (circles) particle residuals (left top). Principal component maps at the Carbon K-edge (right top), Nitrogen K-edge (left bottom), and Sulfur L-edge (right bottom). Two types of sulfur spectra were observed: one consistent with $\mathrm{H}_{2} \mathrm{SO}_{4} /\left(\mathrm{NH}_{4}\right)_{2} \mathrm{SO}_{4}$ (measured on nitrogen containing particles) and a second (measured on carbon containing sea salt particles) that is consistent with a mixture of $\mathrm{CH}_{3} \mathrm{SO}_{3}{ }^{-} / \mathrm{SO}_{4}{ }^{2-}$. 


\section{References}

1 Myneni, S. C. B. Soft X-ray spectroscopy and spectromicroscopy studies of organic molecules in the environment. Applications of Synchrotron Radiation in LowTemperature Geochemistry and Environmental Sciences 49, 485-579 (2002).

2 Ade, H. \& Urquhart, S. G. NEXAFS spectroscopy and microscopy of natural and synthetic polymers. (World Scientific Publishing, 2002).

3 Hitchcock, A. P., Morin, C., Heng, Y. M., Cornelius, R. M. \& Brash, J. L. Towards practical soft X-ray spectromicroscopy of biomaterials. J. Biomater. Sci.-Polym. Ed. 13, 919-937 (2002).

4 Yoon, T. H. Applications of Soft X-ray Spectromicroscopy in Material and Environmental Sciences. Appl. Spectrosc. Rev. 44, 91-122, DOI: 10.1080/05704920802352531 (2009).

5 Ade, H. \& Stoll, H. Near-edge X-ray absorption fine-structure microscopy of organic and magnetic materials. Nature Materials 8, 281-290 (2009).

6 Attwood, D. Soft $X$-rays and extreme ultraviolet radiation: Principles and applications. (The Press Syndicate of the University of Cambridge, 2000).

7 Kirz, J., Ade, H., Jacobsen, C. et al. Soft-X-ray microscopy with coherent X-rays. Review of Scientific Instruments 63, 557-563 (1992).

8 Morrison, G. R., Bridgewater, S., Browne, M. T. et al. Reviews Scientific Instruments 60, 2464 (1989).

9 McNulty, I., Paterson, D., Arko, J. et al. The 2-ID-B intermediate-energy scanning X-ray microscope at the APS. J. Phys. IV France 104, 11 (2003).

10 Beelen, T. P. M., Shi, W. D., Morrison, G. R. et al. Scanning transmission X-ray microscopy: A new method for the investigation of aggregation in silica. J. Colloid Interface Sci. 185, 217-227 (1997).

11 Kaznatcheev, K. V., Karunakaran, C., Lanke, U. D. et al. Soft X-ray spectromicroscopy beamline at the CLS: Commissioning results. Nucl. Instrum. Methods Phys. Res. Sect. AAccel. Spectrom. Dect. Assoc. Equip. 582, 96-99, DOI: 10.1016/j.nima.2007.08.083 (2007).

12 Mitrea, G., Thierne, J., Guttmann, P., Heim, S. \& Gleber, S. X-ray spectromicroscopy with the scanning transmission X-ray microscope at BESSY II. Journal of Synchrotron Radiation, 26-35 (2007).

13 Raabe, J., Tzvetkov, G., Flechsig, U. et al. PolLux: A new facility for soft x-ray spectromicroscopy at the Swiss Light Source. Review of Scientific Instruments 79, 113704, DOI: 10.1063/1.3021472 (2008).

14 Zangrando, M., Finazzi, M., Zacchigna, M. et al. A multi-purpose experimental station for soft x-ray microscopy on BACH beamline at Elettra. Soft X-Ray and EUV Imaging Systems II 4506, 154-162 (2001).

15 Barrett, R., Kaulich, B., Salome, M. \& Susini, J. Current status of the scanning X-ray microscope at the ESRF. AIP Conference Proceedings|AIP Conference Proceedings, 458-463 (2000). 
16 Shin, H.-J., Chung, Y. \& Kim, B. The first undulator beamline at the Pohang Light Source for high-resolution spectroscopy and spectromicroscopy. Journal of Electron Spectroscopy and Related Phenomena 101-103, 985-989 (1999).

17 Chao, W. L., Harteneck, B. D., Liddle, J. A., Anderson, E. H. \& Attwood, D. T. Soft Xray microscopy at a spatial resolution better than $15 \mathrm{~nm}$. Nature 435, 1210-1213, DOI: 10.1038/nature03719 (2005).

18 Kilcoyne, A. L. D., Tyliszczak, T., Steele, W. F. et al. Interferometer-controlled scanning transmission X-ray microscopes at the Advanced Light Source. Journal of Synchrotron Radiation 10, 125-136, DOI: 10.1107/S0909049502017739 (2003).

19 Jacobsen, C., Williams, S., Anderson, E. et al. Diffraction-limited imaging in a scanningtransmission X-ray microscope. Opt. Commun. 86, 351-364 (1991).

20 Maser, J., Osanna, A., Wang, Y. et al. Soft X-ray microscopy with a cryo scanning transmission X-ray microscope: I. Instrumentation, imaging and spectroscopy. Journal of Microscopy 197, 68-79 (2000).

21 Feser, M., Carlucci-Dayton, M., Jacobsen, C. et al. Applications and instrumentation advances with the Stony Brook scanning transmission X-ray microscope. Proceedings of SPIE - The International Society for Optical Engineering 3449, 19-29 (1998).

22 Rarback, H., Shu, D., Feng, S. C. et al. Scanning x-ray microscope with 75-nm resolution. Review of Scientific Instruments 59, $52-59$ (1988).

23 Feser, M., Hornberger, B., Jacobsen, C. et al. Integrating silicon detector with segmentation for scanning transmission X-ray microscopy. Nucl. Instrum. Methods Phys. Res. Sect. A-Accel. Spectrom. Dect. Assoc. Equip. 565, 841-854, DOI: 10.1016/j.nima.2006.05.086 (2006).

24 Gianoncelli, A., Morrison, G. R., Kaulich, B., Bacescu, D. \& Kovac, J. Scanning transmission x-ray microscopy with a configurable detector. Applied Physics Letters 89, 251117 (2006).

25 Hornberger, B., Feser, M. \& Jacobsen, C. Quantitative amplitude and phase contrast imaging in a scanning transmission X-ray microscope. Ultramicroscopy 107, 644-655 (2007).

26 Jacobsen, C., Lindaas, S., Williams, S. \& Zhang, X. Scanning luminescence X-ray microscopy: Imaging fluorescence dyes at suboptical resolution. Journal of Microscopy 172, 121-129 (1993).

27 Stöhr, J. NEXAFS Spectroscopy. 1st edn, Vol. 25 (Springer Verlag, 2003).

28 Smith, N. Science with soft $x$ rays. Physics Today 54, 29-34 (2001).

29 Henke, B. L., Gullikson, E. M. \& Davis, J. C. X-Ray Interactions: Photoabsorption, Scattering, Transmission, and Reflection at $\mathrm{E}=50-30,000 \mathrm{eV}, \mathrm{Z}=1-92$. Atomic Data and Nucl. Data Tables 54, 181-342 (1993).

30 Thompson, A., Attwood, D., Gullikson, E. M. et al. in LBNL/PUB-490 (Technical and Electronic Information Department, Lawrence Berkeley National Laboratory, Berkeley, CA 94720, 2001).

31 http://www-cxro.lbl.gov/. 
32 Muntean, L., Planques, R., Kilcoyne, A. L. D. et al. Chemical mapping of polymer photoresists by scanning transmission x-ray microscopy. Journal of Vacuum Science and Technology B 23, 1630-1636, DOI: 10.1116/1.1978899 (2005).

33 Hitchcock, A. P., Koprinarov, I., Tyliszczak, T. et al. Optimization of scanning transmission X-ray microscopy for the identification and quantitation of reinforcing particles in polyurethanes. Ultramicroscopy 88, 33-49 (2001).

34 Dynes, J. J., Lawrence, J. R., Korber, D. R. et al. Quantitative mapping of chlorhexidine in natural river biofilms. Sci. Total Environ. 369, 369-383, DOI: 10.1016/j.scitotenv.2006.04.033 (2006).

35 Urquhart, S. G. \& Ade, H. Trends in the carbonyl core $(\mathrm{C} 1 \mathrm{~s}, \mathrm{O} 1 \mathrm{~s}) \rightarrow \mathrm{p}^{*} \mathrm{C}=\mathrm{O}$ transition in the near-edge X-ray absorption fine structure spectra of organic molecules. Journal of Physical Chemistry B 106, 8531-8538, DOI: 10.1021/jp0255379 (2002).

36 Keiluweit, M. \& Kleber, M. Molecular-level interactions in soils and sediments: The role of aromatic p-systems. Environ. Sci. Technol. 43, 3421-3429 (2009).

37 Vernooij, M. G. C., Mohr, M., Tzvetkov, G. et al. On source identification and alteration of single diesel and wood smoke soot particles in the atmosphere; An X-ray microspectroscopy study. Environ. Sci. Technol. 43, 5339-5344, DOI10.1021/es800773h (2009).

38 Tivanski, A. V., Hopkins, R. J., Tyliszczak, T. \& Gilles, M. K. Oxygenated interface on biomass burn tar balls determined by single particle scanning transmission X-ray microscopy. Journal of Physical Chemistry A 111, 5448-5458, DOI: 10.1021/jp070155u (2007).

39 Michelsen, H. A., Tivanski, A. V., Gilles, M. K. et al. Particle formation from pulsed laser irradiation of soot aggregates studied with a scanning mobility particle sizer, a transmission electron microscope, and a scanning transmission x-ray microscope. Applied Optics 46, 959-977, ISSN: 0003-6935 (2007).

40 Braun, A., Huggins, F. E., Shah, N. et al. Advantages of soft X-ray absorption over TEM-EELS for solid carbon studies - a comparative study on diesel soot with EELS and NEXAFS. Carbon 43, 117-124, DOI: 10.1016/j.carbon.2004.08.029 (2005).

41 Katrinak, K. A., Rez, P. \& Buseck, P. R. Structural variations in individual carbonaceous particles from an urban aerosol. Environ. Sci. Technol. 26, 1967-1976 (1992).

42 Hopkins, R. J., Tivanski, A. V., Marten, B. D. \& Gilles, M. K. Chemical bonding and structure of black carbon reference materials and individual carbonaceous atmospheric aerosols. Journal of Aerosol Science 38, 573-591, DOI: 10.1016/j.jaerosci.2007.03.009 (2007).

43 Hitchcock, A. P., Dynes, J. J., Johansson, G., Wang, J. \& Botton, G. Comparison of NEXAFS microscopy and TEM-EELS for studies of soft matter. Micron 39, 311-319, DOI: 10.1016/j.micron.2007.09.008 (2008).

44 Wang, J., Morin, C., Li, L. et al. Radiation damage in soft X-ray microscopy. Journal of Electron Spectroscopy and Related Phenomena 170, 25-36 (2009). 
45 Schäfer, T., Michel, P., Claret, F. et al. Radiation sensitivity of natural organic matter: Clay mineral association effects in the Callovo-Oxfordian argillite. Journal of Electron Spectroscopy and Related Phenomena 170, 49-56, doi:10.1016/j.elspec.2008.05.007 (2009).

46 Braun, A., Kubatova, A., Wirick, S. \& Mun, S. B. Radiation damage from EELS and NEXAFS in diesel soot and diesel soot extracts. Journal of Electron Spectroscopy and Related Phenomena 170, $42-48$ (2009).

47 Beetz, T. \& Jacobsen, C. Soft X-ray radiation-damage studies in PMMA using a cryoSTXM. Journal of Synchrotron Radiation 10, 280-283, DOI: 10.1107/S0909049503003261 (2003).

48 Cody, G. D., Brandes, J., Jacobsen, C. \& Wirick, S. Soft X-ray induced chemical modification of polysaccharides in vascular plant cell walls. Journal of Electron Spectroscopy and Related Phenomena 170, 57-64, DOI: 10.1016/j.elspec.2008.09.007 (2009).

49 Coffey, T., Urquhart, S. G. \& Ade, H. Characterization of the effects of soft X-ray irradiation on polymers. Journal of Electron Spectroscopy and Related Phenomena 122, 65-78 (2002).

50 Howells, M. R., Hitchcock, A. P. \& Jacobsen, C. J. Introduction: Special issue on radiation damage. Journal of Electron Spectroscopy and Related Phenomena 170, 1-3 (2009).

51 Wang, J., Stover, H. D. H. \& Hitchcock, A. P. Chemically selective soft X-ray directwrite patterning of multilayer polymer films. Journal of Physical Chemistry C 111, 16330-16338, DOI: 10.1021/jp072570s (2007).

52 Rightor, E. G., Hitchcock, A. P., Ade, H. et al. Spectromicroscopy of poly(ethylene terephthalate): Comparison of spectra and radiation damage rates in $\mathrm{x}$-ray absorption and electron energy loss. Journal of Physical Chemistry B 101, 1950-1960 (1997).

53 Ade, H. \& Hitchcock, A. P. NEXAFS microscopy and resonant scattering: Composition and orientation probed in real and reciprocal space. Polymer 49, 643-675, DOI: 10.1016/j.polymer.2007.10.030 (2008).

54 Olynick, D. L., Liddle, J. A., Tivanski, A. V. et al. Scanning x-ray microscopy investigations into the electron-beam exposure mechanism of hydrogen silsesquioxane resists. Journal of Vacuum Science and Technology B 24, 3048-3054, DOI: 10.1116/1.2395957 (2006).

55 Guay, D., Stewart-Ornstein, J., Zhang, X. R. \& Hitchcock, A. P. In situ spatial and timeresolved studies of electrochemical reactions by scanning transmission X-ray microscopy. Anal. Chem. 77, 3479-3487, DOI: 10.1021/ac048077j (2005).

56 Hopkins, R. J., Desyaterik, Y., Tivanski, A. V. et al. Chemical speciation of sulfur in marine cloud droplets and particles: Analysis of individual particles from the marine boundary layer over the California current. J. Geophys. Res.-Atmos. 113, D04209, DOI: 10.1029/2007JD008954 (2008). 
57 Laskin, A., Iedema, M. J. \& Cowin, J. P. Time-resolved aerosol collector for CCSEM/EDX single-particle analysis. Aerosol Science and Technology 37, 246-260 (2003).

58 Russell, L. M., Maria, S. F. \& Myneni, S. C. B. Mapping organic coatings on atmospheric particles. Geophysical Research Letters 29 (2002).

59 Brownlee, D., Tsou, P., Aleon, J. et al. Research article - Comet 81P/Wild 2 under a microscope. Science 314, 1711-1716, DOI: 10.1126/science.1135840 (2006).

60 Cody, G. D., Ade, H., Alexander, C. M. O. et al. Quantitative organic and light-element analysis of comet 81P/Wild 2 particles using $\mathrm{C}-, \mathrm{N}-$, and $\mathrm{O}-\mu$-XANES. Meteoritics and Planetary Science 43, 353-365 (2008).

61 http://unicorn.mcmaster.ca/aXis2000.html.

62 Koprinarov, I. N., Hitchcock, A. P., McCrory, C. T. \& Childs, R. F. Quantitative mapping of structured polymeric systems using singular value decomposition analysis of soft X-ray images. Journal of Physical Chemistry B 106, 5358-5364, DOI: 10.1021/jp0132811 (2002).

63 Lerotic, M., Jacobsen, C., Gillow, J. B. et al. Cluster analysis in soft X-ray spectromicroscopy: Finding the patterns in complex specimens. Journal of Electron Spectroscopy and Related Phenomena 144, 1137-1143 (2005).

64 Lerotic, M., Jacobsen, C., Schafer, T. \& Vogt, S. Cluster analysis of soft X-ray spectromicroscopy data. Ultramicroscopy 100, 35-57, DOI: 10.1016/j.ultramic.2004.01.008 (2004).

65 http://xray1.physics.sunysb.edu/data/software.php.

66 Moffet, R. C., Henn, T. R., Laskin, A. \& Gilles, M. K. Automated assay of internally mixed individual particles using X-ray spectromicroscopy maps. to be submitted (2010).

67 http://www.mathworks.com/matlabcentral/fileexchange/24006.

68 Rothe, J., Denecke, M. A. \& Dardenne, K. Soft X-ray spectromicroscopy investigation of the interaction of aquatic humic acid and clay colloids. J. Colloid Interface Sci. 231, 9197, DOI: 10.1006/jcis.2000.7124 (2000).

69 Plaschke, M., Rothe, J., Schafer, T. et al. Combined AFM and STXM in situ study of the influence of Eu(III) on the agglomeration of humic acid. Colloid Surf. A-Physicochem. Eng. Asp. 197, 245-256 (2002).

70 Plaschke, M., Rothe, J., Denecke, M. A. \& Fanghanel, T. Soft X-ray spectromicroscopy of humic acid europium(III) complexation by comparison to model substances. Journal of Electron Spectroscopy and Related Phenomena 135, 53-62, DOI: 10.1016/j.elspec.2003.12.007 (2004).

71 Rothe, J., Plaschke, M. \& Denecke, M. A. Scanning transmission X-ray microscopy as a speciation tool for natural organic molecules. Radiochim. Acta 92, 711-715 (2004).

72 Plaschke, M., Rothe, J., Altmaier, M., Denecke, M. A. \& Fanghanel, T. Near edge X-ray absorption fine structure (NEXAFS) of model compounds for the humic acid/actinide ion interaction. Journal of Electron Spectroscopy and Related Phenomena 148, 151-157, DOI: 10.1016/j.elspec.2005.05.001 (2005). 
73 Schäfer, T., Buckau, G., Artinger, R. et al. Origin and mobility of fulvic acids in the Gorleben aquifer system: implications from isotopic data and carbon/sulfur XANES. Org. Geochem. 36, 567-582, DOI: 10.1016/j.orggeochem.2004.10.011 (2005).

74 Claret, F., Schafer, T., Rabung, T. et al. Differences in properties and Cm(III) complexation behavior of isolated humic and fulvic acid derived from Opalinus clay and Callovo-Oxfordian argillite. Appl. Geochem. 20, 1158-1168, DOI: 10.1016/j.apgeochem.2005.01.008 (2005).

75 Naber, A., Plaschke, M., Rothe, J., Hofmann, H. \& Fanghanel, T. Scanning transmission $\mathrm{X}$-ray and laser scanning luminescence microscopy of the carboxyl group and Eu(III) distribution in humic acid aggregates. Journal of Electron Spectroscopy and Related Phenomena 153, 71-74, DOI: 10.1016/j.elspec.2006.06.005 (2006).

76 Christl, I. \& Kretzschmar, R. C-1s NEXAFS spectroscopy reveals chemical fractionation of humic acid by cation-induced coagulation. Environ. Sci. Technol. 41, 1915-1920, DOI: 10.1021/es062141s (2007).

77 Rothe, J., Kneedler, E. M., Pecher, K. et al. Spectromicroscopy of Mn distributions in micronodules produced by biomineralization. Journal of Synchrotron Radiation 6, 359361 (1999).

78 Schäfer, T., Hertkorn, N., Artinger, R., Claret, F. \& Bauer, A. Functional group analysis of natural organic colloids and clay association kinetics using C(1s) spectromicroscopy. Journal De Physique IV 104, 409-412 (2003).

79 Schmidt, C., Thieme, J., Neuhausler, U. et al. Spectromicroscopy of soil colloids. Journal De Physique IV 104, 405-408 (2003).

80 Schumacher, M., Christl, I., Scheinost, A. C., Jacobsen, C. \& Kretzschmar, R. Chemical heterogeneity of organic soil colloids investigated by scanning transmission X-ray microscopy and C-1s NEXAFS microspectroscopy. Environ. Sci. Technol. 39, 9094-9100 (2005).

81 Lehmann, J., Liang, B. Q., Solomon, D. et al. Near-edge X-ray absorption fine structure (NEXAFS) spectroscopy for mapping nano-scale distribution of organic carbon forms in soil: Application to black carbon particles. Global Biogeochemical Cycles 19 (2005).

82 Solomon, D., Lehmann, J., Kinyangi, J., Liang, B. Q. \& Schafer, T. Carbon K-edge NEXAFS and FTIR-ATR spectroscopic investigation of organic carbon speciation in soils. Soil Sci. Soc. Am. J. 69, 107-119 (2005).

83 Kinyangi, J., Solomon, D., Liang, B. I. et al. Nanoscale biogeocomplexity of the organomineral assemblage in soil: Application of STXM microscopy and C 1s-NEXAFS spectroscopy. Soil Sci. Soc. Am. J. 70, 1708-1718, DOI: 10.2136/sssaj2005.0351 (2006).

84 Wan, J., Tyliszczak, T. \& Tokunaga, T. K. Organic carbon distribution, speciation, and elemental correlations within soil micro aggregates: Applications of STXM and NEXAFS spectroscopy. Geochimica et Cosmochimica Acta 71, 5439-5449, DOI: 10.1016/j.gca.2007.07.030 (2007).

85 Lehmann, J., Solomon, D., Kinyangi, J. et al. Spatial complexity of soil organic matter forms at nanometre scales. Nature Geoscience 1, 238-242 (2008). 
86 Brandes, J. A., Lee, C., Wakeham, S. et al. Examining marine particulate organic matter at sub-micron scales using scanning transmission X-ray microscopy and carbon X-ray absorption near edge structure spectroscopy. Mar. Chem. 92, 107-121, DOI: 10.1016/j.marchem.2004.06.020 (2004).

87 Schäfer, T., Claret, F., Bauer, A. et al. Natural organic matter (NOM)-clay association and impact on Callovo-Oxfordian clay stability in high alkaline Solution: Spectromicroscopic evidence. Journal De Physique IV 104, 413-416 (2003).

88 Yoon, T. H., Benzerara, K., Ahn, S. et al. Nanometer-scale chemical heterogeneities of black carbon materials and their impacts on PCB sorption properties: Soft X-ray spectromicroscopy study. Environmental Science and Technology 40, 5923-5929, DOI: 10.1021/es060173+ (2006).

89 Haberstroh, P. R., Brandes, J. A., Gelinas, Y. et al. Chemical composition of the graphitic black carbon fraction in riverine and marine sediments at sub-micron scales using carbon X-ray spectromicroscopy. Geochimica Et Cosmochimica Acta 70, 1483-1494, DOI: 10.1016/j.gca.2005.12.001 (2006).

90 Thieme, J., Gleber, S. C., Guttmann, P. et al. Microscopy and spectroscopy with X-rays for studies in the environmental sciences. Mineralogical Magazine 72, 211-216 (2008).

91 Hitchcock, A. P., Morin, C., Tyliszczak, T. et al. Soft X-ray microscopy of soft matter Hard information from two softs. Surface Review and Letters 9, 193-201, DOI: 10.1142/S0218625X02001781 (2002).

92 Lawrence, J. R., Swerhone, G. D. W., Leppard, G. G. et al. Scanning transmission X-ray, laser scanning, and transmission electron microscopy mapping of the exopolymeric matrix of microbial biofilms. Applied and Environmental Microbiology 69, 5543-5554, DOI: 10.1128/AEM.69.9.5543-5554.2003 (2003).

93 Chan, C. S., De Stasio, G., Welch, S. A. et al. Microbial polysaccharides template assembly of nanocrystal fibers. Science 303, 1656-1658 (2004).

94 Toner, B., Fakra, S., Villalobos, M., Warwick, T. \& Sposito, G. Spatially resolved characterization of biogenic manganese oxide production within a bacterial biofilm. Applied and Environmental Microbiology 71, 1300-1310, DOI: 10.1128/AEM.71.3.13001310.2005 (2005).

95 Benzerara, K., Menguy, N., Lopez-Garcia, P. et al. Nanoscale detection of organic signatures in carbonate microbialites. Proceedings of the National Academy of Sciences of the United States of America 103, 9440-9445 (2006).

96 Dynes, J. J., Tyliszczak, T., Araki, T. et al. Speciation and quantitative mapping of metal species in microbial biofilms using scanning transmission X-ray microscopy.

Environmental Science and Technology 40, 1556-1565, DOI: 10.1021/es0513638 (2006).

97 Felten, A., Bittencourt, C., Pireaux, J. J. et al. Individual multiwall carbon nanotubes spectroscopy by scanning transmission X-ray microscopy. Nano Letters 7, 2435-2440, DOI: $10.1021 / \mathrm{nl} 071134 \mathrm{e}(2007)$. 
98 Schafer, T., Chanudet, V., Claret, F. \& Filella, M. Spectromicroscopy mapping of colloidal/particulate organic matter in Lake Brienz, Switzerland. Environ. Sci. Technol. 41, 7864-7869 (2007).

99 Hunter, R. C., Hitchcock, A. P., Dynes, J. J., Obst, M. \& Beveridge, T. J. Mapping the Speciation of Iron in Pseudomonas aeruginosa Biofilms Using Scanning Transmission Xray Microscopy. Environ. Sci. Technol. 42, 8766-8772, DOI: 10.1021/es801642z (2008).

100 MaClean, L. C. W., Tyliszczak, T., Gilbert, P. et al. A high-resolution chemical and structural study of framboidal pyrite formed within a low-temperature bacterial biofilm. Geobiology 6, 471-480, DOI: 10.1111/j.1472-4669.2008.00174.x (2008).

101 Toner, B. M., Santelli, C. M., Marcus, M. A. et al. Biogenic iron oxyhydroxide formation at mid-ocean ridge hydrothermal vents: Juan de Fuca Ridge. Geochimica Et Cosmochimica Acta 73, 388-403, DOI: 10.1016/j.gca.2008.09.035 (2009).

102 Dynes, J. J., Lawrence, J. R., Korber, D. R. et al. Morphological and biochemical changes in Pseudomonas fluorescens biofilms induced by sub-inhibitory exposure to antimicrobial agents. Can. J. Microbiol. 55, 163-178, DOI: 10.1139/W08-109 (2009).

103 Sandford, S. A., Aleon, J., Alexander, C. M. O. et al. Organics captured from comet 81P/Wild 2 by the Stardust spacecraft. Science 314, 1720-1724, DOI:10.1126/science.1135841 (2006).

104 Zolensky, M. E. Report - Mineralogy and petrology of comet 81P/Wild 2 nucleus samples (vol 314, pg 1735, 2006). Science 316, 543-543, DOI: 10.1126/science.1135842 (2007).

105 Flynn, G. J., Keller, L. P., Feser, M., Wirick, S. \& Jacobsen, C. The origin of organic matter in the solar system: Evidence from the interplanetary dust particles. Geochimica Et Cosmochimica Acta 67, 4791-4806, DOI: 10.1016/j.gca.2003.09.001 (2003).

106 Keller, L. P., Messenger, S., Flynn, G. J. et al. The nature of molecular cloud material in interplanetary dust. Geochimica Et Cosmochimica Acta 68, 2577-2589, DOI: 10.1016/j.gca.2003.10.044 (2004).

107 Flynn, G. J., Keller, L. P., Wirick, S., Jacobsen, C. \& Sutton, S. R. Analysis of interplanetary dust particles by soft and hard X-ray microscopy. Journal De Physique IV 104, 367-372 (2003).

108 Flynn, G. J., Keller, L. P., Jacobsen, C. \& Wirick, S. An assessment of the amount and types of organic matter contributed to the Earth by interplanetary dust. Space Life Sciences: Steps toward Origin(S) of Life 33, 57-66, DOI: 10.1016/j.asr.2003.09.036 (2004).

109 Jacobsen, C., Wirick, S., Flynn, G. \& Zimba, C. Soft X-ray spectroscopy from image sequences with sub-100 nm spatial resolution. J. Microsc.-Oxf. 197, 173-184 (2000).

110 Cody, G. D., Alexander, C. M. O., Yabuta, H. et al. Organic thermometry for chondritic parent bodies. Earth and Planetary Science Letters 272, 446-455, DOI:

10.1016/j.epsl.2008.05.008 (2008). 
111 Botto, R. E., Cody, G. D., Kirz, J. et al. Selective chemical mapping of coal microheterogeneity by scanning-transmission X-ray microscopy. Energy \& Fuels 8, 151154 (1994).

112 Cody, G. D., Ade, H., Wirick, S., Mitchell, G. D. \& Davis, A. Determination of chemical-structural changes in vitrinite accompanying luminescence alteration using $\mathrm{C}$ NEXAFS analysis. Org. Geochem. 28, 441-455 (1998).

113 Cody, G. D., Botto, R. E., Ade, H. et al. Inner-shell spectroscopy and imaging of a subbituminous coal - in-situ analysis of organic and inorganic microstructure using C(1s)-NEXAFS, Ca(2p)-NEXAFS, and C1(2s)-NEXAFS. Energy \& Fuels 9, 525-533, doi: 10.1021/ef00051a018 (1995).

114 Cody, G. D., Botto, R. E., Ade, H. et al. C-NEXAFS microanalysis and scanning-X-ray microscopy of microheterogeneities in a high-volatile a bituminous coal. Energy \& Fuels 9, 75-83, doi: 10.1021/ef00049a012 (1995).

115 Cody, G. D., Botto, R. E., Ade, H. \& Wirick, S. The application of soft X-ray microscopy to the in-situ analysis of sporinite in coal. Int. J. Coal Geol. 32, 69-86 (1996).

116 Flynn, G. J., Keller, L. P., Jacobsen, C. \& Wirick, S. Carbon and potassium mapping and carbon bonding state measurements on interplanetary dust. Meteorit. Planet. Sci. 33, A50-A50 (1998).

117 Braun, A., Shah, N., Huggins, F. E. et al. A study of diesel PM with X-ray microspectroscopy. Fuel 83, 997-1000, DOI: 10.1016/j.fuel.2003.08.015 (2004).

118 Hopkins, R. J., Lewis, K., Desyaterik, Y. et al. Correlations between optical, chemical, and physical properties of biomass burn aerosols. Geophysical Research Letters 34, L18806, DOI: 10.1029/2007GL030502 (2007).

119 Moffet, R. C., Henn, T. R., Tivanski, A. V. et al. Microscopic characterization of carbonaceous aerosol particle aging in the outflow from Mexico City. Atmos. Chem. Phys. Discuss. 9, 16993-17033 (2009).

120 Gilles, M. K., Kilcoyne, A. D. L., Tyliszczak, T. et al. Scanning transmission X-ray microscopy imaging of aerosol particles. EOS Trans. AGU Fall Meet. Suppl., 84, Abstract A51F-0735 (2003).

121 Braun, A. Carbon speciation in airborne particulate matter with C (1s) NEXAFS spectroscopy. Journal of Environmental Monitoring 7, 1059-1065 (2005).

122 Akhter, M. S., Chughtai, A. R. \& Smith, D. M. The structure of hexane soot I: Spectroscopic studies. Appl. Spectrosc. 39, 143-153 (1985).

123 Aiken, A. C., Decarlo, P. F., Kroll, J. H. et al. O/C and OM/OC ratios of primary, secondary, and ambient organic aerosols with high-resolution time-of-flight aerosol mass spectrometry. Environ. Sci. Technol. 42, 4478-4485 (2008).

124 Braun, A., Shah, N., Huggins, F. E. et al. X-ray scattering and spectroscopy studies on diesel soot from oxygenated fuel under various engine load conditions. Carbon 43, 25882599, DOI: 10.1016/j.carbon.2005.05.017 (2005). 
125 Lenardi, C., Marino, M., Barborini, E., Piseri, P. \& Milani, P. Evaluation of hydrgoen chemisorption in nanostructured carbon films by near edge x-ray absorption spectroscopy. European Physics Journal B 46, 441-447, doi:DOI: 10.1140/epjb/e2005-00268-2 (2005).

126 Gago, R., Jiménez, I. \& Albella, J. M. Detecting with X-ray absorption spectroscopy the modifications of the bonding structure of graphitic carbon by amorphisation, hydrogenation and nitrogenation. Surface Science 482-485, 530-536 (2001).

127 Bond, T. C. \& Bergstrom, R. W. Light absorption by carbonaceous particles: An investigative review. Aerosol Science and Technology 40, 1-41, DOI: 10.1080/02786820500421521 (2006).

128 Li, J., Posfai, M., Hobbs, P. V. \& Buseck, P. R. Individual aerosol particles from biomass burning in southern Africa: 2, Compositions and aging of inorganic particles. J. Geophys. Res.-Atmos. 108 (2003).

129 Pósfai, M., Gelencser, A., Simonics, R. et al. Atmospheric tar balls: Particles from biomass and biofuel burning. J. Geophys. Res.-Atmos. 109 (2004).

130 Pósfai, M., Simonics, R., Li, J., Hobbs, P. V. \& Buseck, P. R. Individual aerosol particles from biomass burning in southern Africa: 1. Compositions and size distributions of carbonaceous particles. J. Geophys. Res.-Atmos. 108 (2003).

131 Hand, J. L., Malm, W. C., Laskin, A. et al. Optical, physical, and chemical properties of tar balls observed during the Yosemite Aerosol Characterization Study. J. Geophys. Res.Atmos. 110 (2005).

132 Maria, S. F., Russell, L. M., Gilles, M. K. \& Myneni, S. C. B. Organic aerosol growth mechanisms and their climate-forcing implications. Science 306, 1921-1924, DOI: 10.1126/science.1103491 (2004).

133 Knopf, D. A., Wang, B., Laskin, A., Moffet, R. C. \& Gilles, M. K. Anthropogenic organic aerosols as potential ice nuclei for cirrus clouds. submitted for publication (2010).

134 Takahama, S., Gilardoni, S., Russell, L. M. \& Kilcoyne, A. L. D. Classification of multiple types of organic carbon composition in atmospheric particles by scanning transmission X-ray microscopy analysis. Atmos. Environ. 41, 9435-9451, DOI: 10.1016/j.atmosenv.2007.08.051 (2007).

135 Day, D. A., Takahama, S., Gilardoni, S. \& Russell, L. M. Organic composition of single and submicron particles in different regions of western North America and the eastern Pacific during INTEX-B 2006. Atmos. Chem. Phys. 9, 5433-5446 (2009).

136 Leaitch, W. R., Macdonald, A. M., Anlauf, K. G. et al. Evidence for Asian dust effects from aerosol plume measurements during INTEX-B 2006 near Whistler, BC. Atmos. Chem. Phys. 9, 3523-3546 (2009).

137 Liu, S., Takahama, S., Russell, L. M., Gilardoni, S. \& Baumgardner, D. Oxygenated organic functional groups and their sources in single and submicron organic particles in MILAGRO 2006 campaign. Atmos. Chem. Phys. 9, 6849-6863 (2009).

138 Tonner, B. P., Droubay, T., Denlinger, J. et al. Soft X-ray spectroscopy and imaging of interfacial chemistry in environmental specimens. Surf. Interface Anal. 27, 247-258 (1999). 
139 Moffet, R. C., Desyaterik, Y., Hopkins, R. J. et al. Characterization of aerosols containing $\mathrm{Zn}, \mathrm{Pb}$, and $\mathrm{Cl}$ from an industrial region of Mexico City. Environ. Sci. Technol. 42, 7091-7097, DOI: 10.1021/es7030463 (2008).

140 Schnaas, L., Rothenberg, S. J., Flores, M. F. et al. Blood lead secular trend in a cohort of children in Mexico City (1987-2002). Environmental Health Perspectives 112, 11101115 (2004).

141 Lam, P. J., Bishop, J. K. B., Henning, C. C. et al. Wintertime phytoplankton bloom in the subarctic Pacific supported by continental margin iron. Global Biogeochemical Cycles 20, DOI: 10.1029/2005GB002557 (2006).

142 Gleber, G., Thieme, J., Niemeyer, J. \& Feser, M. Interaction of organic substances with iron studied by O1s spectroscopy - Development of an analysis program. Journal De Physique IV 104, 429-432 (2003).

143 Miot, J., Benzerara, K., Morin, G. et al. Iron biomineralization by anaerobic neutrophilic iron-oxidizing bacteria. Geochimica Et Cosmochimica Acta 73, 696-711, DOI: 10.1016/j.gca.2008.10.033 (2009).

144 Chan, C. S., Fakra, S., Edwards, D. C., Emerson, D. \& Banfield, J. Iron oxyhydroxide mineralization on microbial extracellular polysaccharides. Geochimica et Cosmochimica Acta (2009).

145 Toner, B. M., Fakra, S. C., Manganini, S. J. et al. Preservation of iron(II) by carbon-rich matrices in a hydrothermal plume. Nature Geoscience 2, 197-201, DOI: 10.1038/NGEO433 (2009).

146 Takahama, S., Gilardoni, S. \& Russell, L. M. Single-particle oxidation state and morphology of atmospheric iron aerosols. J. Geophys. Res.-Atmos. 113, D22202, DOI: 10.1029/2008JD009810 (2008).

147 Hitchcock, A. P., Tourillon, G., Garrett, R. et al. Inner-shell excitation of gas-phase and polymer thin-film 3-alkylthiophenes by electron energy loss and X-ray photoabsorption spectroscopy. Journal of Physical Chemistry 94, 2327-2333 (1990).

148 Sarret, G., Connan, J., Kasrai, M. et al. Chemical forms of sulfur in geological and archaeological asphaltenes from Middle East, France, and Spain determined by suflur K-, and L-edge X-ray absorption near-edge structure spectroscopy. Geochimica Et Cosmochimica Acta 63, 3767-3779 (1999).

149 Zaveri, R. A., Berkowitz, C. M., Brechtel, F. J. et al. Nighttime chemical evolution of aerosol and trace gases in a power plant plume: Implications for secondary organic nitrate and organosulfate aerosol formation, $\mathrm{NO}_{3}$ radical chemistry, and $\mathrm{N}_{2} \mathrm{O}_{5}$ heterogeneous hydrolysis. J. Geophys. Res.-Atmos. accepted (2010).

150 Surratt, J. D., Kroll, J. H., Kleindienst, T. E. et al. Evidence for organosulfates in secondary organic aerosol. Environ. Sci. Technol. 41, 517-527 (2007).

151 Pratt, K. A., Twohy, C. H., Murphy, S. M. et al. Observation of playa salts as nuclei of orographic wave clouds. J. Geophys. Res.-Atmos. submitted (2010).

152 Hiranamu, N., Moffet, R. C., Gilles, M. K. et al. Personal Communication. (2010). 
153 Bernard, S., Benzerara, K., Beyssac, O. et al. Ultrastructural and chemical study of modern and fossil sporoderms by Scanning Transmission X-ray Microscopy (STXM). Rev. Palaeobot. Palynology 156, 248-261, DOI: 10.1016/j.revpalbo.2008.09.002 (2009).

154 Amri, C. E., Maurel, M. C., Sagon, G. \& Barone, M. H. The micro-distribution of carbonaceous matter in the Murchison meteorite as investigated by Raman imaging. Spectrochim. Acta A, Mol. Biomol. Spectrosc. 61, 2049-2056 (2005).

155 Benzerara, K., Morin, G., Yoon, T. H. et al. Nanoscale study of As biomineralization in an acid mine drainage system. Geochimica Et Cosmochimica Acta 72, 3949-3963, DOI: 10.1016/j.gca.2008.05.046 (2008).

156 Kaegi, R., Wagner, T., Hetzer, B. et al. Size, number and chemical composition of nanosized particles in drinking water determined by analytical microscopy and LIBD. Water Res. 42, 2778-2786 (2008).

157 Morin, C., Ikeura-Sekiguchi, H., Tyliszczak, T. et al. X-ray spectromicroscopy of immiscible polymer blends: polystyrene-poly(methyl methacrylate). Journal of Electron Spectroscopy and Related Phenomena 121, 203-224 (2001).

158 Winesett, D. A. \& Tsou, A. H. The application of high resolution chemical imaging techniques for butyl rubber blends. Rubber Chem. Technol. 81, 265-275 (2008).

159 Tivanski, A. V. \& Ghorai, S. Personal Communication. (2010).

160 Drake, I. J., Liu, T. C. N., Gilles, M. et al. An in situ cell for characterization of solids by soft x-ray absorption. Review of Scientific Instruments 75, 3242-3247, DOI: 10.1063/1.1791320 (2004).

161 de Smit, E., Swart, I., Creemer, J. F. et al. Nanoscale chemical imaging of a working catalyst by scanning transmission X-ray microscopy. Nature 456, 222-U239, DOI: 10.1038/nature07516 (2008).

162 de Smit, E., Swart, I., Creemer, J. F. et al. Nanoscale chemical imaging of the reduction behavior of a single catalyst particle. Angew. Chem.-Int. Edit. 48, 3632-3636, DOI: 10.1002/anie.200806003 (2009).

163 Ghorai, S. \& Tivanski, A. V. Hygroscopic behavior and phase transitions of aerosols studied by single particle scanning transmission X-ray microscopy. submitted to Analytical Chemistry (2010).

164 Zelenay, V., Ammann, M., Krepelová, A. et al. Following the water uptake and release in individual micrometer sized ammonium sulfate and ammonium sulfate/adipic acid particles using x-ray microspectroscopy. submitted to Journal of Physical Chemistry (2010).

165 Tzvetkov, G., Graf, B., Wiegner, R. et al. Soft X-ray spectromicroscopy of phase-change microcapsules. Micron 39, 275-279, DOI: 10.1016/j.micron.2007.04.002 (2008).

166 Thibault, P., Dierolf, M., Menzel, A. et al. High-resolution scanning x-ray diffraction microscopy. Science 321, 379-382 (2008). 